\title{
Uma abordagem para obtenção e disponibilização de informações geográficas voluntárias no contexto de gestão de risco de inundação
}

Lívia Castro Degrossi 



\section{Uma abordagem para a obtenção e disponibilização de informações geográficas voluntárias no contexto de gestão de risco de inundação}

\section{Lívia Castro Degrossi}

Orientador: Prof. Dr. João Porto de Albuquerque Pereira

Dissertação apresentada ao Instituto de Ciências Matemáticas e de Computação - ICMC-USP, como parte dos requisitos para obtenção do título de Mestre em Ciências - Ciências de Computação e Matemática Computacional. VERSÃO REVISADA

USP - São Carlos

Maio de 2014 
Ficha catalográfica elaborada pela Biblioteca Prof. Achille Bassi e Seção Técnica de Informática, ICMC/USP, com os dados fornecidos pelo(a) autor(a)

\begin{tabular}{|c|c|}
\hline \multirow[t]{3}{*}{ D321a } & $\begin{array}{l}\text { Degrossi, Lívia Castro } \\
\text { Uma abordagem para obtenção e disponibilização em } \\
\text { tempo real de informaçoses geográficas voluntárias no } \\
\text { contexto de gestão de risco de inundação / Lívia } \\
\text { Castro Degrossi; orientador João Porto de } \\
\text { Albuquerque Pereira. -- São Carlos, } 2014 \text {. } \\
\quad 73 \text { p. }\end{array}$ \\
\hline & $\begin{array}{l}\text { Dissertação (Mestrado - Programa de Pós-Graduação } \\
\text { em Ciências de Computação e Matemática } \\
\text { Computacional) -- Instituto de Ciências Matemáticas } \\
\text { e de Computação, Universidade de São Paulo, } 2014 .\end{array}$ \\
\hline & $\begin{array}{l}\text { 1. Gestão de risco de inundação. 2. Volunteered } \\
\text { Geographic Information. I. Pereira, João Porto de } \\
\text { Albuquerque, orient. II. Título. }\end{array}$ \\
\hline
\end{tabular}


Aos meus pais, Suely e Homero, e minha irmã, Marília. 



\section{Agradecimentos}

Agradeço primeiramente a Deus pela força e perseverança para superar todos os desafios. Agradeço aos meus pais Homero e Suely pelo incentivo e apoio durante toda essa trajetória. À minha irmã Marília por sempre me aconselhar e me apoiar. Aos meus avós Valentim, Nair, Cida e Rubens (in memorian) e minha tia Maristela por sempre torcerem por mim e transmitirem a mim seus conhecimentos sobre a vida.

Ao meu orientador João fica meu agradecimento por seus ensinamentos, conselhos e palavras de incentivo. Agradeço por ter sido um orientador atencioso e amigo.

Aos meus amigos José Dario, Venilton, Faimison e Rafael Durelli pelo apoio durante as atividades realizadas. Em especial aos meus queridos amigos Alinne e Francisco Carlos por todo apoio, carinho e companheirismo, sem eles essa trajetória teria sido mais difícil. Aos meus amigos de orientação Flávio, Luiz Fernando e Raul por toda a troca de conhecimentos e experiências.

Agradeço a todos os meus amigos, que aqui não foram citados, por todos os momentos compartilhados e opiniões sinceras.

Aos professores e funcionários do ICMC agradeço pela dedição e disposição nos serviços prestados.

À CAPES pelo apoio financeiro. 

O número e a intensidade dos desastres naturais têm aumentado em todo o mundo devido às mudanças climáticas. Atualmente, as inundações representam a maior parte dos desastres naturais e causam mais danos, mortes e impactos econômicos do que qualquer outro tipo de fenômeno natural. No Brasil, as inundações se intensificam principalmente no período de chuvas, entre os meses de Dezembro e Março, ocasionando dezenas de mortes, além de impactos econômicos, sociais e ambientais. Assim, prevenir esse tipo de desastre tem se tornado um fator importante para minimizar os impactos por ele provocados. Para isso, são necessárias informações atualizadas, completas e precisas sobre o atual estado das variáveis ambientais. Nesse contexto, as informações voluntárias estão sendo utilizadas como fonte de dados complementar para a gestão de risco de inundação, devido ao número elevado de voluntários que atuam como "sensores". Contudo, outras informações relacionadas à inundação estão dispersas em diferentes fontes de dados, dificultando as ações de resposta das agências de emergência. Neste trabalho é proposta uma abordagem que visa apoiar a gestão de risco de inundação, fornecendo mecanismos para a obtenção de informações voluntárias para esse contexto e permitindo a disponibilização dessas por meio de serviços geoespaciais em tempo real. Para tanto, mecanismos de interpretação foram definidos para apoiar os voluntários durante a análise e medição da altura da água, sendo essas informações fornecidas por meio de uma plataforma de crowdsourcing. Além disso, um framework foi desenvolvido a fim de disponibilizar as informações voluntárias de forma interoperável por meio de serviços geoespaciais. Ao final, foram realizados estudos experimentais para avaliar a eficácia dos mecanismos desenvolvidos para a obtenção de informações voluntárias para gestão de risco de inundação. 

The number and intensity of natural disasters have increased worldwide due to climate change. Currently, floods represent most natural disasters and cause more damage, deaths and economic impacts than any other natural phenomenon. In Brazil, the floods are intensified especially during the rainy season, between the months of December and March, causing dozens of deaths, as well as economic, social and environmental impacts. Thus, preventing this kind of disaster has become an important factor to minimize the impacts caused by it. For this, it's necessary up-to-date, complete and accurate information about the current state of the environmental variable. In this context, volunteer information is being used as a complementary data source for flood risk management, due to the high number of volunteers who act as "sensors". However, other information related to flooding are scattered in different data sources, hindering response actions of emergency agencies. This dissertation proposes an approach to support flood risk management, providing mechanisms for obtaining volunteer information for this context and allowing the availability of these by means of geospatial services in real time. For this, interpretation mechanisms were defined to support the volunteers during the analysis and measurement of the water height, being this information provided by means of crowdsourcing platform. Additionally, a framework was developed to provide volunteer information in an interoperable way through geospatial services. Finally, experimental studies were conducted to evaluate the effectiveness of the mechanisms developed to obtaining volunteer information for flood risk management. 

1 Introdução 1

1.1 Contextualização . . . . . . . . . . . . . . . . . . . . . . 1

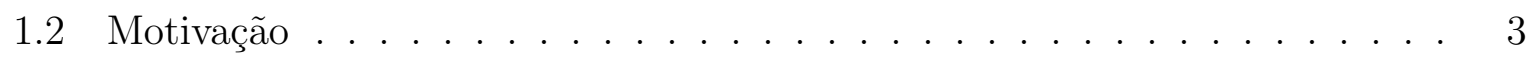

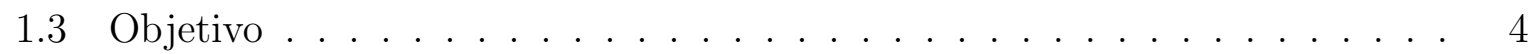

1.4 Organização . . . . . . . . . . . . . . . . . . 4

2 Fundamentação Teórica 5

2.1 Considerações Iniciais . . . . . . . . . . . . . . . . . . . . . 5

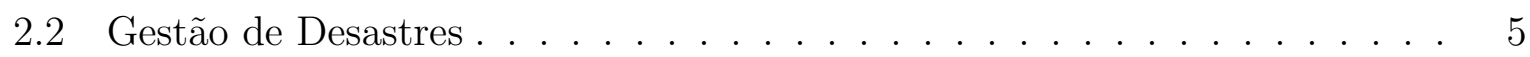

2.2.1 Gestão de Risco de Inundação . . . . . . . . . . . . . . . . . . . . 7

2.3 Volunteered Geographic Information . . . . . . . . . . . . . . . . . . . 9

2.3.1 Observatório Cidadão . . . . . . . . . . . . . . . . . . . . . . . . . . . . 10

2.3 .2 Ushahidi . . . . . . . . . . . . . . . . . . . . . . . . . . . . . . . . . . .

2.4 Arquitetura Orientada a Serviços . . . . . . . . . . . . . . . . . . . . . . . . . . . . . . . . . . 15

2.5 SOA para dados geoespaciais . . . . . . . . . . . . . . . . . . . . 15

2.5.1 Infraestrutura de Dados Espaciais . . . . . . . . . . . . . . 16

2.6 Serviço Geoespacial . . . . . . . . . . . . . . . . . . . . . . . . . . . . . . . . . 17

2.6.1 Sensor Observation Service . . . . . . . . . . . . . . . . . . . . . . . . . . . . . .

2.7 Integração de VGI e Geosensores . . . . . . . . . . . . . . . . . . 20

2.8 Considerações Finais . . . . . . . . . . . . . . . . . . . . . . . . . 22

3 Abordagem para Obtenção e Disponibilização de VGI 23

3.1 Considerações Iniciais . . . . . . . . . . . . . . . . . . . . . . . . . . 23

3.2 Visão Geral da Abordagem . . . . . . . . . . . . . . . . . . . . . . 24

3.3 Mecanismo para Interpretação das Variáveis Ambientais . . . . . . . . . . 26

3.4 Observatório Cidadão de Enchentes . . . . . . . . . . . . . . . . . . 31

3.5 Framework Volunteered Observation Service . . . . . . . . . . . . . . 35

3.5.1 Projeto do Framework . . . . . . . . . . . . . . . . . 39

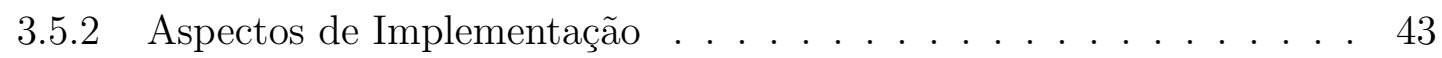

3.5 .3 Interações . . . . . . . . . . . . . . . . . . . . . . . . . . . . . . . . . . . . . 44

3.6 Considerações Finais . . . . . . . . . . . . . . . . . . 46 
4 Avaliação da Abordagem $\quad 47$

4.1 Considerações Iniciais . . . . . . . . . . . . . . . . . . . . 47

4.2 Experimentação . . . . . . . . . . . . . . . . . . . . . 47

4.3 Avaliação Experimental . . . . . . . . . . . . . . . . . . . . . . . . . 49

4.4 Resultados . . . . . . . . . . . . . . . . . . . . . 52

4.5 Avaliação do Framework . . . . . . . . . . . . . . . . . . . . . 56

4.6 Considerações Finais . . . . . . . . . . . . . . . . . . 56

5 Conclusão $\quad 59$

5.1 Visão Geral . . . . . . . . . . . . . . . . . . . . . . . 59

5.2 Contribuições . . . . . . . . . . . . . . . . . . . . . . 60

5.3 Dificuldades e Limitações . . . . . . . . . . . . . . . . . . . . . . 60

5.4 Trabalhos Futuros . . . . . . . . . . . . . . . . . . . . . 61

A Experimento: Volunteered Geographic Information para Gestão de Risco de Inundação 
2.1 Fases da Gestão de Desastres. . . . . . . . . . . . . . . . . . . . . . . 7

2.2 Componentes da Arquitetura Orientada a Serviço. . . . . . . . . . . . . . . 14

2.3 Ciclo de vida da metodologia de desenvolvimento de processos de negócio (Papazoglou e Heuvel, 2007) . . . . . . . . . . . . . . . . . . 16

2.4 Fluxograma do Consumidor (Adaptado de OGC (2007b)). . . . . . . . . 19

2.5 Fluxograma do Produtor (Adaptado de OGC (2007b)). . . . . . . . . . . 20

3.1 Arquitetura da abordagem AGORA. . . . . . . . . . . . . . 25

3.2 Régua linimétrica fixada junto ao leito do rio. . . . . . . . . . . . . 27

3.3 Pontos da cidade de São Carlos com régua (Zaffani e Mendiondo, 2012). . . 28

3.4 Faixa de cores pintada no leito do rio. . . . . . . . . . . . . . . 29

3.5 Boneco semelhante à figura humana pintado no leito do rio. . . . . . . . . 30

3.6 Marcações no boneco para medição da altura da água. . . . . . . . . . . . . 30

3.7 Marcações do nível de água em ponto não controlado. . . . . . . . . . . . . . 31

3.8 Categorias do Observatório Cidadão de Enchentes. . . . . . . . . . . . . . 32

3.9 Observatório Cidadão de Enchentes. . . . . . . . . . . . . . . . . 33

3.10 Aplicativo para celular do Observatório Cidadão de Enchentes para envio de relatos. . . . . . . . . . . . . . . . . . . 34

3.11 Interface de configuração do framework Volunteered Observation Service. 36

3.12 Visão geral do funcionamento do framework. . . . . . . . . . . . . . 36

3.13 Diagrama de caso de uso do framework. . . . . . . . . . . . . . . 37

3.14 Fornecimento das informações necessárias ao framework. . . . . . . . . . . 38

3.15 Seleção das categorias pelo usuário do framework . . . . . . . . . . . . . . . 38

3.16 Processo de uso da abordagem. . . . . . . . . . . . . . . . . . . . 39

3.17 Modelo de observação do SOS. . . . . . . . . . . . . . . . . . 40

3.18 Modelo de dados do VOS. . . . . . . . . . . . . . . . . . . . 41

3.19 Diagrama de classe do front-end do VOS. . . . . . . . . . . . . . . . . . . . . . . . . . . . . .

3.20 Diagrama de classe do back-end do VOS. . . . . . . . . . . . . . . . . 42

3.21 Relação entre os módulos front-end, back-end, plataforma Ushahidi e serviço SOS. . . . . . . . . . . . . . . . . . . . . . . . 43

3.22 Documento XML com informações do banco de dados. . . . . . . . . . . . 44

3.23 Interação entre o cliente e o framework. . . . . . . . . . . . . . . 45

3.24 Interação entre o cliente e o SOS. . . . . . . . . . . . . . . . . 46 
4.1 Processo de experimentação (Adaptado de (Wohlin et al., 2000)). . . . . . 49

4.2 Variáveis Dependentes e Independentes do Experimento. . . . . . . . . . . 50

4.3 Diferença entre as médias dos valores das informações voluntárias e dos dados do sensor. . . . . . . . . . . . . . . . . . . . 55

4.4 Recuperação das informações voluntárias do Observatório Cidadão de Enchentes pelo framework. . . . . . . . . . . . . . . . . 57

4.5 Aplicação GeoDashboard para o monitoramento de rios da cidade de São Carlos/SP . . . . . . . . . . . . . . . . . 57 


\section{Lista de Tabelas}

3.1 Relação entre dados da observação e dados do relato . . . . . . . . . . . . 40

3.2 Descrição das classes do módulo front-end. . . . . . . . . . . . . . . . . . 42

3.3 Descrição das classes do módulo back-end. . . . . . . . . . . . . . . . . . 42

4.1 Média das informações voluntárias . . . . . . . . . . . . . . . . . . 51

4.2 Média dos dados de sensor . . . . . . . . . . . . . . . . . 51

4.3 Experiência dos participantes no contexto de gestão de risco de inundação obtida por meio do questionário. . . . . . . . . . . . . . . . . . . 52

4.4 Diferença entre o valor observado pelo voluntário e o valor medido pelo sensor. . . . . . . . . . . . . . . . . 53

4.5 Resultado do Teste de Shapiro Wilk. . . . . . . . . . . . . . . 54

4.6 Resultado do Teste de Levene e do Teste T. . . . . . . . . . . . . . . . 55

4.7 Média dos valores das informações voluntárias e do sensor. . . . . . . . . . 55 



\title{
Lista de Abreviaturas e Siglas
}

\author{
AJAX \\ Asynchronous Javascript and XML \\ ANEAC \\ Associação Nacional dos Engenheiros e Arquitetos da Caixa Econômica Federal \\ AUDICAIXA \\ AUDITAR \\ DENS \\ DOM \\ GD \\ Associação dos Auditores Internos da Caixa Econômica Federal \\ União dos Auditores Federais de Controle Externo \\ Digital Earth's Nervous System \\ Document Object Model \\ Gestão de Desastres \\ GNU \\ General Public License \\ GPS \\ GRI \\ GWT \\ Global Positioning System \\ Gestão de Risco de Inundação \\ Google Web Toolkit \\ HTTP \\ Hypertext Transfer Protocol \\ IDE \\ IDL \\ IFC \\ IP \\ Infraestrutura de Dados Espaciais \\ Interface Description Language \\ Instituto de Fiscalização e Controle \\ Índice de Perigo \\ $\mathrm{OC}$ \\ Observatório Cidadão \\ OCE \\ Observatório Cidadão de Enchentes \\ OGC \\ Open Geospatial Consortium \\ O\&M \\ Observation and Measurement \\ REST \\ Representational State Transfer \\ SES \\ SensorML \\ Sensor Event Service \\ SOA \\ SOS \\ SOAP \\ SWE \\ UDDI \\ Volunteered Observation Service \\ Service Oriented Architecture \\ Sensor Observation Service \\ Simple Object Acess Protocol \\ Sensor Web Enablement \\ Universal Description, Discovery and Integration \\ UNACON \\ URI \\ Sindicato Nacional dos Analistas e Técnicos de Finanças e Controle \\ Uniform Resource Identifier \\ URL \\ Uniform Resource Locator \\ VGI \\ Volunteered Geographic Information \\ Volunteered Observation Service
}


XML

eXtensible Markup Language

WSDL

Web Service Description Language 


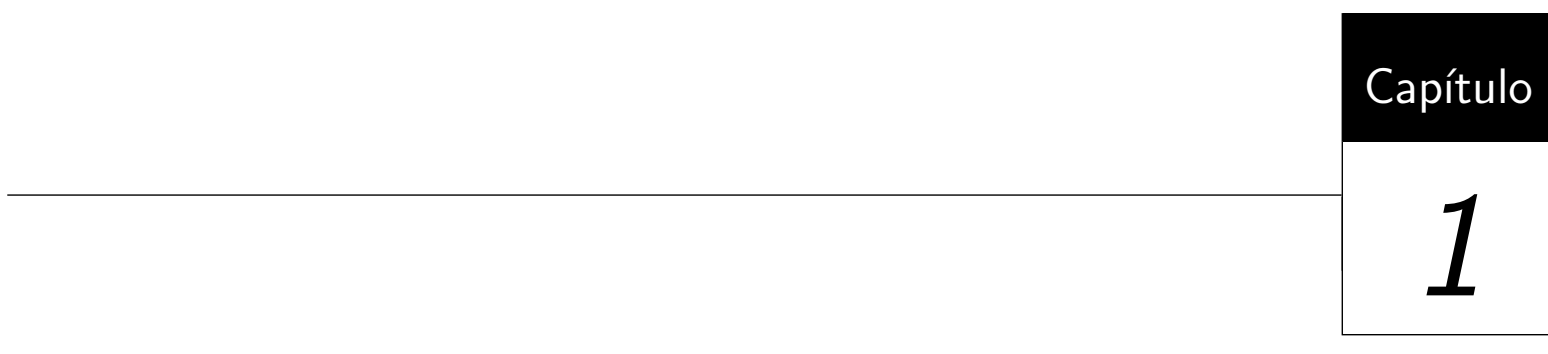

Introdução

\subsection{Contextualização}

As alterações climáticas, como precipitações extremas, vendavais, granizos, entre outros, estão aumentando o número e a intensidade de desastres naturais em todo o mundo (UN, 2013). Um desastre natural caracteriza-se pela ocorrência de um fenômeno natural sobre um sistema social, gerando uma situação de perigo a pessoas e bens, e acarretando danos (materiais e humanos) e prejuízos (socioeconômicos) (Kobiyama et al., 2006; Marcelino, 2007). Entre 2000 e 2012, os desastres naturais provocaram aproximadamente U\$ 1,7 trilhão em prejuízos econômicos, além de afetar 2,9 bilhões de pessoas e provocar a morte de 1,2 milhão (UNISDR, 2013). A ocorrência de desastres naturais está ligada não somente às características geoambientais, mas também à vulnerabilidade do sistema social (Alcántara-Ayala, 2002). Além disso, a urbanização mal planejada contribui para o perigo crescente de inundação, devido à ocupação desordenada e ao intenso processo de urbanização (Jha et al., 2012b). Assim, a prevenção a desastres naturais e a redução da vulnerabilidade são temas de grande preocupação para organizações locais, nacionais e internacionais (Levy et al., 2005).

Nessa perspectiva, a gestão de desastres (GD) visa reduzir ou evitar potenciais perdas e garantir assistência às vítimas (Poser e Dransch, 2010). A GD pode ser definida como um processo contínuo composto por quatro fases principais (mitigação, preparação, resposta e recuperação), que atuarão antes, durante e depois de um desastre natural (Poser e 
Dransch, 2010). Em particular, informações espaciais têm sido fundamentais para todo o processo de GD (Tu et al., 2009). Além disso, esse tipo de informação é essencial em todas as fases do processo para que ações sejam realizadas a fim de reduzir os impactos provocados ou identificar sua iminência. Para isso, as informações devem ser confiáveis, precisas e atualizadas (Poser e Dransch, 2010; Tu et al., 2009). Ainda, para obter uma visão geral da situação, informações de diferentes fontes precisam ser integradas (Poser e Dransch, 2010).

Em particular, as inundações representam cerca de $30 \%$ dos desastres naturais que ocorrem em todo o mundo, causando mais danos, mortes e impactos econômicos do que qualquer outro tipo de evento (van der Kooij, 2013). No Brasil, os problemas com inundações se intensificam no período de chuvas, que compreende os meses de dezembro a março. A gestão de risco de inundação (GRI) consiste no processo de gerenciar uma situação de risco de inundação existente (Plate, 2002). Seu objetivo é controlar os impactos provocados pela inundação, estando preparado para ela. Uma preparação eficaz requer que as áreas de risco sejam monitoradas antes que um desastre ocorra (Kobiyama et al., 2006; van der Kooij, 2013). Para isso, são necessárias informações precisas sobre o atual estado das variáveis ambientais, as quais permitem a simulação dos efeitos e da severidade de um desastre (van der Kooij, 2013; Plate, 2002). Esse tipo de simulação contribui para reduzir o impacto das inundações, ao permitir que a população das áreas afetadas tomem medidas preventivas, além de permitir que agências de emergência desenvolvam ações de resposta.

Informações espaciais coletadas por voluntários, denominadas Volunteered Geographic Information (VGI) (Goodchild, 2007), estão sendo utilizadas como fonte de dados para a gestão de desastres. Isso se deve ao fato de que VGI oferece um número potencialmente grande de voluntários que atuam como "sensores", observando importantes parâmetros locais para a gestão de desastres (Poser e Dransch, 2010).

Nesse cenário, as plataformas de crowdsourcing são utilizadas como ferramenta para auxiliar as organizações envolvidas na gestão de desastres a prestar assistência às vítimas dos desastres naturais, coletando informações de voluntários. Elas também possibilitam a obtenção de dados de mídias sociais, a fim fornecer às agências de emergência e a outras partes interessadas informações em tempo real e geolocalizadas. Além disso, essas plataformas permitem que os voluntários enviem relatos via e-mail, mensagem de texto (SMS), aplicativos para celular e por meio do Web site, sendo esses dados localizados em mapas interativos em tempo real. Atualmente, diferentes plataformas de crowdsourcing estão em funcionamento, mapeando desde tempestades até terremotos (Haiti 2010), inundações (Paquistão 2010/2011), entre outros. O monitoramento contínuo do risco de inundação requer informações locais específicas, como precipitação e altura da água, para avaliar 
o potencial risco de inundação. Ainda, muitas vezes essas informações estão dispersas em diferentes fontes de dados, o que dificulta sua obtenção. Nesse sentido, Schade et al. (2013) e Longueville et al. (2010a) propuseram uma abordagem a fim de recuperar tais informações. Contudo, os autores não consideraram as informações oriundas de plataformas de crowdsourcing.

\subsection{Motivação}

Atualmente, diferentes tipos de desastres naturais têm ocorrido em todo o mundo, acarretando grandes prejuízos econômicos, materiais e humanos. Gerir um desastre natural com eficácia tem se tornado um fator importante a fim de minimizar os impactos por ele provocados. Em particular, a gestão de risco de inundação requer informações específicas a fim de monitorar uma área de risco, antes que uma inundação ocorra.

A gestão de desastres tem contado com o uso de plataformas de crowdsourcing para coletar informações voluntárias. Contudo, as plataformas de crowdsourcing existentes obtêm informações voluntárias relacionadas à fase de resposta, como informações sobre vítimas, extensão do desastre, serviços disponíveis, etc. Ainda, não há uma plataforma de crowdsourcing configurada que possibilite aos voluntários enviar informações sobre medições das variáveis ambientais relacionadas à fase de preparação da gestão de risco de inundação. Além disso, a gestão de desastres necessita de informações de diferentes fontes de dados, para obter uma visão geral da situação. Durante o desastre, localizar e acessar os dados necessários ainda é uma tarefa muito difícil, sobretudo a recuperação de informações voluntárias. Segundo Tu et al. (2009), dentre os problemas enfrentados pelas agências de emergência durante a gestão de desastre está a dificuldade em contar com um único repositório que possibilite publicar e compartilhar informações e, também, a não existência de um padrão de metadados para descrever os recursos de dados. Esses problemas dificultam a organização e o acesso aos dados, prejudicando a construção efetiva da resiliência, adaptação e resposta aos desastres.

A fase de preparação da gestão de risco de inundação é uma área pouco explorada e com poucas ferramentas de apoio. No contexto desse trabalho, poucos estudos foram encontrados sobre a fase de preparação da GRI. Isso motiva a pesquisar mais profundamente sobre essa fase e propor mecanismos e ferramentas que a auxiliem e sejam compreensíveis/acessíveis por todos os envolvidos. Assim, esse trabalho de mestrado contribui para o desenvolvimento de uma abordagem que visa apoiar tal fase, facilitando a obtenção e o acesso às informações, colaborando com a construção efetiva da resiliência. 


\subsection{Objetivo}

O objetivo deste trabalho foi propor uma abordagem que visa apoiar a gestão de risco de inundação. A finalidade dessa abordagem é fornecer mecanismos para a obtenção de informações voluntárias úteis para a gestão de inundação, além de disponibilizar essas informações de forma interoperável por meio de serviços geoespaciais. Assim, essa abordagem consiste em três partes principais: a) mecanismos para apoiar os voluntários a melhor interpretar as variáveis ambientais (altura da água e áreas alagadas); b) um Observatório Cidadão de Enchentes, criado a partir da configuração de uma plataforma de crowdsourcing existente, para a obtenção de informações voluntárias úteis para a GRI (por exemplo, altura da água no leito do rio e áreas alagadas) e c) um framework que permite disponibilizar, de forma interoperável, as informações geográficas voluntárias juntamente com dados de redes de sensores, usando serviços geoespaciais.

Como apoio à abordagem proposta, uma plataforma de crowdsourcing foi configurada, a fim de coletar informações voluntárias relacionadas à gestão de risco de inundação e um framework Web foi desenvolvido para recuperar informações voluntárias, de plataformas de crowdsourcing, e disponibilizá-las por meio de serviços geoespaciais.

Por fim, um experimento foi realizado para avaliar a eficácia dos métodos desenvolvidos em disponibilizar informações específicas para a gestão de risco de informação.

\subsection{Organização}

Esta dissertação está organizada da seguinte forma. No Capítulo 2 são apresentados os principais conceitos utilizados para o desenvolvimento desse trabalho. No Capítulo 3 é apresentada a abordagem proposta. No Capítulo 4 é apresentada o experimento conduzido como parte da avaliação da abordagem. Por fim, no Capítulo 5, são apresentadas as conclusões desse trabalho, ressaltando suas contribuições, dificuldades e limitações encontradas durante seu desenvolvimento e sugestões de trabalhos futuros. 


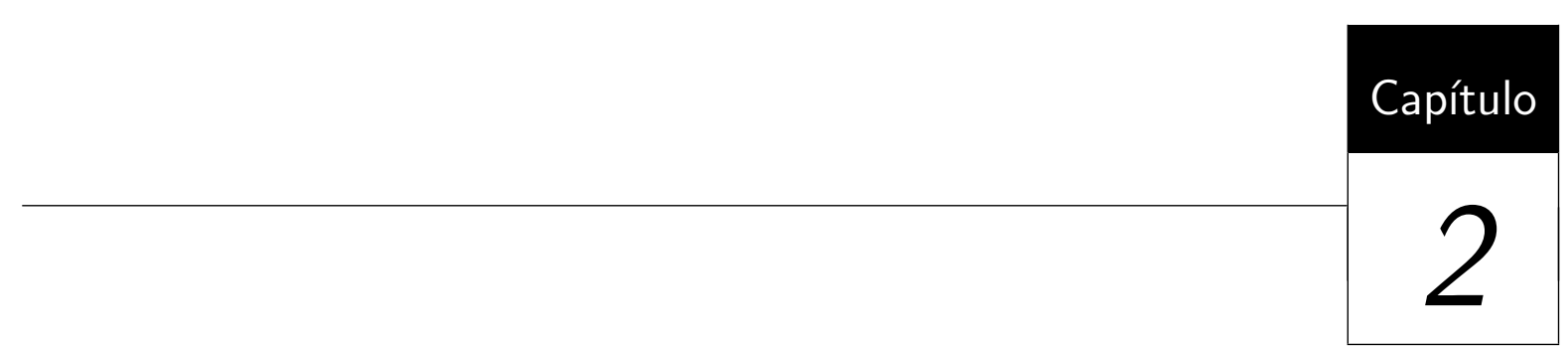

Fundamentação Teórica

\subsection{Considerações Iniciais}

Neste capítulo são apresentados os conceitos e tecnologias sobre as quais este projeto de mestrado está fundamentado. O capítulo está organizado da seguinte forma: na Seção 2.2 é apresentada a definição de gestão de desastres, bem como todas as fases que compõem seu ciclo de vida, e a definição de gestão de risco de inundação. Na Seção 2.3 é abordado o conceito de Volunteered Geographic Information, visto que este vem sendo utilizado durante todo o ciclo de vida da gestão de desastres. Além disso, é abordado o conceito de Observatório Cidadão, pois esse utiliza informações voluntárias como fonte de informação. Na Seção 2.4, o conceito de Arquitetura Orientada a Serviço é definido. Na Seção 2.5 o uso desse estilo arquitetural para dados geoespaciais é abordado. Na Seção 2.6 é apresentado o serviço geoespacial Sensor Observation Service, proposto pela Open Geospatial Consortium. Por fim, na Seção 2.7 é discutido a integração de informações VGI e de geosensores.

\subsection{Gestão de Desastres}

Nos últimos anos, tem-se observado uma crescente atenção dada aos riscos ambientais e seu potencial impacto sobre desastres naturais, sobretudo devido ao crescimento da frequência com que esses desastres têm ocorrido. Um desastre natural é o resultado de 
um fenômeno natural extremo sobre um sistema social que causa sérios danos (materiais e humanos) e prejuízos (socioeconômicos) à sociedade (Kobiyama et al., 2006; Marcelino, 2007).

Recentemente, desastres naturais como o terremoto ocorrido no Haiti (2010), no Chile (2010), Christchurch (2011), as inundações no Paquistão (2010/2011), em Queensland (2011), o terremoto e o tsunami em Tohoku (2011) provocaram 333.944 vítimas e \$US 199.3 a 327.3 bilhões em perdas econômicas (Erskine e Gregg, 2012). Os impactos provocados por um desastre natural podem ser reduzidos por meio de uma gestão de desastre natural efetiva (Baharin et al., 2009). Nesse sentido, a gestão de desastres é um processo contínuo que visa reduzir ou evitar potenciais perdas e garantir assistência às vítimas (Poser e Dransch, 2010). Ela é a disciplina responsável por mitigar, preparar, responder e recuperar de desastres naturais, com o objetivo de salvar vidas, propriedades e o meio ambiente (Asimakopoulou e Bessis, 2011).

A GD é composta por atividades antes, durante e depois de um desastre natural e está dividida em quatro fases principais: mitigação, preparação, resposta e recuperação (Figura 2.1) (Poser e Dransch, 2010; Vivacqua e Borges, 2012), sendo que nem sempre ocorrem isoladamente ou nesta ordem. Todas as fases possuem diferentes necessidades de informação para melhor realizar suas atividades, por isso elas precisam ser precisas e atualizadas. Assim, informações de diferentes fontes de dados (sensores, sismógrafos, satélites, entre outros) precisam ser integradas. Essas informações ajudam a aprimorar a resiliência de comunidades vulneráveis, além de auxiliar nas atividades exercidas pelas agências de emergência durante todo o ciclo de vida da GD. As características de cada fase são apresentadas a seguir.

- Mitigação: esta fase refere-se às ações destinadas a reduzir a vulnerabilidade da comunidade ou minimizar os efeitos de futuros desastres (Poser e Dransch, 2010; Vivacqua e Borges, 2012). As atividades pertencentes a essa fase têm como objetivo eliminar ou reduzir a probabilidade de ocorrência de desastres. Sua eficácia dependerá da disponibilidade de informações referentes a perigos, riscos e medidas a serem tomadas (Vivacqua e Borges, 2010);

- Preparação: envolve planejar a melhor maneira de responder a um desastre antes que ele ocorra (Poser e Dransch, 2010; Vivacqua e Borges, 2010), incluindo treinamento de equipes, avaliação contínua do plano, recursos e manutenção de equipamentos, e realização de estudos dos impactos que possam surgir de um desastre em particular (Vivacqua e Borges, 2012);

- Resposta: dentre as fases envolvidas no ciclo de vida da gestão de desastres, esta é considerada a mais complexa. Ela é caracterizada por ter início logo após um 
desastre ter ocorrido. Algumas de suas características são: imprevisibilidade, velocidade dos acontecimentos, número de pessoas envolvidas, decisões e ações rápidas, indisponibilidade de recursos, entre outras (Vivacqua e Borges, 2012). Em princípio, esta fase constitui colocar em ação os planos desenvolvidos e exercitados na fase anterior (Poser e Dransch, 2010; Vivacqua e Borges, 2012), a fim de conter os danos causados pelo desastre;

- Recuperação: esta fase tem início assim que o desastre é controlado e pode se estender por dias, semanas, meses ou até anos. O principal objetivo desta fase é reparar, reconstruir ou recuperar o que foi perdido durante o desastre (Poser e Dransch, 2010; Vivacqua e Borges, 2012). Essa é frequentemente considerada como um conjunto de atividades que visam reestabelecer a comunidade atingida.

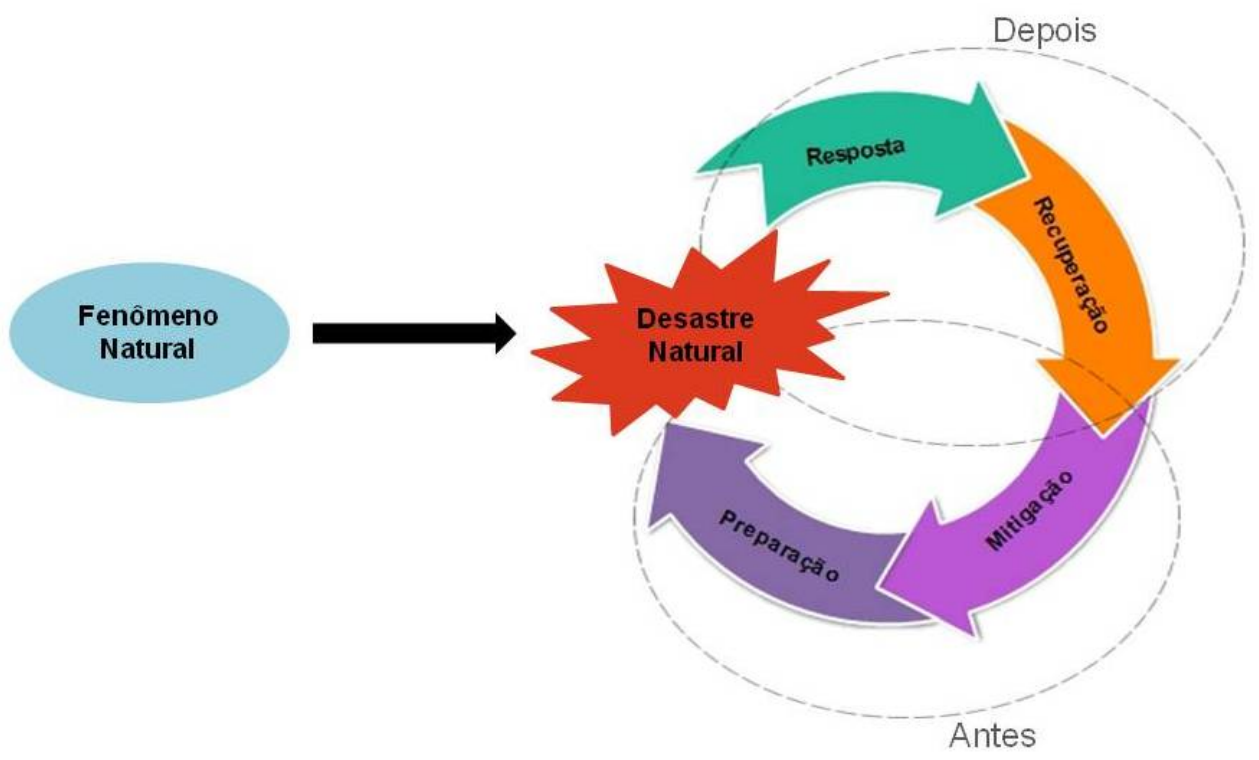

Figura 2.1: Fases da Gestão de Desastres.

Em particular, no Brasil, a constante ocorrência de inundações, durante o período de chuvas que compreende os meses de Dezembro até Março, em várias cidades, requer um gerenciamento eficaz das fontes de dados a fim de minimizar os impactos provocados. A gestão de risco de inundação é a subárea da gestão de desastres voltada especificamente para o gerenciamento de inundações.

\subsubsection{Gestão de Risco de Inundação}

A gestão de risco de inundação (GRI) é o processo de gerenciar uma situação de risco de inundação existente. Seu objetivo é controlar uma inundação, estando preparado para ela e minimizando seus impactos (Plate, 2002). Ainda, a GRI abrange ações antes, durante 
e depois de uma inundação ocorrer. Essas ações envolvem alertas precoces e previsão de cenário, planos de contingência e restauração (Mendiondo, 2005). Segundo Crichton e Mounsey (1997), o risco de inundação pode ser considerado como a relação entre ameaça, vulnerabilidade e exposição, sendo a ameaça o fenômeno natural que atinge uma determinada região, nesse contexto, a inundação; a exposição representada pelas pessoas e bens econômicos que se encontram na área afetada; e a vulnerabilidade indicada pela capacidade de uma região em sofrer o impacto causado por um evento extremo.

Dentre os desastres naturais que ocorrem em todo o mundo, as inundações são as mais frequentes. Além disso, o número de pessoas afetadas e os danos financeiros e econômicos têm aumentado a cada ano (Jha et al., 2012a). O crescente aumento no número de inundações está relacionado às mudanças climáticas, sendo agravada devido ao crescimento urbano desordenado e ao fenômeno da urbanização acelerada sem a disponibilidade dos serviços essenciais (MIN, 2013; da Silva, 2009).

Na GRI, a fase de preparação possui como objetivo principal reduzir o risco residual por meio de sistemas de alerta e medidas que podem ser realizadas a fim de minimizar os impactos provocados por uma inundação. Para isso, é necessário o monitoramento constante dos riscos existentes e uma avaliação do perigo decorrente a partir de informações recentes. Cada dólar investido em prevenção de inundação reduz em U $\$ 25$ dólares os danos incorridos no caso de um desastre natural (Mendiondo, 2005). Inundações urbanas são especialmente importantes, pois muitos cidadãos se concentram em torno das áreas de risco (Mendiondo, 2005). Em particular, inundações bruscas são eventos que causam numerosos danos devido à dificuldade de prever um evento desse tipo, em virtude do curto tempo de deslocamento da onda de cheia, a qual impede previsões com maior antecedência (Fava et al., 2013).

Atualmente, informações geográficas e tecnologias relacionadas possuem papel fundamental em todas as fases da GRI. Desastres naturais são tipicamente monitorados utilizando diferentes dispositivos, como sensores, satélites, sismógrafos, entre outros. Contudo, esses dispositivos não oferecem informações sobre os impactos provocados por tais desastres. Poser e Dransch (2010) utilizaram informações geográficas provindas de cidadãos afetados pela inundação para estimar os impactos por ela causados. Assim, informações voluntárias, comumente conhecidas como VGI, podem ser uma fonte de informação valiosa sobre os impactos decorrentes de desastres naturais (Longueville et al., 2010a), devido ao número potencialmente grande de voluntários que atuam como "sensores"observando importantes parâmetros da gestão de desastres em um ambiente local (Poser e Dransch, 2010). 


\subsection{Volunteered Geographic Information}

Com o avanço da Internet e dos dispositivos móveis, os usuários passaram não só a utilizar as informações geográficas disponíveis online, mas também a fornecê-las. Esse tipo de informação é denominada Volunteered Geographic Information (VGI) (Goodchild, 2007). Outrora, a criação de informações geográficas era realizada somente por agências oficiais. Contudo, com o aumento das interações viabilizadas pela Web 2.0, o uso de dispositivos com GPS (Global Positioning System) e o acesso a Internet com conexão de alta capacidade, informações geográficas estão sendo produzidas por cidadãos que possuem pouca qualificação formal. Entre as vantagens associadas ao VGI, pesquisadores destacam seu uso para enriquecer, atualizar ou completar conjuntos de dados geoespaciais existentes (Goodchild, 2007). Em diferentes contextos as informações voluntárias possuem melhor qualidade que os dados disponibilizados por organizações especializadas, visto que em diferentes partes do mundo essas informações estão desatualizadas ou então foram adquiridas com tecnologias antigas e menos precisas do que as disponíveis atualmente para o público geral (Goodchild e Li, 2012).

Um certo número de aplicações desfrutam do uso de VGI como fonte de informação. Um dos exemplos mais interessantes do uso de VGI é a plataforma Wikimapia ${ }^{1}$. Essa é uma plataforma de mapeamento colaborativo que tem como objetivo marcar e descrever objetos geográficos em todo o mundo. De maneira semelhante, a plataforma colaborativa OpenStreetMap ${ }^{2}$ visa criar um mapa de todo o mundo a partir de dados fornecidos por cidadãos. A origem dessa plataforma foi inspirada no sucesso de outra plataforma colaborativa, a Wikipedia ${ }^{3}$. Essa é uma enciclopédia colaborativa e multilíngue, onde o conteúdo é escrito colaborativamente por voluntários ao redor do mundo.

Desastres naturais recentes têm mostrado que informações de voluntários, fornecidas pela Internet, podem melhorar a consciência situacional, fornecendo uma visão geral sobre a presente situação (Poser e Dransch, 2010). Tal fato ocorre, pois VGI oferece uma grande oportunidade para aumentar a consciência devido ao número potencialmente grande de voluntários, mais de seis bilhões de pessoas, que agem como "sensores", observando importantes parâmetros da gestão de desastres em um ambiente local (Goodchild, 2007; Poser e Dransch, 2010; Schade et al., 2013). Ainda, apesar dos recentes avanços no desenvolvimento de sensores, suas observações podem não estar disponíveis devido a interrupções de comunicação ou, até mesmo, a destruição do sensor, além de os mesmo não serem capazes de medir certos fenômenos, como tempestades de granizo (Poser e Dransch, 2010).

\footnotetext{
${ }^{1}$ http://www.wikimapia.org

${ }^{2}$ http://www.openstreetmap.org

${ }^{3}$ http://www.wikipedia.org
} 
Poser e Dransch (2010) utilizaram informações fornecidas por cidadãos, afetados pela inundação ocorrida no ano de 2002 na cidade de Eilenburg, na Alemanha, para estimar os impactos por ela causados. Além disso, o uso de informação proveniente de voluntários mostrou-se essencial após o terremoto no Haiti em 2010, pois os mapas existentes da cidade de Porto Príncipe (área mais atingida) estavam desatualizados e não continham informações suficientes, dificultando a coordenação das atividades das equipes de resgate (Roche et al., 2011). Em particular, o uso de VGI no contexto de gestão de desastres vem sendo amplamente utilizado. Alguns exemplos são as inundações ocorridas no Paquistão em 2010, Queensland em 2010/2011, Tailândia em 2011, terremoto no Haiti em 2010, queimada na França em 2009, entre outros (Kaewkitipong et al., 2012; Longueville et al., 2009; McDougall, 2011; Munro, 2010; Zook et al., 2010).

Contudo, apesar das vantagens da participação da população em coletar informações, há um grande número de desafios a serem enfrentados. Apesar do potencial do VGI, a qualidade dos dados é a maior preocupação. Informações provenientes de muitos indivíduos pode ocasionar dúvidas sobre a credibilidade (Erskine e Gregg, 2012). Segundo Longueville et al. (2010b), a credibilidade do VGI pode ser entendida como uma noção subjetiva que descreve se parte de uma informação pode ser confiável, considerando qualquer possível erro intencional ou não, omissão ou exagero. Além disso, não se sabe de antemão quanto e a partir de onde a informação será fornecida. Outro desafio enfrentado refere-se à localização. Diferentemente dos sensores in-situ, as pessoas estão em constante movimento, assim as observações por elas realizadas precisam ser localizadas para que se tornem úteis (Poser e Dransch, 2010). Além disso, VGI é, muitas vezes, considerada como insuficientemente estruturada, documentada e validada (Longueville et al., 2010b).

Nesse cenário, diferentes plataformas de software vêm sendo empregadas com o intuito de coletar informações voluntárias, permitir sua visualização e análise. Em particular, essas são utilizadas como ferramentas para ajudar vítimas de desastres naturais. Além disso, diversas aplicações de software utilizam informações voluntárias como fonte de dados em tempo real para a GD.

\subsubsection{Observatório Cidadão}

Atualmente, diversas plataformas de crowdsourcing apoiam a gestão de desastres, permitindo coletar informações de cidadãos das áreas atingidas, bem como sua análise e visualização. O termo crowdsourcing refere-se a uma forma de organizar o trabalho, o qual envolve um sistema de informação para coordenar e acompanhar as tarefas realizadas por pessoas (Miorandi et al., 2013). Além disso, esse termo pode ser entendido como um modelo de produção no qual a inteligência e os conhecimentos de voluntários são utilizados para resolver problemas, criar conteúdo ou desenvolver novas tecnologias. Ao utilizar 
voluntários para desempenhar uma tarefa específica, como o monitoramento ambiental, esses se tornam coletivamente um Observatório Cidadão (OC), onde os dados podem ser coletados, coligidos e publicados (Miorandi et al., 2013). Assim, o termo Observatório Cidadão pode ser entendido como uma plataforma de software a fim de obter informações voluntárias sobre um tema específico, por meio de diferentes dispositivos (navegador de um computador, aplicativo para celular e SMS), além de permitir sua visualização. Esse, por sua vez, pode ser utilizado para compartilhar informações sobre os riscos relacionados à inundação, como altura da água no leito do rio ou áreas alagadas.

Um OC foi utilizado durante o terremoto que atingiu o Haiti em 2010 (Zook et al., 2010). Nele os cidadãos das áreas atingidas podiam enviar relatos sobre incidentes ocorridos nessas áreas. Assim, a relação entre os eventos ocorridos e pontos específicos das áreas atingidas eram facilmente discernidos, além de apoiar as agências de emergência a melhor determinar onde empregar seus recursos. Nesse mesmo ano, um terremoto atingiu o Chile, acarretando em milhares de vítimas. Inicialmente, foram coletadas informações da população local, por meio de mensagens de texto, e de fontes de mídias tradicionais (Carlsen et al., 2011). Essas informações foram, então, mapeadas para um OC, apoiando as agências de emergência e órgãos governamentais. Em 2011, durante as inundações ocorridas em Queensland, a Australian Broadcasting Corporation lançou um OC para mapear as áreas inundadas (McDougall, 2011). Esse permitiu que indivíduos enviassem informações sobre a inundação por meio de e-mail, mensagens de texto, Twitter ou pela própria plataforma, sendo essas informações disponibilizadas para qualquer pessoa que tivesse acesso à internet. Ainda, outros observatórios cidadão foram empregados durante eventos extremos, como durante as inundações no Paquistão em 2010 ${ }^{4}$, Boulder (USA) em $2013^{5}$, entre outros. Dentre as plataformas de crowdsourcing existentes, utilizadas como observatórios cidadãos, a plataforma Ushahidi vem sendo usada em dezenas de desastres naturais em todo o mundo (Meier, 2013).

\subsubsection{Ushahidi}

Ushahidi, que significa "testemunho" em Suaíli, foi desenvolvida no início de 2008 a fim de mapear relatos sobre incidentes de violência contra a população do Quênia após as eleições presidenciais. O principal objetivo da plataforma é utilizar os benefícios da informação voluntária para compartilhar informações sobre acontecimentos ocorridos onde rumores e incertezas são dominantes (Okolloh, 2009), além de criar um sistema que facilita alertas precoces e auxilia na visualização de dados para resposta e recuperação de eventos extremos (Ushahidi, 2013). Além disso, a plataforma permite que qualquer pessoa ao redor

\footnotetext{
${ }^{4} \mathrm{http}: / /$ pakreport.org/ushahidi/

${ }^{5}$ https://boulderflood2013b.crowdmap.com/
} 
do mundo possa configurar sua própria plataforma a fim de obter relatos, por meio de diferentes dispositivos, e mapeá-los.

Um relato é formado por um conjunto de informações fornecidas pelo voluntário, as quais descrevem o incidente por ele observado. Esse é constituído por informações obrigatórias, informações que o voluntário deve inserir em todos os relatos, e informações opcionais (nome, sobrenome, e-mail, link de fonte de notícia, link de vídeo externo e foto), que podem ou não serem inseridas. As informações obrigatórias são formadas pelo título, descrição, nome do local e categoria do relato. Cada uma dessas informações pode ser entendida como:

- Título: representa o assunto abordado no relato;

- Descrição: representa o incidente reportado;

- Nome do Local: representa o local o qual o voluntário está se referindo, por exemplo, uma rua, um bairro;

- Categoria: representa um tópico específico do assunto abordado pela plataforma, por exemplo, em caso de eventos extremos, uma categoria pode ser definida como: alimentos, abrigos, hospitais, fontes de água, etc;

Inicialmente, os voluntários podiam enviar seus relatos por meio do Web site, por mensagens de texto (SMS) e e-mail, sendo o aplicativo para celular e a rede social, Twitter, incorporados nos últimos anos.

Um dos desafios presentes ao utilizar informações voluntárias, está relacionado à incerteza acerca da credibilidade dos relatos fornecidos. Pensando nisso, os desenvolvedores da plataforma desenvolveram um mecanismo para apoiar a classificação da veracidade de um relato. Antes de serem disponibilizados online, os relatos inseridos na plataforma passam por uma aprovação. Essa é realizada pelo administrador da plataforma de forma manual. Todos os relatos nela inseridos são classificados, primeiramente, como não aprovados. Cabe ao administrador verificar seu conteúdo e aprová-lo. Uma vez aprovado, o relato pode ter dois status: verificado e não verificado. O status verificado indica que o administrador pode confirmar a informação contida no relato por meio de outras fontes de informação ou por outros voluntários. O status não verificado indica que o administrador não encontrou outras fontes de informação que comprovassem a informação contida no relato. Da mesma forma, os relatos enviados via SMS são manualmente checados pelo administrador da plataforma, antes de serem disponibilizados online.

Desde o seu lançamento, a plataforma vem sendo utilizada para governança local, monitoramento ambiental, mapeamento de saúde pública, monitoramento dos direitos 
humanos, observações eleitorais, protestos não violentos, resposta a desastres e mapeamento de crise (Iacucci, 2013). Além disso, devido as diferentes possibilidades de cenário, a plataforma vem sendo, ou foi, empregada na Namíbia, Uganda, República Democrática do Congo, Haiti, Gaza, Chile, Queensland, Síria e Brasil.

No Brasil, essa plataforma é empregada para o mapeamento de diferentes tópicos, como emendas parlamentares e alagamentos. Atualmente, existem duas instâncias dessa para o monitoramento de emendas parlamentares, sendo uma utilizada para o contexto do Distrito Federal e outra para esfera nacional. Em ambos os casos, um cidadão pode inserir, na forma de relato, o número, o valor, o autor, entre outras informações, de uma emenda parlamentar. Em particular, grande parte das informações é inserida pelo Instituto de Fiscalização e Controle (IFC), grupo de voluntários, profissionais da área de fiscalização e controle, ligados a entidades como AUDITAR (União dos Auditores Federais de Controle Externo), UNACON (Sindicato Nacional dos Analistas e Técnicos e Finanças e Controle), AUDICAIXA (Associação dos Auditores Internos da Caixa Econômica Federal), ANEAC (Associação Nacional dos Engenheiros e Arquitetos da Caixa Econômica Federal), entre outras. Além disso, essa plataforma é, também, utilizada para o monitoramento de pontos de alagamento na cidade de São Paulo/SP, sendo as informações fornecidas pelos próprios cidadãos. Nessa, os voluntários podem enviar suas observações por meio do Web site ou do aplicativo para celular.

\subsection{Arquitetura Orientada a Serviços}

O ambiente de negócio tem se tornado mais dinâmico, apresentando comportamento volátil e exigindo maior agilidade por parte das empresas em se adaptar mais rapidamente às necessidades de negócio. Essa dinamicidade impõe a necessidade em desenvolver sistemas mais flexíveis e ágeis, permitindo alta capacidade de customização, para que as novas demandas de negócios possam ser atendidas em tempo hábil (Marzullo, 2009). Dentro desse cenário, o conceito de Arquitetura Orientada a Serviços (do inglês, Service Oriented Architecture (SOA)) vem sendo empregado.

SOA estabelece um modelo arquitetônico que visa aprimorar a eficiência, a agilidade e a produtividade de uma empresa, posicionando os serviços como os principais meios para a solução lógica dos objetivos estratégicos associados à computação orientada a serviços (Erl, 2009; Fugita e Hirama, 2012). Esse estilo arquitetural é caracterizado por disponibilizar suas funcionalidades na forma de serviços. Um serviço é uma unidade de software que tem como propósito desempenhar uma função específica. Esse, por sua vez, possui funcionalidades distintas que encapsulam um conceito de negócio. Segundo Fugita e Hirama (2012); Sommerville (2011), uma SOA é caracterizada pela interação entre três 
tipos de agentes de software: provedor de serviço, consumidor de serviço e registro de serviço (Figura 2.2).

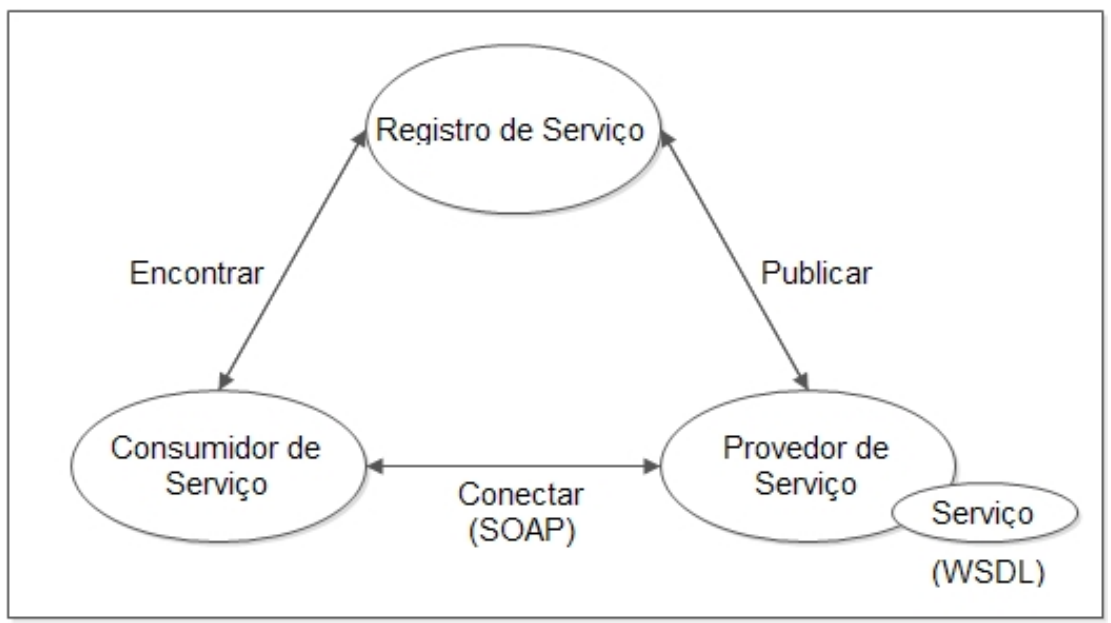

Figura 2.2: Componentes da Arquitetura Orientada a Serviço.

- Provedor de serviço: agente responsável por desenvolver o serviço, fornecer suas descrições e prestar suporte técnico ao mesmo;

- Consumidor de serviço: agente que necessita solicitar a execução de uma funcionalidade. O consumidor busca nos registros a descrição de um serviço que satisfaça às suas necessidades;

- Registro de Serviço: agente que registra informações sobre as funções oferecidas, os requisitos para se utilizar o serviço e informações para se conectar ao provedor do serviço.

Atualmente, a plataforma tecnológica de serviço web (do inglês, Web Service) é a mais associada à realização da SOA (Erl, 2009). Essa plataforma é utilizada para integrar sistemas e, também, na comunicação entre diferentes aplicações. Os serviços web permitem, então, que novas aplicações possam interagir com aplicações já existentes e sistemas desenvolvidos em diferentes plataformas possam se comunicar. Dessa forma, cada serviço pode ser desenvolvido em uma linguagem de programação diferente, sendo que um serviço pode se conectar a outro sem que estejam escritos com a mesma linguagem de programação. Para isso, essa tecnologia se baseia em quatro padrões que possibilitam a integração e comunicação entre as aplicações.

- Simple Object Acess Protocol (SOAP): é um protocolo para troca de mensagens entre serviços web. Esse protocolo oferece um formato comum de troca de mensagens entre os serviços e utiliza o XML (eXtensible Markup Language) como 
padrão para codificação dos dados. Além disso, SOAP descreve os meios nos quais uma mensagem SOAP pode ser transportada em diferentes cenários (Roshen, 2009);

- Web Service Description Language (WSDL): é um padrão baseado em XML para descrever formalmente a interface do serviço. Esse padrão define como as operações do serviço, nome da operação, parâmetro e seus tipos, bem como suas associações devem ser definidos (Sommerville, 2011). Além disso, o documento WSDL descreve um contrato entre o consumidor e o provedor de serviço. Esse documento representa dois aspectos principais do serviço: a interface abstrata e a descrição da implementação concreta. A primeira descreve a estrutura geral da interface, incluindo as operações do serviço, seus parâmetros e os tipos abstratos de dados. Por outro lado, a descrição da implementação concreta conecta a descrição da interface abstrata a um endereço de rede, protocolo de comunicação e estruturas de dados concretos (Roshen, 2009);

- Universal Description, Discovery and Integration (UDDI): é o padrão utilizado para definir formalmente um meio para registrar, cancelar o registro e procurar por serviço web no registro de serviços.

Os serviços web são utilizados para disponibilizar serviços na web. Um dos principais motivos pelo qual os serviços web tornaram-se atrativos é devido ao fato deste modelo ser baseado em padrões. Entretanto, hoje a maioria das empresas ainda está longe de se beneficiar do potencial dessa tecnologia, incorporada em sua capacidade de compor serviços. O desenvolvimento da metodologia de ciclo de vida é de importância crucial para projetar, construir, monitorar e gerenciar aplicações corporativas SOA que sustentam os ecossistemas de negócios existentes que são altamente complexos e ágeis em sua natureza. A metodologia de desenvolvimento orientada a serviços baseada em processos de negócio é fundamentada em um roteiro que compreende uma fase preparatória para planejar o desenvolvimento, e cinco fases distintas que se concentram em processos de negócios: análise e design, construção e testes, fornecimento, implantação e execução e monitoramento (Papazoglou e Heuvel, 2007), como mostrado na Figura 2.3.

\subsection{SOA para dados geoespaciais}

A arquitetura SOA para dados geoespaciais vem sendo utilizada em diferentes contextos ao longo dos anos. Diversas iniciativas têm contribuído para conceber e implementar uma Infraestrutura de Dados Espaciais que fosse abrangente e aproximasse diferentes provedores de dados geográficos (Oliveira et al., 2010). Para aplicações que utilizam dados espaciais, a tecnologia de serviço web proporciona uma forma de acesso padronizado e 


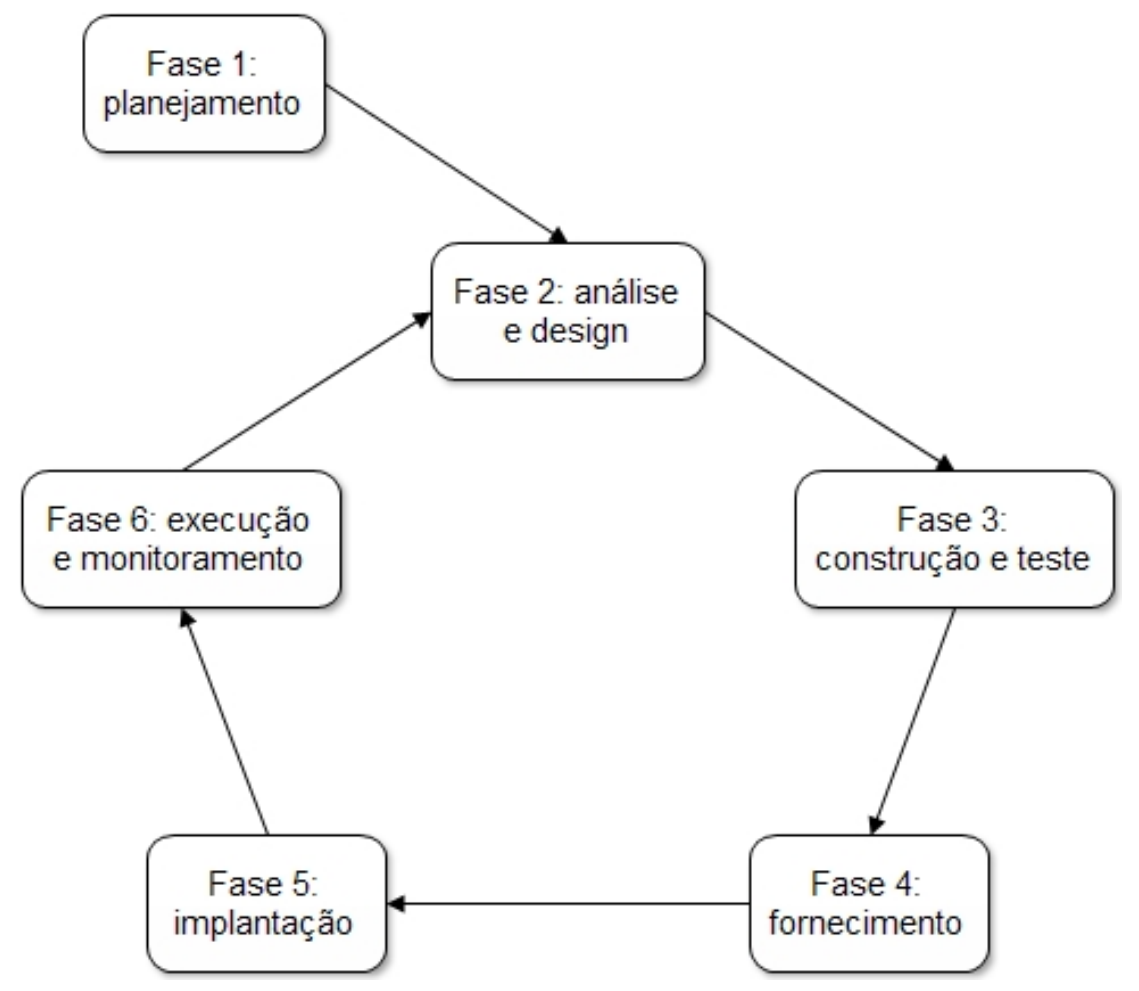

Figura 2.3: Ciclo de vida da metodologia de desenvolvimento de processos de negócio (Papazoglou e Heuvel, 2007).

tecnologicamente neutra. O grande volume de dados transmitidos pelos serviços geoespaciais tornam o desenvolvimento de serviços web mais difícil. Esses serviços visam facilitar a troca e a utilização de informações geográficas armazenadas em bancos de dados heterogêneos distribuídos (Tu e Abdelguerf, 2006). A organização Open Geospatial Consortium usa os conceitos de SOA para viabilizar a interoperabilidade na utilização de dados espaciais por sistemas de diferentes empresas e tecnologias. Para isso, ela disponibiliza normas e especificações para a implementação de serviços web que são capazes de receber ou transmitir dados espaciais.

\subsubsection{Infraestrutura de Dados Espaciais}

O termo "Infraestrutura de Dados Espaciais" (IDE) (do inglês, Spatial Data Infrastructure) é utilizado para designar uma coleção base de tecnologias, políticas e arranjos institucionais que facilitam a disponibilização e o acesso a dados espaciais (Aalders e Moellering, 2001; GSDI, 2004). Ela provê uma base para a descoberta de dados geográficos, avaliação e aplicação desses para diferentes contextos. A palavra infraestrutura é utilizada para promover o conceito de um ambiente de confiança e apoio, facilitando o acesso à informação geográfica relacionada, utilizando um conjunto de práticas padrão, protocolos e especificações. Uma IDE deve ser mais que dados ou banco de dados, essa deve armazenar dados geográficos e atributos, metadados, além de fornecer um meio para descobrir, 
visualizar e avaliar os dados, além de métodos para prover o acesso aos dados geográficos (GSDI, 2004; Rajabifard e Williamson, 1999). O objetivo principal de uma IDE está em facilitar e coordenar o intercâmbio e compartilhamento de dados espaciais entre as partes interessadas de diferentes níveis da comunidade de dados espaciais. Além disso, uma IDE destina-se a criar um ambiente no qual as partes interessadas podem cooperar entre si, para melhor atingir seus objetivos (Aalders e Moellering, 2001; Rajabifard e Williamson, 1999).

No contexto de GRI, uma IDE (nacional ou regional) é apropriada para apoiar a prevenção e gestão das áreas vulneráveis a partir de informações atualizadas (Leyh et al., 2012). Informações geográficas atualizadas e precisas são vitais para a tomada de decisão em nível local, nacional e internacional. Nesse contexto, uma IDE apoia a descoberta de informações, o acesso e o uso durante o processo de tomada de decisão. Além disso, essa provê acesso aos dados e operações geoespaciais por meio de serviços interoperáveis. Esses serviços são, geralmente, especificados por padrões, como os desenvolvidos pela Open Geospatial Consortium (Béjar et al., 2012).

Uma forma de aprimorar o uso de IDEs para apoiar a capacitação espacial de uma sociedade é fornecer aplicações Web especializadas que fazem uso de serviços web para dados geoespaciais (Béjar et al., 2012). A Open Geospatial Consortium é uma organização que desenvolve padrões para serviços web geoespaciais.

\subsection{Serviço Geoespacial}

A Open Geospatial Consortium (OGC) é uma organização voluntária internacional constituída por 473 empresas, agências governamentais e universidades, as quais colaboram em um processo de consenso para desenvolver padrões de interface disponíveis publicamente. Os padrões OGC são documentos técnicos que detalham interfaces e codificações para serviços geoespaciais. Os desenvolvedores de software podem, então, utilizar esses documentos para construir interfaces e codificações em seus softwares e serviços (OGC, 2013a). Uma iniciativa chamada Sensor Web Enablement (SWE), que está sendo desenvolvida por membros da OGC, possui como foco construir um único e revolucionário framework de padrões abertos para que se possam explorar sensores web conectados e quaisquer outros tipos de sensores. O objetivo da SWE é permitir que todos os tipos de sensores web e/ou acessíveis pela Internet, instrumentos e dispositivos de imagem sejam acessíveis e, quando aplicáveis, controlados pela web (Botts et al., 2008).

A OGC fornece diversos padrões de serviços geoespaciais, dentre eles está o Sensor Observation Service, o qual é utilizado em casos onde os dados do sensor devem ser geridos de forma interoperável (OGC, 2013b). 


\subsubsection{Sensor Observation Service}

O padrão Sensor Observation Service (SOS) define uma interface de serviço para gerenciar dados de sensores de forma interoperável. Este serviço web define uma interface que permite consultar dados de observações, metadados dos sensores, bem como representações das propriedades observadas (OGC, 2013b). O objetivo do SOS é prover acesso às observações realizadas pelos sensores e sistemas de sensores de maneira padronizada que é consistente para todos os sistemas de sensores incluindo sensores remotos, in-situ, fixos e móveis (Botts et al., 2008; OGC, 2007b). Para isso, este serviço utiliza duas especificações principais para descrever uma observação e um sensor. A especificação Observation and Measurements (O\&M) é utilizada para descrever uma observação com base em modelos e esquemas XML (OGC, 2011). Nessa, a observação é modelada como um evento que produz um resultado cujo valor é uma estimativa da propriedade observada (OGC, 2007b). Por outro lado, a especificação Sensor Model Language (SensorML) é usada para descrever um sensor ou sistema de sensores. Essa fornece um modelo e um esquema XML para definir características geométricas, dinâmicas e de observações de sensores e sistemas de sensores (OGC, 2007a).

O papel de um SOS é fazer a intermediação entre o cliente e um repositório de dados (observações), permitindo o registro de novos sensores e a remoção de sensores existentes. Além disso, define operações para inserir as observações realizadas pelos sensores. As aplicações envolvidas nesse contexto podem realizar o papel de consumidor do serviço, obtendo informações sobre os sensores e as observações por eles realizadas, bem como produtor, inserindo novos sensores e observações. No primeiro cenário, o SOS disponibiliza três operações principais: GetObservation, DescribeSensor e GetCapabilities. No segundo cenário, duas operações principais: RegisterSensor e InsertObservation.

- GetCapabilities: é a primeira operação a ser invocada pelo consumidor a fim de recuperar metadados do serviço. Nessa operação, nenhum parâmetro é necessário.

- DescribeSensor: recupera metadados dos sensores ou sistema de sensores. Para invocar essa operação alguns parâmetros obrigatórios devem ser inseridos: formato da resposta (especifica o formato de saída desejado), tipo de serviço (SOS) e versão. A resposta dessa operação é um documento SensorML que descreve o sensor.

- GetObservation: fornece acesso às observações realizadas pelo sensor. Essa operação requer alguns atributos obrigatórios, como o tipo de serviço (SOS), a versão do serviço, o offering (especificada pela URI (Uniform Resource Identifier) indicada no documento GetCapabilities), a propriedade observada (especifica o fenômeno para o qual são solicitadas as observações) e o formato da resposta. 
- RegisterSensor: permite o produtor registrar um novo sensor ou sistema de sensores. Para isso, o produtor deve seguir a especificação SensorML para descrever o mesmo.

- InsertObservation: permite o produtor inserir novas observações, contudo o produtor deve, primeiramente, registrar o sensor que produziu tais observações. Além disso, as observações devem ser codificadas seguindo a especificação O\&M.

Um consumidor que deseja obter as observações realizadas por um sensor ou sistema de sensor, deve, primeiramente, recuperar informações sobre os recursos do serviço, para posteriormente obter as observações. Nesse sentido, o consumidor efetua a operação GetCapabilities a fim de recuperar informações sobre os offerings disponíveis para cada sensor. Em seguida, se o consumidor desejar obter mais informações sobre o sensor específico, esse pode realizar a operação DescribeSensor para recuperar metadados do sensor. Por fim, o consumidor realiza a operação GetObservation para recuperar as observações (Figura $2.4)$.

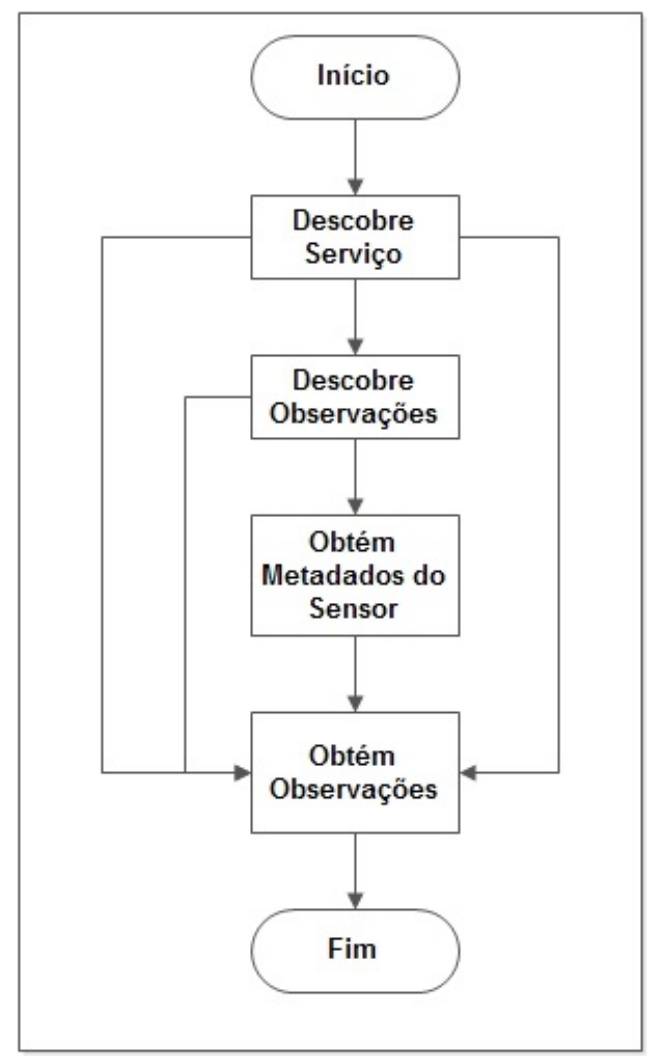

Figura 2.4: Fluxograma do Consumidor (Adaptado de OGC (2007b)).

Por outro lado, um produtor que deseja inserir observações no SOS, deve, primeiramente, registrar o sensor que realizou tais observações. Assim, o produtor realiza a operação RegisterSensor para, posteriormente, realizar a operação InsertObservation. Vale 
ressaltar que uma observação só pode ser inserida no SOS, se o sensor que a realizou já estiver registrado. A Figura 2.5 representa o fluxograma desempenhado pelo produtor.

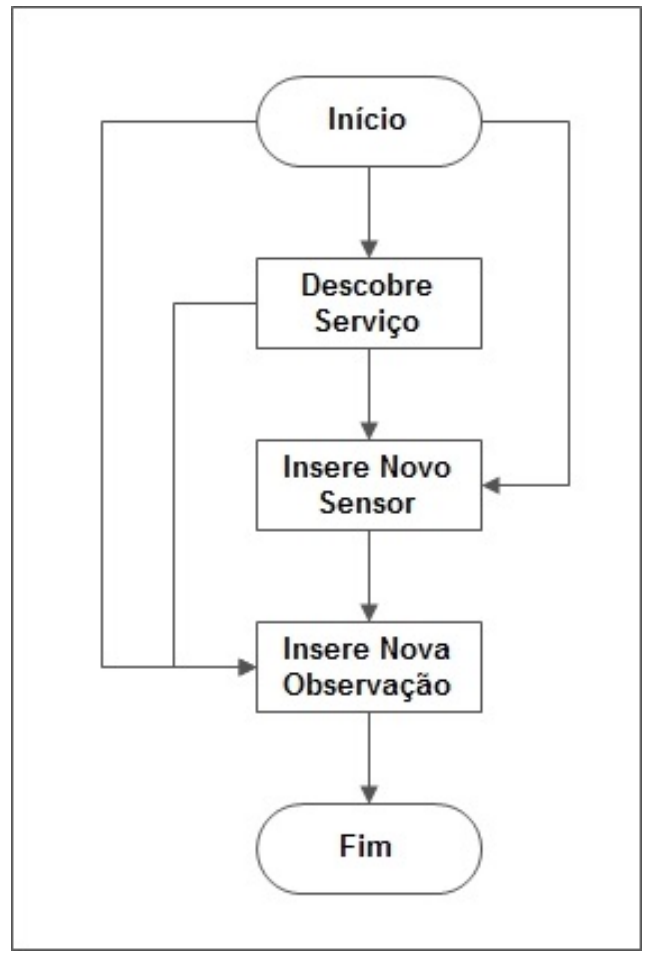

Figura 2.5: Fluxograma do Produtor (Adaptado de OGC (2007b)).

\subsection{Integração de VGI e Geosensores}

Com o avanço da Internet e do uso de dispositivos de monitoramento ambiental (sensores e sistemas de sensores), o volume de dados digitais disponíveis é cada vez maior. Um dos desafios enfrentados pela gestão de desastres é como integrar as diferentes fontes de dados. Essa é considerada crucial, a fim de lidar com a complexidade e incerteza de problemas ambientais (Raymond et al., 2010). Além disso, ela permite uma representação consistente e a propagação de detalhes de uma fonte de dados para outra (Butenuth et al., 2007). Integrar diferentes fontes de informação geográfica exige resolver diversos problemas como a correspondência de objetos dos diferentes conjuntos de dados, diferenças temáticas e geométricas, as diferentes precisões do conjunto de dados (Butenuth et al., 2007) e a heterogeneidade semântica, de maneira a permitir a identificação de características em diferentes conjuntos de dados que representam os mesmos fenômenos (Ramos et al., 2013).

A integração de informações geográficas na gestão de desastres pode levar a diversos benefícios para ambas as agências de emergência e comunidade local. Dentre os benefícios destacam-se o desenvolvimento de indicadores locais apropriados, capazes de descrever os impactos dos desastres em escala local, bem como uma análise profunda sobre os impactos, 
considerando que esses tenham sido negligenciados pelo sistema de monitoramento tradicional, uma base de conhecimento mais ampla para a gestão de desastres e a facilitação da comunicação entre as autoridades e a comunidade local (Giordano et al., 2013).

No início de um evento de crise, as agências de emergência precisam de informações atualizadas sobre o presente cenário, a fim de melhor coordenar ações de resposta (Longueville et al., 2010a). Nesse contexto, Longueville et al. (2010a) propõem o sistema Digital Earth's Nervous System (DENS) para o suporte à resposta a desastres e outros campos da gestão de desastres. Nesse, os autores focam nas informações voluntárias, pois os voluntários estão em todos os lugares, são móveis, percebem eventos e conseguem reportá-los em tempo real pela Internet. Além disso, nesse sistema, as informações voluntárias são processadas de forma análoga ao sensoriamento remoto, procurando melhor interpretar o conteúdo gerado pelos voluntários, sendo esse conceito denominado VGI Sensing. Para integrar essas informações aos dados de sensores, os autores argumentam sobre o uso da SWE para VGI, visto que essa fornece um método condescendente com as IDEs. Em particular, eles argumentam sobre o uso do serviço SOS para encapsular as informações voluntárias desde que essas estejam codificadas segundo a especificação O\&M. Essa, por sua vez, permite codificar qualquer tipo de dados desde que esse tenha referências espacial/temporal.

De maneira semelhante, Schade et al. (2013) contribuíram para o avanço do conceito de VGI Sensing, que pode ser entendido como um conjunto de normas e técnicas para simplificar o processamento de conteúdos georreferenciados publicados online por cidadãos. Em particular, os autores utilizam esse conceito para apoiar a detecção de eventos de crise. Para tanto, eles propuseram uma abordagem composta por um fluxo de cinco passos para a detecção de um evento. Inicialmente, um software monitora fontes de informação voluntária, como Twitter, Flickr, YouTube, OpenStreetMap e Geonames. As informações por ele coletadas são representadas por meio da especificação O\&M, podendo ser distribuídas por um serviço SOS. Essas informações são, então, analisadas a fim de identificar padrões específicos, isto é, um evento de crise. Os eventos que requerem maior atenção podem ser comunicados por meio do serviço SES (Sensor Event Service). Ao final, as informações voluntárias podem ser integradas a sistemas de suporte a decisão a fim de apoiar os tomadores de decisão a melhor planejar as ações de resposta. Segundo os resultados obtidos pelos autores, a partir da realização de um estudo de caso, é necessário desenvolver um mecanismo para facilitar a obtenção de informações voluntárias de diferentes plataformas. Assim, eles propuseram um serviço web, chamado Web 2.0 Broker, para acessar essas plataformas por meio de um único ponto. No primeiro protótipo desse serviço, esse obtém informações do Twitter, Flickr, YouTube, OpenStreetMap e Geonames. 
Ambas as abordagens não consideram as informações voluntárias provindas de plataformas de crowdsourcing. Nesse contexto, um dos objetivos desse trabalho é o desenvolvimento de um framework que recupera informações voluntárias, disponíveis em plataformas de crowdsourcing, e as disponibiliza por meio do serviço SOS.

\subsection{Considerações Finais}

Neste capítulo foram reunidos os principais conceitos que serviram como base para o desenvolvimento desse trabalho. Primeiramente, foram abordados os conceitos de gestão de desastres e gestão de risco de inundação. Em seguida, foram apresentados os conceitos de Volunteered Geographic Information e Observatório Cidadão, sendo abordada a plataforma de crowdsourcing Ushahidi. Foi abordado o conceito de Arquitetura Orientada a Serviço, com foco em serviços geoespaciais. Por fim, o serviço SOS, proposto pela OGC, foi apresentado em detalhes. Dentre as plataformas de crowdsourcing existentes, foi possível notar que não há uma plataforma de crowdsourcing configurada para a obtenção de informações voluntárias relacionadas à fase de preparação da gestão de risco de inundação. Além disso, as informações presentes nessas plataformas não são integradas a IDEs. Assim, no próximo capítulo será apresentada a abordagem desenvolvida nesse trabalho de mestrado. 


\section{Abordagem para Obtenção e Disponibilização de VGI}

\subsection{Considerações Iniciais}

As plataformas de crowdsourcing estão sendo utilizadas como ferramenta para auxiliar as organizações envolvidas na gestão de desastres a prestar assistência às vítimas dos desastres naturais. Elas possibilitam utilizar informações provenientes de voluntários para fornecer às agências de emergência e outras partes interessadas informações em tempo real, categorizadas e geolocalizadas. Contudo, as plataformas de crowdsourcing existentes obtêm informações voluntárias relacionadas à fase de resposta, como informações sobre vítimas, extensão do desastre, serviços disponíveis, etc. Ainda não há uma plataforma de crowdsourcing configurada que possibilite coletar informações voluntárias úteis relacionadas à fase de preparação da gestão de risco de inundação. Assim, é importante a configuração de uma plataforma para esse contexto. Além disso, é importante a disponibilização dessas informações de forma interoperável, a fim de possibilitar sua integração com IDEs.

Nesse cenário, neste capítulo é proposta uma abordagem que visa apoiar a gestão de risco de inundação. Essa abordagem está preocupada em como as informações geográficas voluntárias podem ser utilizadas a fim de fornecer dados específicos para a GRI. Assim, a abordagem consiste de três partes principais: a) mecanismos de interpretação para 
apoiar os voluntários a melhor interpretar a variável ambiental (altura da água); b) um Observatório Cidadão de Enchentes, criado a partir da configuração de uma plataforma de crowdsourcing existente, para a obtenção de informações geográficas voluntárias úteis para a GRI (por exemplo, altura da água no leito do rio e áreas alagadas) e c) um framework que permite disponibilizar as informações geográficas voluntárias, juntamente com dados de sensores, usando padrões SWE.

\subsection{Visão Geral da Abordagem}

Esta abordagem está inserida em uma pesquisa sobre gestão de risco de inundação, desenvolvida por um grupo interdisciplinar, o qual é formado por pesquisadores da área de hidrologia, de redes de computadores, com ênfase em redes de sensores sem fio, e de sistema de informação. Essa pesquisa é composta por três projetos ([FAPESP 2008/58161-1], [RNP CIA^2], [FAPESP 2012/18675-1]), sendo cada um deles pertencente a uma área. Em particular, essa abordagem é parte do escopo de um projeto de pesquisa intitulado AGORA (A Geospatial Open collaboRative Approach for Building Resilience against Flooding) ([FAPESP 2012/18675-1]), proposto por de Albuquerque e Zipf (2012), que visa desenvolver uma abordagem geoespacial colaborativa aberta para melhorar a resiliência da comunidade contra inundações e seus impactos. A abordagem AGORA combina dados provenientes de rede de sensores, de modelos de mudança climática, informações voluntárias e resultados de pesquisa, para fornecer alertas antecipados e projeções de risco de longo prazo. Além disso, essa abordagem tem como público alvo os tomadores de decisão e, também, a comunidade. Para tanto, essa é dividida em três pilares distintos: aquisição, integração e aplicação (Figura 3.1), sendo cada pilar composto por dois componentes.

A camada de aquisição é composta por um componente para a obtenção de informações voluntárias, proposto nesse trabalho, e por um componente para o gerenciamento dinâmico e em tempo real de geosensores heterogêneos envolvidos na GRI. Esse, por sua vez, envolve a descoberta de geosensores, o acesso aos dados por eles produzidos, bem como a atribuição de uma tarefa específica a um determinado geosensor. A camada de integração é composta por um componente para o gerenciamento e a fusão de informações, o qual consiste em uma arquitetura geoespacial colaborativa para gerenciar e integrar dados de sensores, informações voluntárias e dados de fontes oficiais relacionados à inundação. O segundo componente dessa camada está voltado para a garantia da qualidade das informações, sendo esse desenvolvido por pesquisadores da Universidade de Heidelberg, na Alemanha. Por fim, a camada de aplicação é composta por um componente de apoio à decisão, que consiste em uma IDE que integra dados convencionais (dados de sensores e dados oficiais) e informações voluntárias e os disponibiliza para os tomadores de decisão, a fim de apoiar 


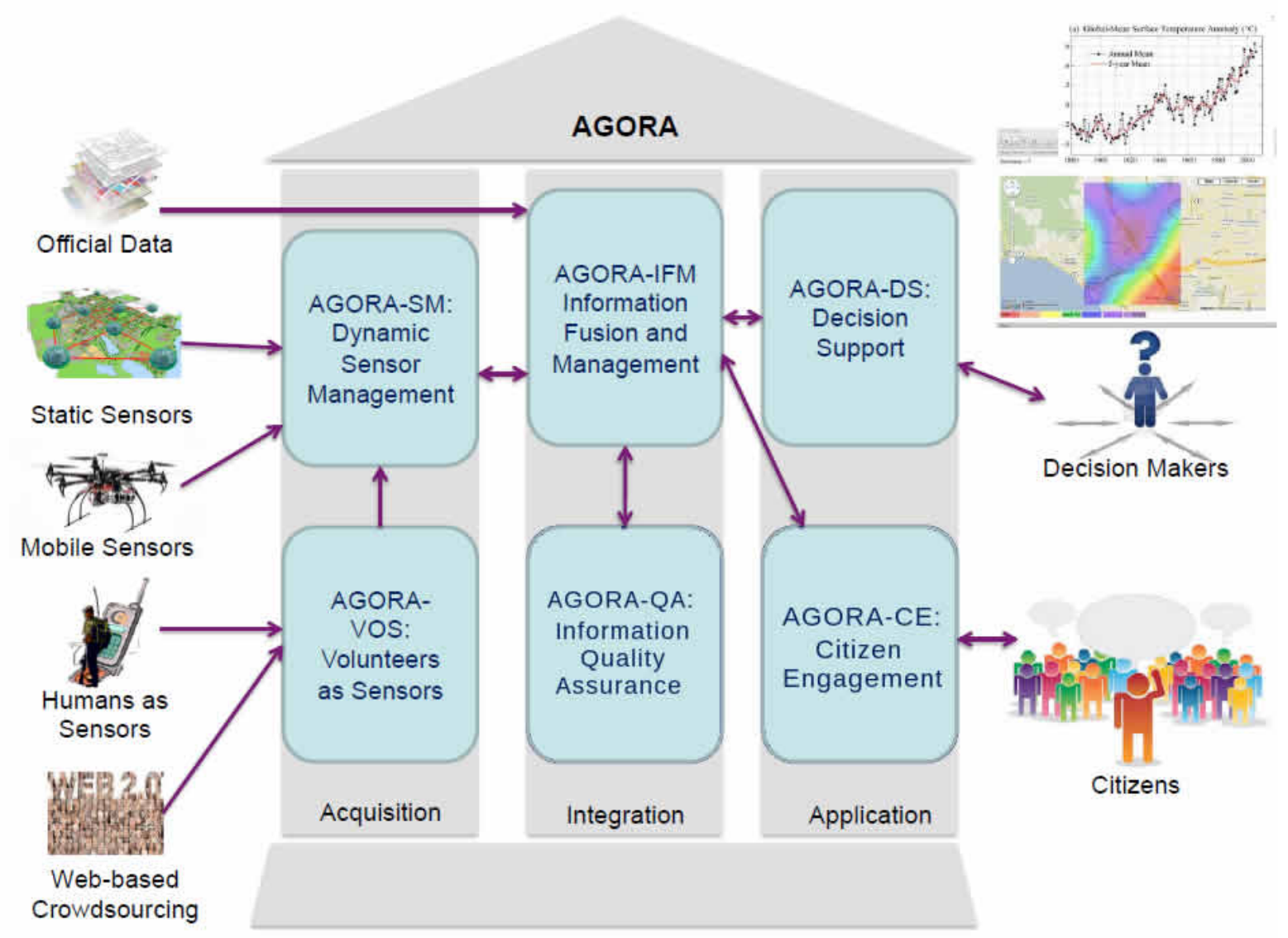

Figura 3.1: Arquitetura da abordagem AGORA. 
o processo de tomada de decisão na GRI, e por um componente para o engajamento dos cidadãos, cujo intuito é disponibilizar alertas antecipados e exibir em mapas o índice de perigo.

De maneira geral, a obtenção de informações voluntárias para o contexto de GRI é realizada por meio de redes sociais, como Facebook ${ }^{1}$, Twitter ${ }^{2}$, Instagram ${ }^{3}$, Flickr ${ }^{4}$, entre outras, e plataformas de crowdsourcing. Contudo, em particular, essas plataformas não estão configuradas para obter informações geográficas voluntárias úteis relacionadas à fase de preparação da GRI. Além disso, essas informações não são integradas a IDE, pois não são disponibilizadas de forma interoperável. Assim, esse trabalho possui como objetivo principal desenvolver uma abordagem para a obtenção de informações voluntárias úteis para o contexto de GRI, por meio da configuração de uma plataforma de crowdsourcing existente, e a disponibilização dessas informações de forma interoperável, utilizando padrões de serviço geoespacial (SWE) possibilitando, assim, a integração dessas a IDEs. Além disso, para facilitar o fornecimento de informações úteis pelos voluntários, são propostos mecanismos para auxiliá-los a melhor interpretar a variável ambiental (altura da água). A definição desses mecanismos foi realizada em conjunto com os pesquisadores da área de hidrologia, envolvidos nesse projeto de pesquisa, e tem como objetivo maximizar o uso dessas informações em modelos hidrológicos.

\subsection{Mecanismo para Interpretação das Variáveis Ambi- entais}

Devido à vasta extensão dos rios brasileiros e da impossibilidade de disponibilizar recursos que tornem a medição das variáveis ambientais, em pontos estratégicos, mais precisa, nesta seção são propostos quatro mecanismos que visam apoiar os voluntários a melhor interpretar tais variáveis, sendo esses mecanismos propostos juntamente com especialistas da área de hidrologia. Dessa forma, três diferentes cenários foram considerados a fim de que o voluntário possa interpretar as variáveis ambientais em qualquer situação.

O primeiro cenário corresponde a um ponto controlado, ou seja, há um recurso de interpretação que possibilita realizar a medição de forma mais precisa. Nesse cenário há uma régua linimétrica fixada no leito do rio (Figura 3.2) que apoia a medição da altura da água do mesmo. Essa régua possui escala de $1 \mathrm{~cm} \mathrm{em} 1 \mathrm{~cm}$ e foi proposta pois auxilia os voluntários a realizar medições de forma mais precisa. Além disso, essa foi instalada em

\footnotetext{
${ }^{1}$ http://www.facebook.com

${ }^{2}$ http://www.twitter.com

${ }^{3}$ http://www.instagram.com

${ }^{4}$ http://www.flickr.com
} 


\section{CAPÍTULO 3. ABORDAGEM PARA OBTENÇÃO E DISPONIBILIZAÇÃO DE VGI}

quatorze pontos (Figura 3.3) localizados nos cinco córregos mais relevantes da área urbana da cidade de São Carlos/SP (Zaffani e Mendiondo, 2012). Cada córrego selecionado tem ao menos dois pontos, sendo um na montante ${ }^{5}$ e outro na jusante ${ }^{6}$, antes da confluência desse com outros córregos.

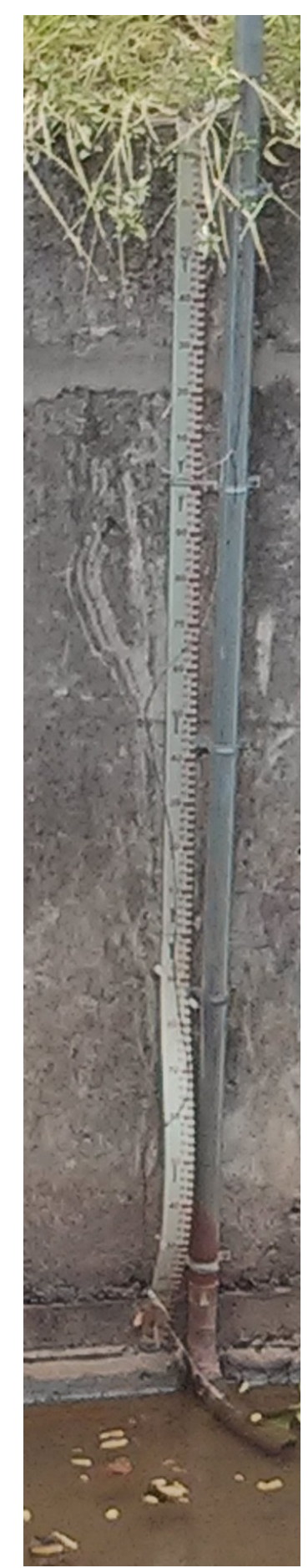

Figura 3.2: Régua linimétrica fixada junto ao leito do rio.

\footnotetext{
${ }^{5}$ Extremidade do rio onde a água nasce (nascente).

${ }^{6}$ Extremidade do rio para onde se dirige a corrente de água (foz).
} 


\section{CAPÍTULO 3. ABORDAGEM PARA OBTENÇÃO E DISPONIBILIZAÇÃO DE VGI}

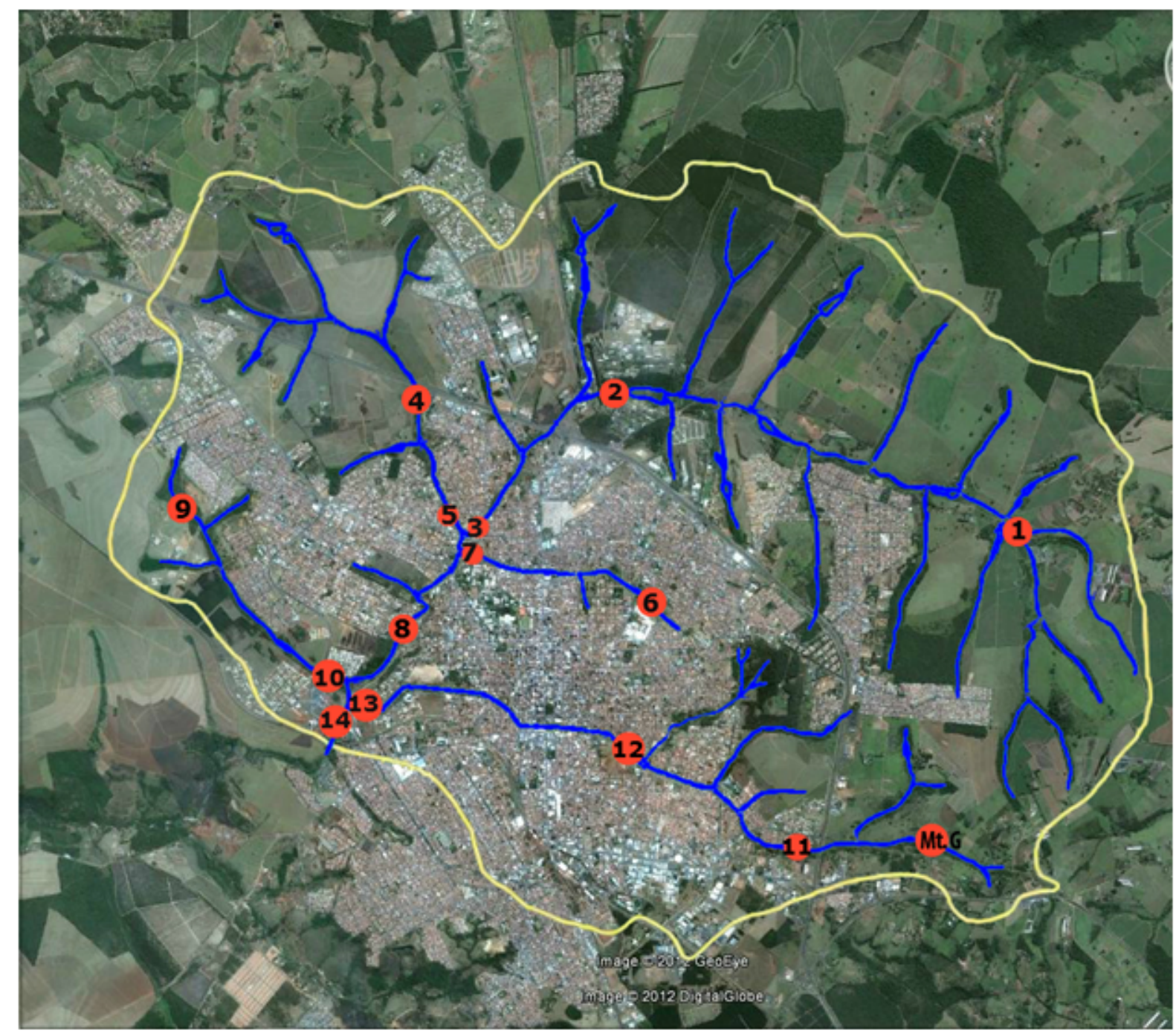

Figura 3.3: Pontos da cidade de São Carlos com régua (Zaffani e Mendiondo, 2012).

O segundo cenário corresponde a um ponto semicontrolado, ou seja, um ponto onde há um recurso de interpretação que permite determinar o valor da altura da água no leito do rio de forma menos precisa. Nesse cenário há dois tipos de recursos para interpretação, um boneco similar à figura humana e faixas de cores (verde, amarelo, laranja e vermelho). As faixas de cores (Figura 3.4) correspondem ao índice de perigo (IP), isto é, o perigo ao qual a população está exposta, o risco de instabilidade humana. Esse risco representa as forças exercidas sobre um indivíduo em correntes de água, ou seja, o nível de vulnerabilidade desse exposto a enchentes (Rotava et al., 2013). Cada faixa de cor corresponde à altura da água equivalente a um nível de perigo. Dessa forma, a faixa verde corresponde ao IP com variação de 0 a 0,5, a faixa amarela, com variação de 0,5 a 1,0, a faixa laranja, com variação de 1,0 a 1,5 e, por fim, a faixa vermelha corresponde ao IP com valores maiores que 1,5 . 


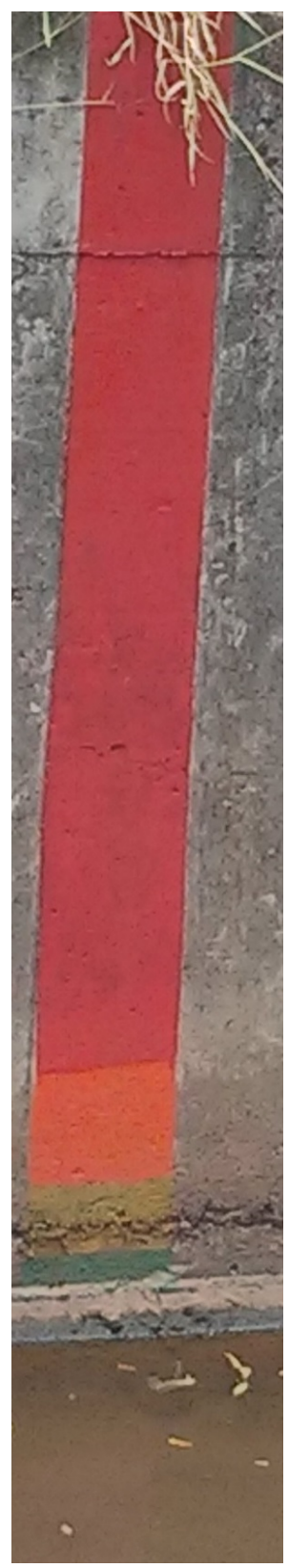

Figura 3.4: Faixa de cores pintada no leito do rio.

Além disso, um boneco foi proposto para auxiliar os voluntários a determinar a altura da água com maior facilidade. Assim, o voluntário pode utilizá-lo como recurso visual para tal determinação, pois esse está pintado no leito do rio em alguns pontos da cidade de São Carlos/SP (Figura 3.5) ou como recurso imaginário, auxiliando a determinação da altura da água em pontos onde não há recursos disponíveis. Em ambos os casos, a altura considerada do boneco é de 1,75 m, sendo a medição da altura da água realizada de acordo com marcações pré-definidas, isto é, tornozelo, joelho, cintura, pescoço e acima da cabeça (corpo total) (Figura 3.6). 


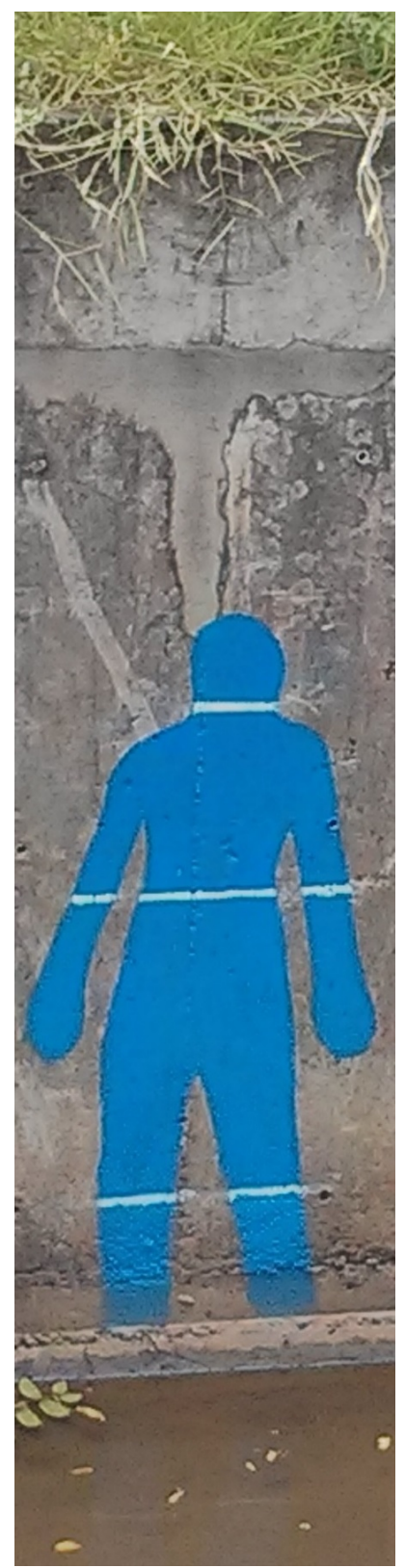

Figura 3.5: Boneco semelhante à figura humana pintado no leito do rio.

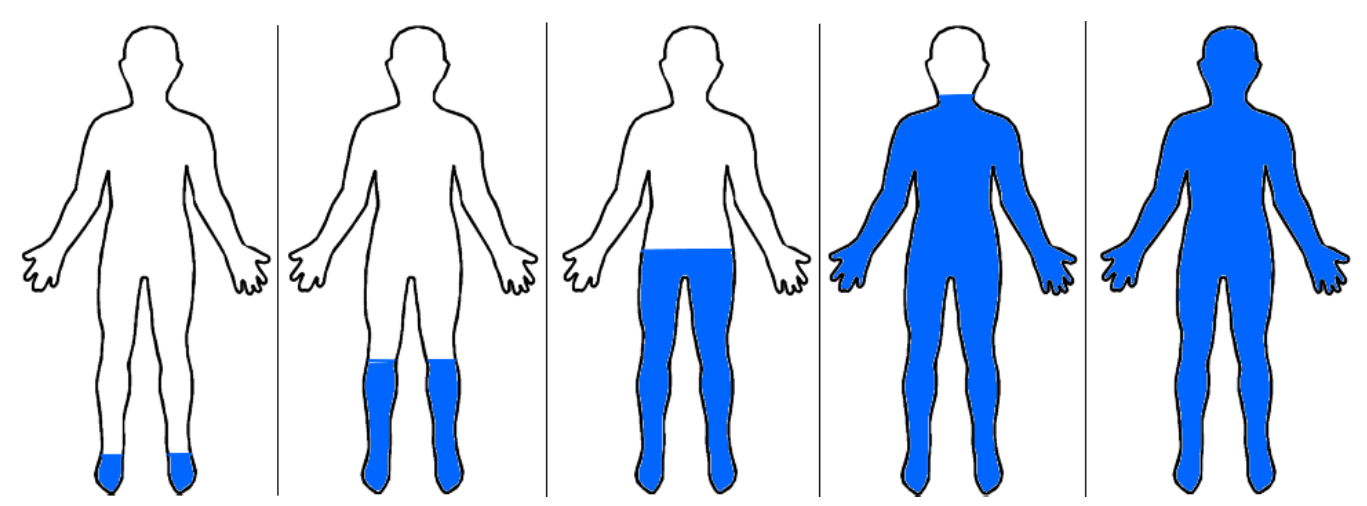

Figura 3.6: Marcações no boneco para medição da altura da água. 
Por fim, o terceiro cenário corresponde a um ponto não controlado, isto é, não há nenhum recurso no leito do rio que auxilie os voluntários a interpretar a altura da água. Dessa forma, propõe-se um mecanismo que facilite tal interpretação. Para esse mecanismo, são adotadas marcações que se aproximam do conhecimento popular e que são de simples determinação. Assim, a altura da água é dividida em:

- Baixa: indica que a altura da água está próxima ao fundo do leito do rio;

- Normal: indica que a altura da água está aproximadamente na metade da profundidade total do leito do rio;

- Alta: indica que a altura da água ocupa toda a profundidade do leito do rio;

- Transbordando: indica que a altura da água está acima da profundidade total do leito do rio, contudo a água ainda não atingiu a área ao redor (ruas e calçadas).

Essas marcações (Figura 3.7) são comumente citadas na mídia ao relatar a altura da água de um rio. Desse modo, espera-se que os voluntários possam interpretar essa variável com maior facilidade.

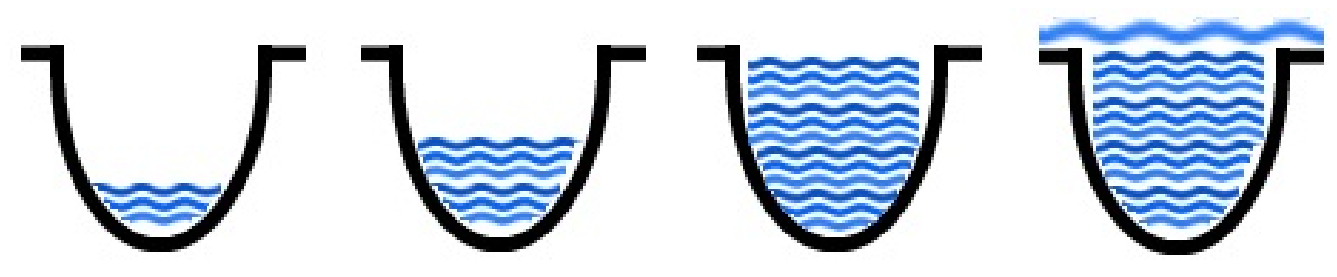

Figura 3.7: Marcações do nível de água em ponto não controlado.

\subsection{Observatório Cidadão de Enchentes}

O Observatório Cidadão de Enchentes (OCE) consiste em uma plataforma de crowdsourcing que possibilita a coleta de informações voluntárias. Seu principal objetivo é obter informações voluntárias relacionadas à gestão de risco de inundação, mais especificamente sobre áreas alagadas e altura da água no leito do rio. Para isso, os voluntários podem enviar informações de diferentes dispositivos, como o aplicativo para celular ou pelo Web site. Para tanto, o OCE consiste em uma instância da plataforma de crowdsourcing Ushahidi, pois essa é mundialmente utilizada por ativistas, agências de emergência e cidadãos para mapear eventos extremos (Ushahidi, 2014).

A fim de facilitar o fornecimento de informações sobre o risco de inundação no OCE, os mecanismos de interpretação são representados por categorias distintas (Figura 3.8), sendo as marcações de cada mecanismo representadas por subcategorias. Dessa forma, o 
voluntário pode identificar mais facilmente a categoria que melhor representa o cenário observado.

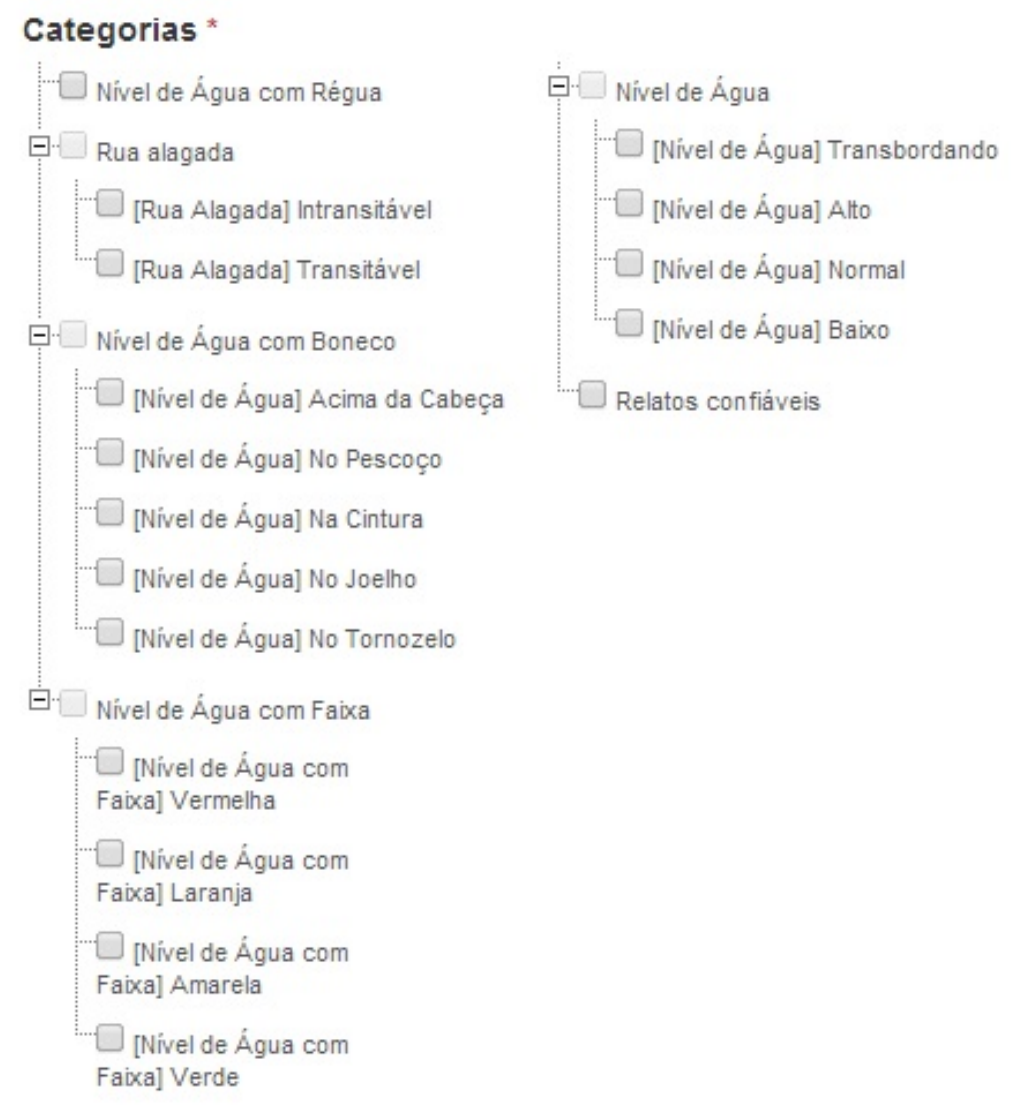

Figura 3.8: Categorias do Observatório Cidadão de Enchentes.

Para enviar um relato, os voluntários podem utilizar tanto o aplicativo para celular, disponível para os sistemas operacionais iOS e Android, quanto o Web site (Figura 3.9 e Figura 3.10). O envio de um relato requer que o voluntário forneça algumas informações obrigatórias, sendo as demais informações opcionais:

- Título: representa o assunto abordado no relato;

- Descrição: representa a observação realizada pelo voluntário, por exemplo, a altura da água ou área alagada;

- Categoria: representa o mecanismo utilizado para interpretação da variável ambiental, o qual fornece informações sobre a altura da água no leito do rio;

- Nome do local: representa o local de onde o voluntário está enviando o relato.

Vale ressaltar que no caso do envio pelo Web site, é de responsabilidade do voluntário assinalar no mapa o ponto ao qual o relato está se referindo. Assim, é possível relacionar 


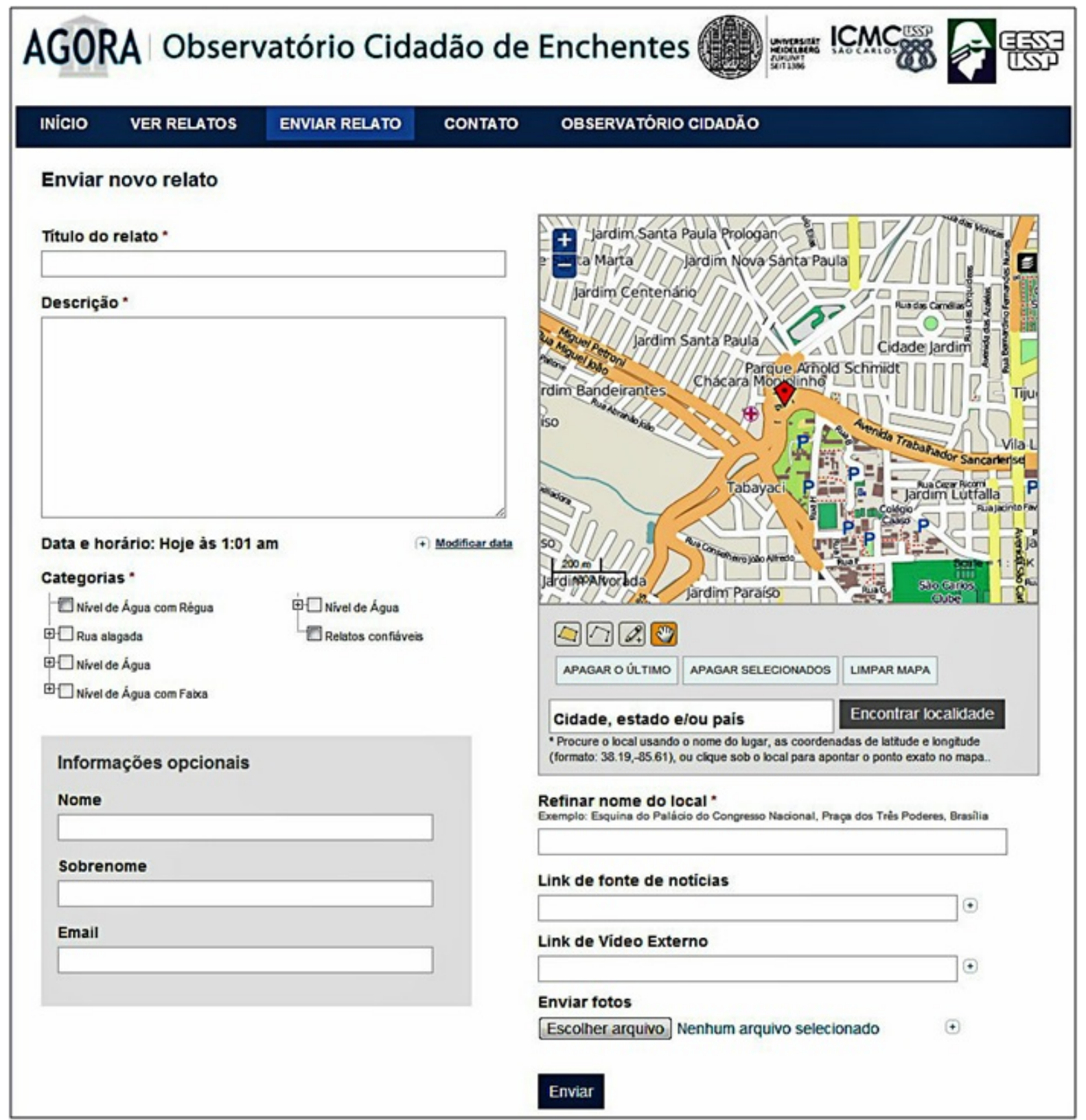

Figura 3.9: Observatório Cidadão de Enchentes. 


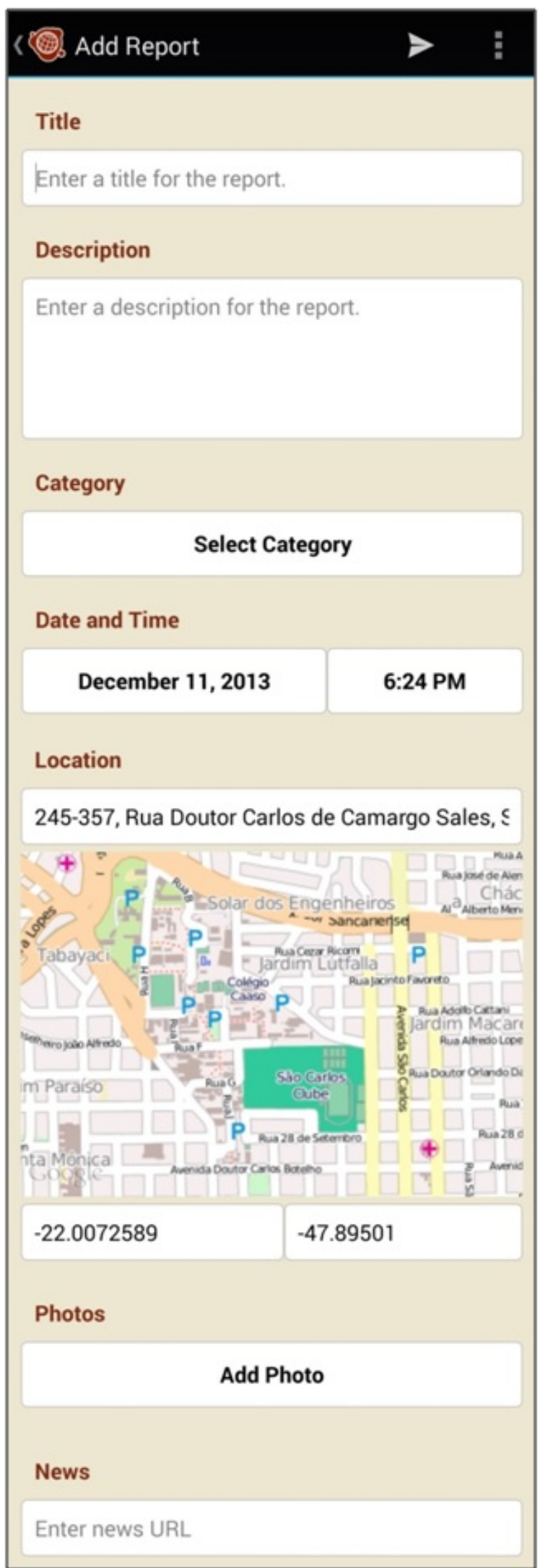

Figura 3.10: Aplicativo para celular do Observatório Cidadão de Enchentes para envio de relatos. 
o incidente reportado a um local específico. Por outro lado, no caso do aplicativo para celular, uma vez disponível o GPS, a posição geográfica é definida de forma automática.

Em virtude da incerteza acerca da credibilidade dessas informações, essas são verificadas antes de serem disponibilizadas para a visualização. O objetivo dessa verificação é reduzir o número de informações falsas ou imprecisas divulgadas para a população e órgãos competentes. Assim, antes dos relatos serem disponibilizados online, os autores desse trabalho aprovam os relatos inseridos na plataforma. Esses, por sua vez, possuem o status verificado ou não verificado, de acordo com a verificação realizada pelos autores sobre o incidente reportado. Inicialmente, os autores desse trabalho exercem o papel de administrador da plataforma, aprovando e verificando os relatos inseridos na mesma. Contudo, espera-se que agências de emergência, envolvidas na GRI, desempenhem futuramente esse papel.

\subsection{Framework Volunteered Observation Service}

A gestão de risco de inundação compreende o processo de gerenciar uma situação de risco de inundação existente, sendo o risco real constantemente reavaliado. Dessa forma, é fundamental dispor de informações precisas, atualizadas e completas sobre o status das variáveis ambientais, não só para a tomada de decisão sobre políticas públicas, como para a redução dos impactos provocados por esses eventos. A ausência de uma fonte de dados centralizada representa uma lacuna importante para os tomadores de decisão. Além disso, as plataformas de crowdsourcing existentes não possuem integração com IDEs baseadas em padrões de serviços geoespaciais interoperáveis, como os padrões da SWE. Assim, neste trabalho foi desenvolvido um framework que visa disponibilizar informações voluntárias de forma interoperável.

O framework, Volunteered Observation Service (VOS) (Figura 3.11), tem como objetivo disponibilizar informações voluntárias de forma interoperável, por meio de padrões de serviço geoespacial, possibilitando, assim, sua integração com outras fontes de dados. Para tanto, as informações voluntárias são recuperadas de plataformas de crowdsourcing e inseridas no serviço SOS, podendo, assim, serem consumidas por qualquer aplicação que utilize os mesmos padrões de interoperabilidade (Figura 3.12). Em particular, devido às características de cada plataforma de crowdsourcing, na primeira versão, o framework recupera somente informações voluntárias provenientes de instâncias da plataforma de crowdsourcing Ushahidi, visto que essa é mundialmente utilizada para o monitoramento de eventos extremos e dos impactos por eles provocados.

O emprego do framework requer o envolvimento de diversos atores nas diferentes atividades envolvidas no seu funcionamento (Figura 3.13). Os voluntários (usuários) são 


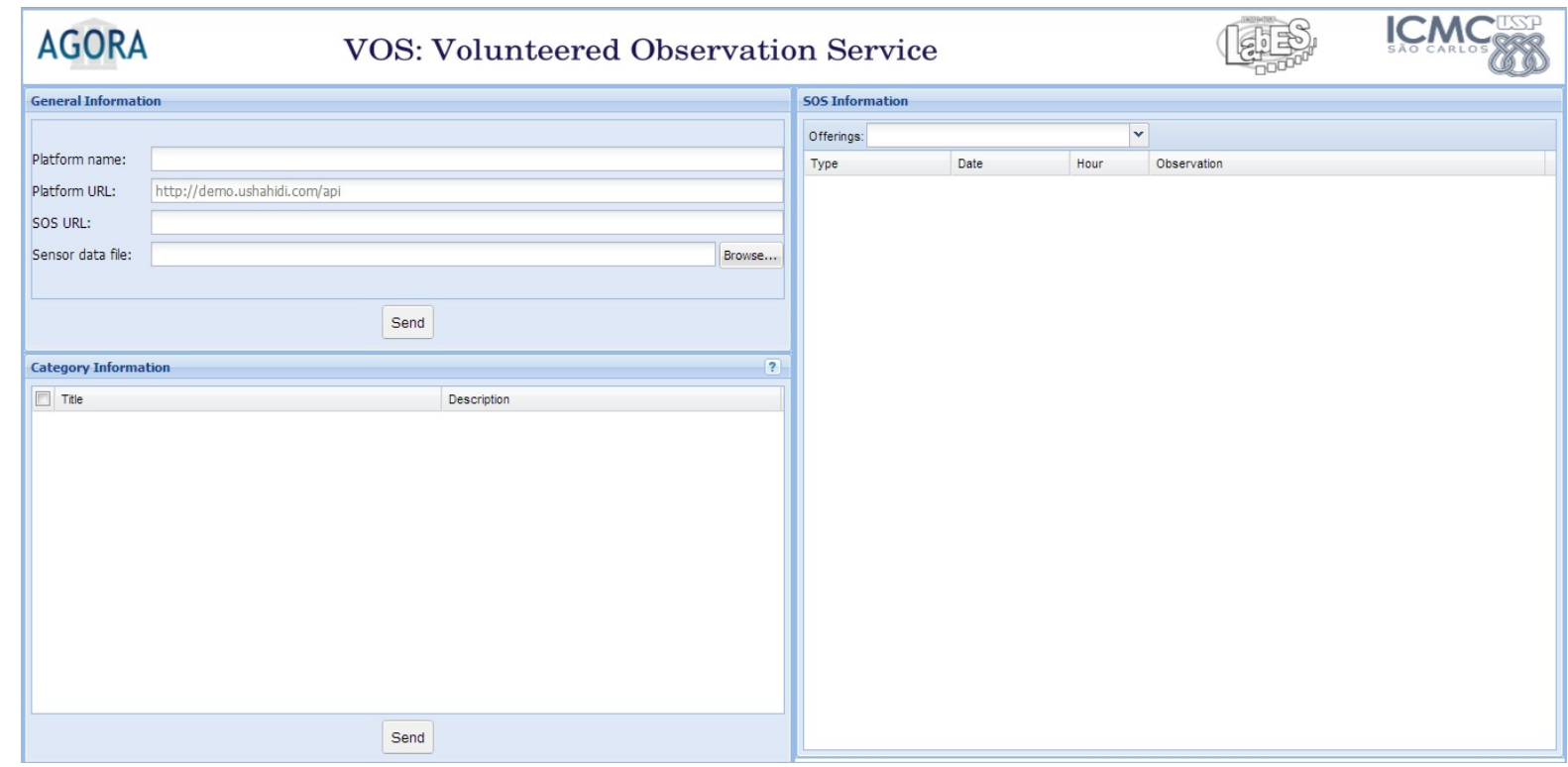

Figura 3.11: Interface de configuração do framework Volunteered Observation Service.

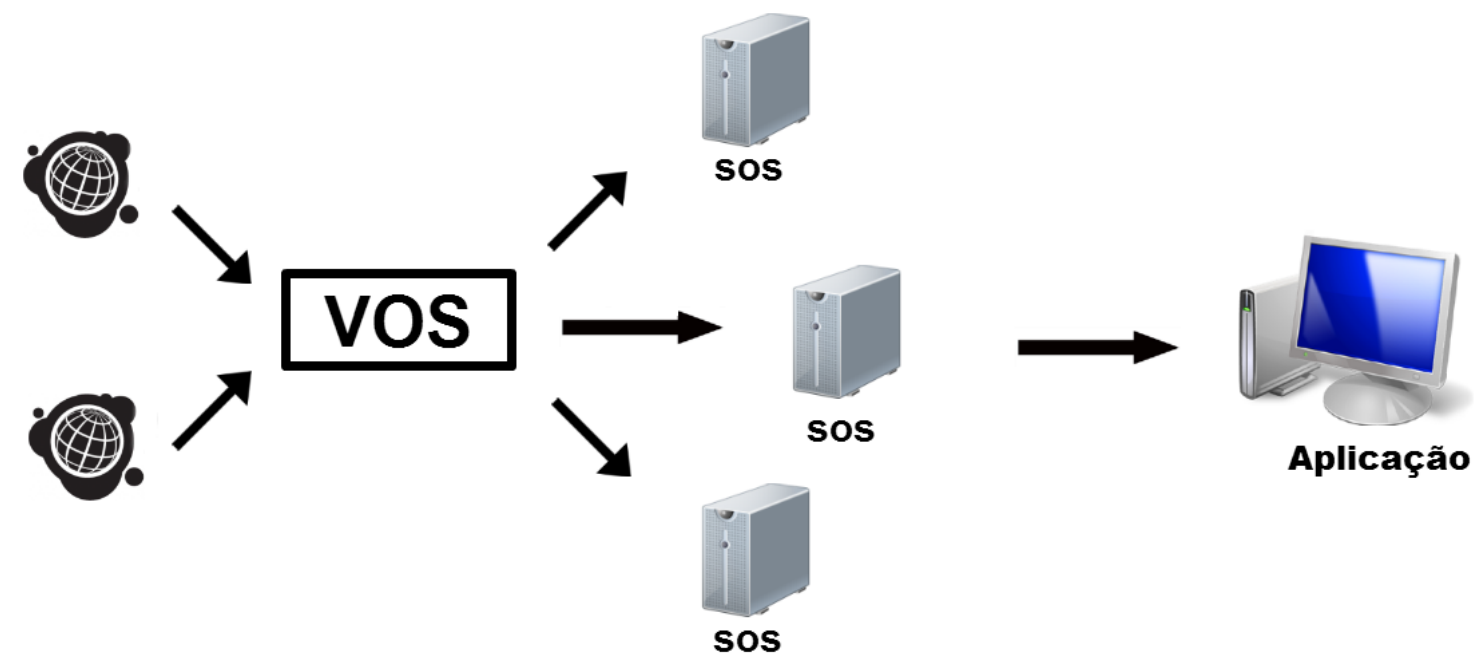

Figura 3.12: Visão geral do funcionamento do framework.

responsáveis por fornecer informações sobre o atual status das variáveis ambientais por meio de uma plataforma de crowdsourcing. Nessas, os voluntários criam relatos contendo informações sobre o incidente observado e, para cada relato, selecionam a categoria que melhor representa o cenário observado. Além disso, os voluntários são responsáveis por assinalar no mapa o ponto geográfico ao qual o relato faz referência. O framework, VOS, é responsável por criar observações no serviço SOS, a partir dos relatos recuperados da plataforma de crowdsourcing. Para tanto, o usuário do framework deve primeiramente fornecer informações sobre a plataforma de crowdsourcing, da qual ele deseja recuperar os relatos, e do serviço SOS, onde as observações serão criadas (Figura 3.14). Uma vez fornecidas essas informações, o framework recupera, primeiramente, as categorias cadastradas 
na plataforma, para que o usuário selecione de quais categorias ele/ela deseja recuperar os relatos (Figura 3.15). Em seguida, o framework recupera os relatos relacionados a essas categorias e cria observações a partir desses relatos, por meio da inserção desses no serviço SOS. Para isso, o framework primeiramente registra no serviço SOS o sensor que realizou tais observações. Em particular, o framework considera a comunidade de voluntários como um único sensor humano, visto que informações sobre cada voluntário não são disponibilizadas pela plataforma de crowdsourcing Ushahidi. Em seguida, os relatos são inseridos no serviço SOS, criando as observações. O serviço SOS é responsável por tornar as observações disponíveis de forma interoperável. Por fim, aplicações cliente, que sigam os mesmos padrões de interoperabilidade, são responsáveis por consumir as observações disponibilizadas pelo serviço SOS. As atividades realizadas pelos diversos atores, envolvidos no emprego do framework, são executadas em uma sequência, a fim de disponibilizar as informações voluntárias de forma interoperável, conforme apresentada na Figura 3.16.

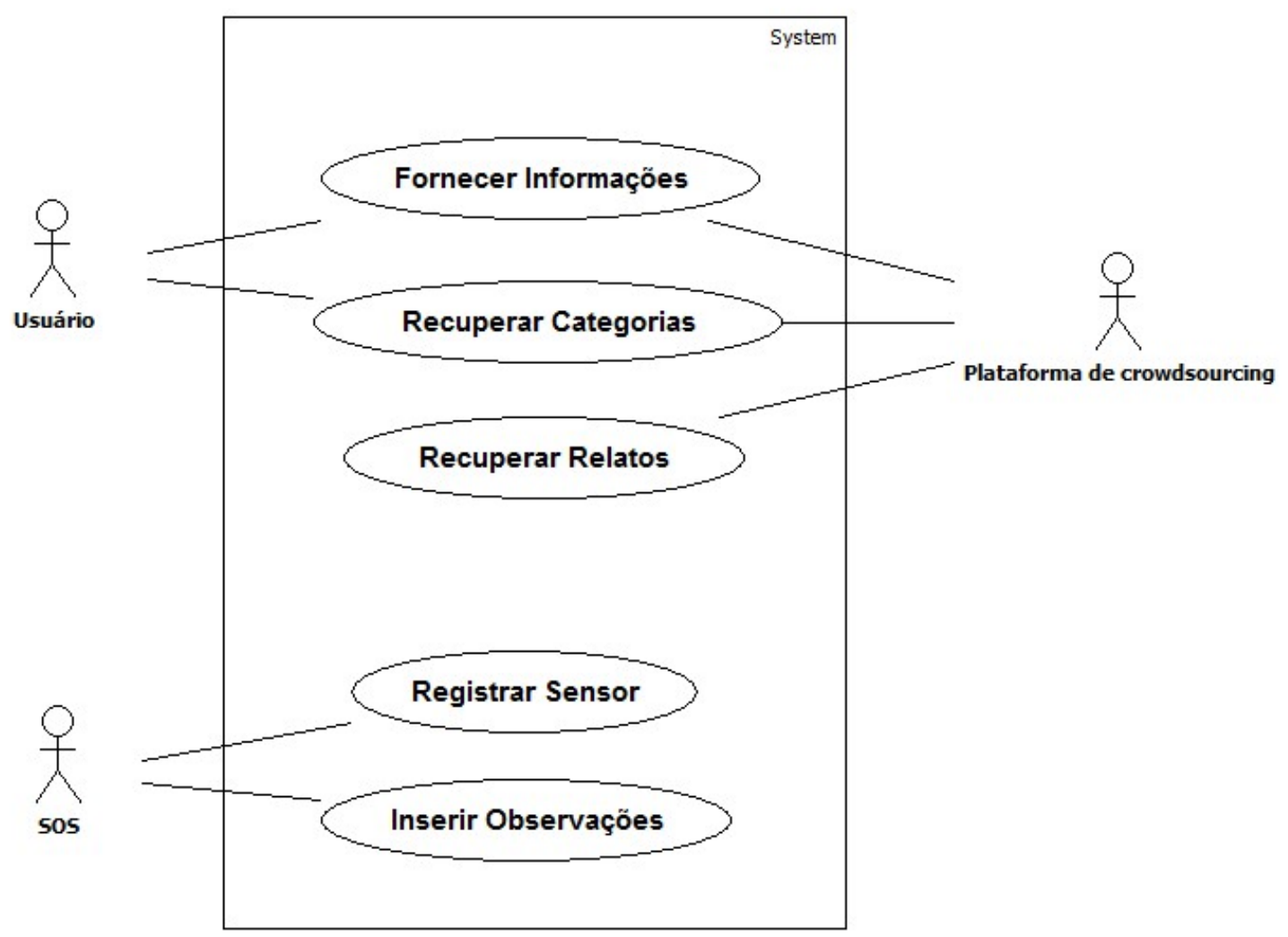

Figura 3.13: Diagrama de caso de uso do framework.

A disponibilização das informações voluntárias e dos dados de sensores, realizada por meio do serviço SOS, foi baseada no fato de que em períodos críticos, as agências de emergência necessitam de informações em tempo real sobre o real estado das variáveis ambientais, a fim de coordenar ações de resposta. Assim, segundo Longueville et al. 
CAPÍTULO 3. ABORDAGEM PARA OBTENÇÃO E DISPONIBILIZAÇÃO DE VGI

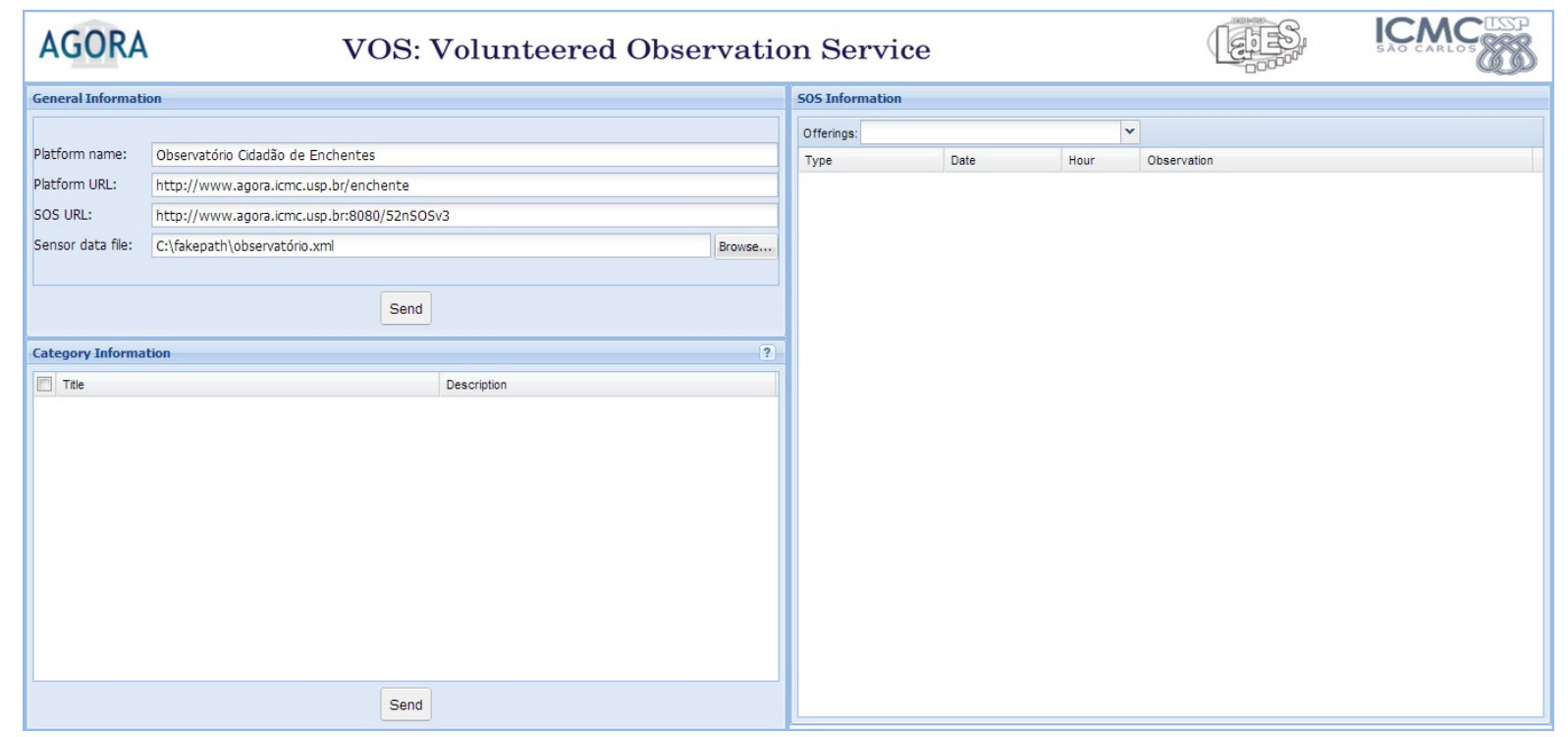

Figura 3.14: Fornecimento das informações necessárias ao framework.

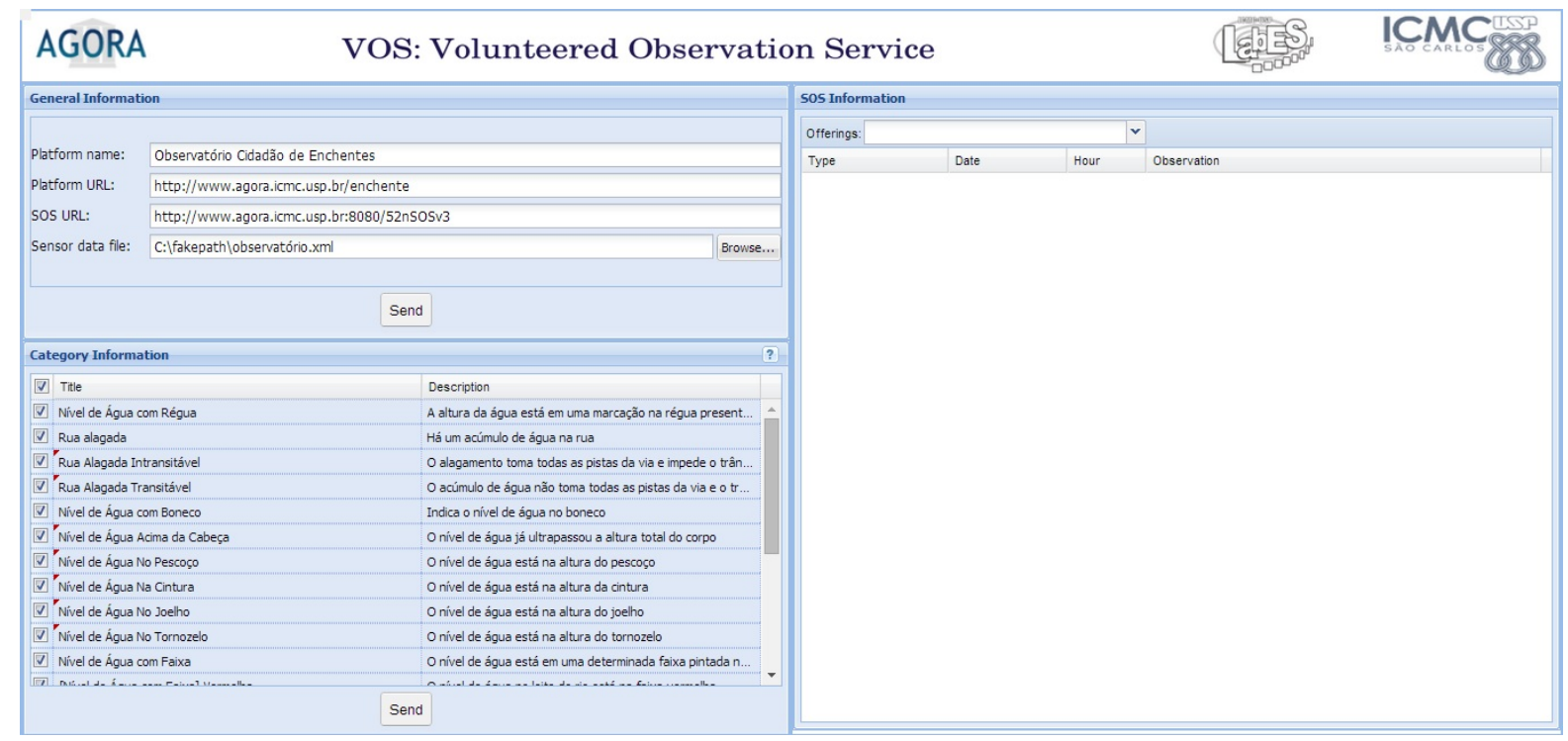

Figura 3.15: Seleção das categorias pelo usuário do framework.

(2010a), o serviço SOS é capaz de fornecer informações de forma contínua, satisfazendo à necessidade de informações em tempo real, visto que esse serviço já está em operação antes da ocorrência de um evento extremo. Além disso, o serviço SOS é utilizado para acessar dados de sensores, sendo que o VOS permite que a comunidade de voluntários atue como um sensor humano. Agregado a isso, as observações encapsuladas por esse serviço são codificadas com base na especificação O\&M (Seção 2.6.1), que pode ser usada para codificar qualquer observação com referência espaço-temporal (OGC, 2011). Assim, as informações voluntárias podem ser facilmente codificadas com base nessa especificação. Ainda, o serviço SOS, utilizado para encapsular dados de sensores e redes de sensores codificados segundo essa especificação, pode encapsular qualquer outro tipo de dado desde 


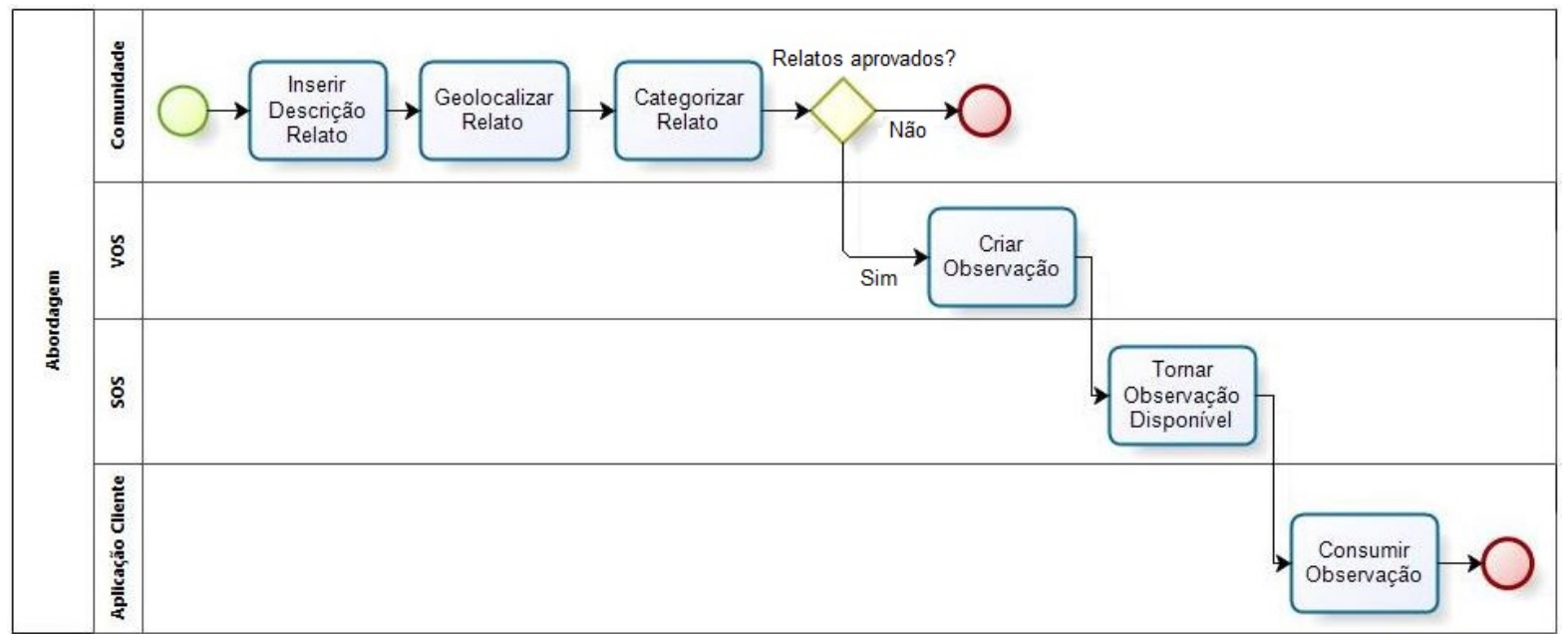

Figura 3.16: Processo de uso da abordagem.

que esse seja codificado com base em O\&M (Longueville et al., 2010a). Além disso, esse serviço é usado para acessar dados geoespaciais dinâmicos de forma interoperável, assim, é possível assegurar que as informações voluntárias possam ser consumidas por qualquer aplicação que utilize os mesmos padrões de interoperabilidade.

\subsubsection{Projeto do Framework}

Devido ao uso do serviço SOS para a disponibilização das informações voluntárias, juntamente com os dados de sensores, para o desenvolvimento do framework, o modelo de dados utilizado por esse serviço foi adotado (Figura 3.17). Esse modelo é baseado na especificação O\&M, a qual fornece um padrão conceitual para a representação de qualquer tipo de resultado de observação. Uma observação é o resultado da aplicação de um procedimento, isto é, um sensor, um algoritmo ou uma cadeia de processo, em uma característica de interesse (objeto do mundo real), produzindo um valor estimado, que descreve o fenômeno observado. Um sensor é uma entidade capaz de realizar uma medição e retornar o seu valor (OGC, 2011). Esse, por sua vez, pode ser caracterizado por um instrumento ou uma pessoa. Dessa forma, uma informação voluntária pode ser representada como uma observação, visto que essa resulta da interpretação de um fenômeno por um voluntário.

Uma observação é composta por diferentes informações: característica de interesse, propriedade observada, procedimento, horário do fenômeno e resultado. Assim, para a criação de uma observação a partir de uma informação voluntária, dados foram extraídos dos relatos provenientes das plataformas de crowdsourcing. Na Tabela 3.1 é apresentada uma relação entre as informações que constituem uma observação e os dados de um relato. Vale ressaltar que a categoria do relato é fundamental no processo de criação de uma observação, pois essa representa a propriedade observada pelo voluntário. 


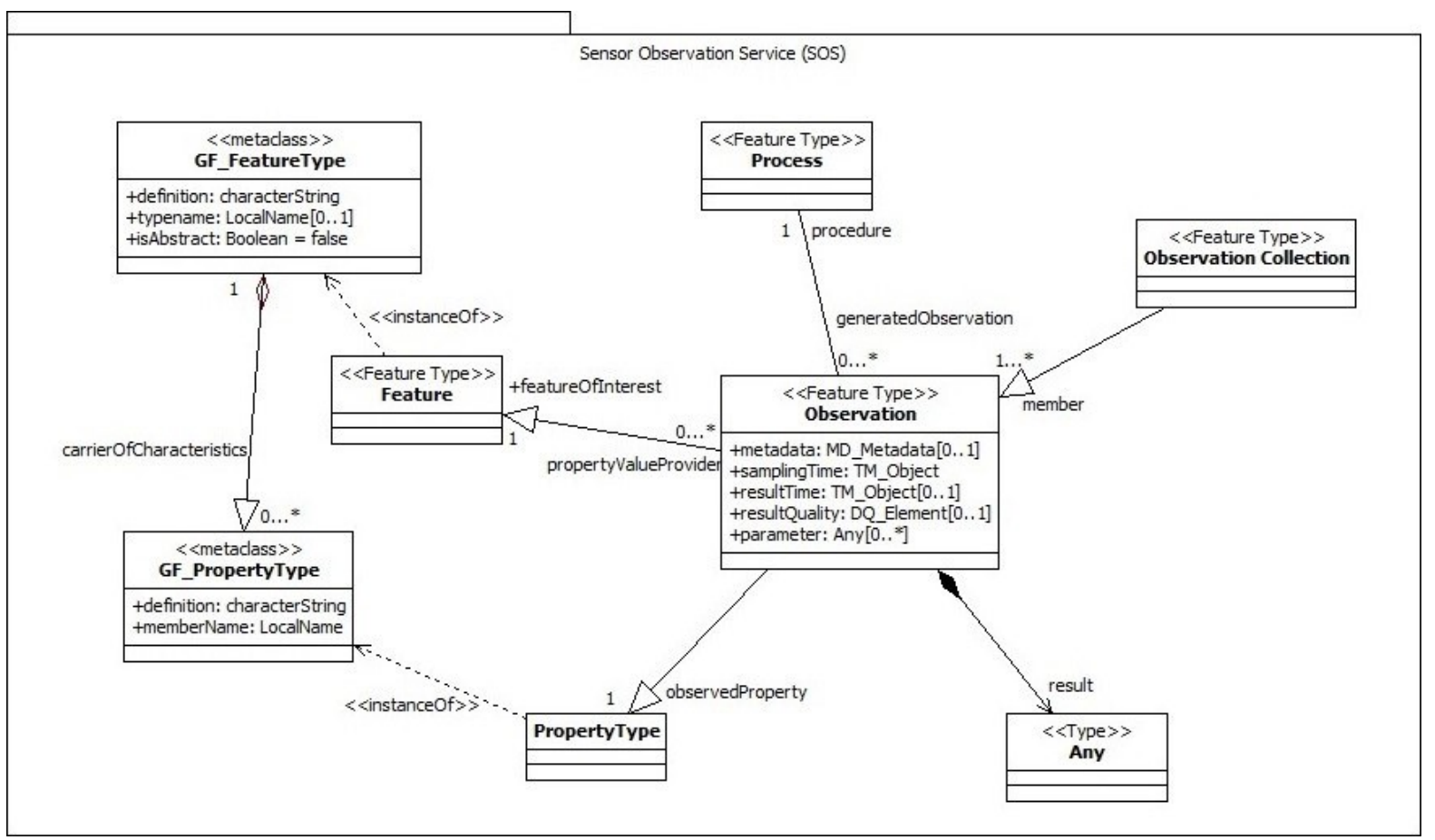

Figura 3.17: Modelo de observação do SOS.

Tabela 3.1: Relação entre dados da observação e dados do relato

\begin{tabular}{|l|l|l|}
\hline \multicolumn{1}{|c|}{ Dados Observação } & \multicolumn{1}{|c|}{ Dados Relato } & \multicolumn{1}{c|}{ Descrição } \\
\hline Característica de Interesse & $\begin{array}{l}\text { Área monitorada pe- } \\
\text { los voluntários }\end{array}$ & $\begin{array}{l}\text { Um objeto do mundo real, } \\
\text { cujas propriedades estão em } \\
\text { observação }\end{array}$ \\
\hline Propriedade Observada & Categoria do Relato & $\begin{array}{l}\text { O fenômeno que está sendo } \\
\text { observado }\end{array}$ \\
\hline Procedimento & $\begin{array}{l}\text { Voluntários (comuni- } \\
\text { dade) }\end{array}$ & $\begin{array}{l}\text { Método, instrumento ou al- } \\
\text { goritmo utilizado para reali- } \\
\text { zar uma medição }\end{array}$ \\
\hline Horário do Fenômeno & $\begin{array}{l}\text { Horário de envio do re-- } \\
\text { lato }\end{array}$ & $\begin{array}{l}\text { Horário em que a medição } \\
\text { do fenômeno foi realizada }\end{array}$ \\
\hline Resultado & Descrição do relato & $\begin{array}{l}\text { Uma estimativa do valor } \\
\text { de uma propriedade obser- } \\
\text { vada gerada por um proce- } \\
\text { dimento }\end{array}$ \\
\hline
\end{tabular}

Por outro lado, um novo modelo de dados (Figura 3.18) foi proposto para armazenar as informações relacionadas exclusivamente ao framework. Esse modelo armazena informações sobre a plataforma de crowdsourcing, como o nome da plataforma e sua URL (Uniform Resource Locator), as categorias selecionadas pelo usuário, a URL do serviço SOS, onde as informações voluntárias são inseridas, e dados sobre a característica de interesse. 


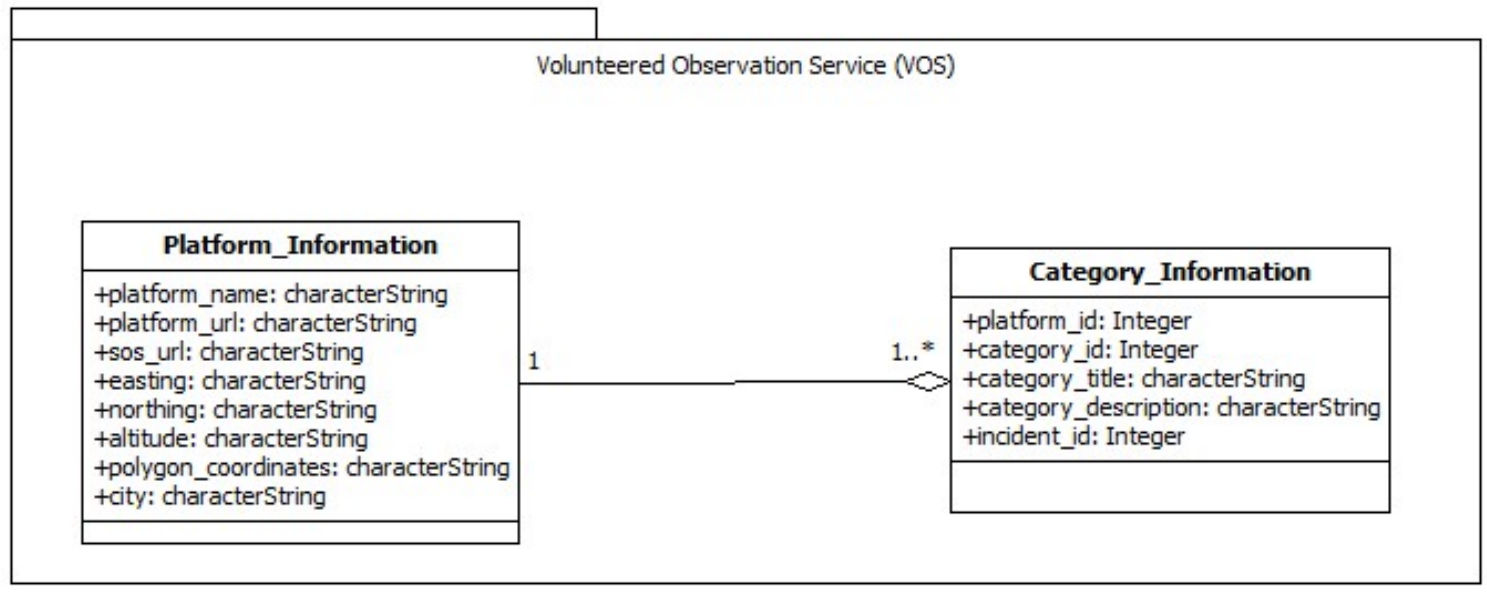

Figura 3.18: Modelo de dados do VOS.

A implementação do framework está dividida em dois módulos, o módulo front-end e o módulo back-end.

\section{Módulo Front-end}

Esse módulo tem como objetivo fornecer uma interface para a entrada e visualização de informações. O diagrama de classes que representa os objetos empregados nesse módulo é apresentado na Figura 3.19, sendo cada uma das classes detalhadas na Tabela 3.2.

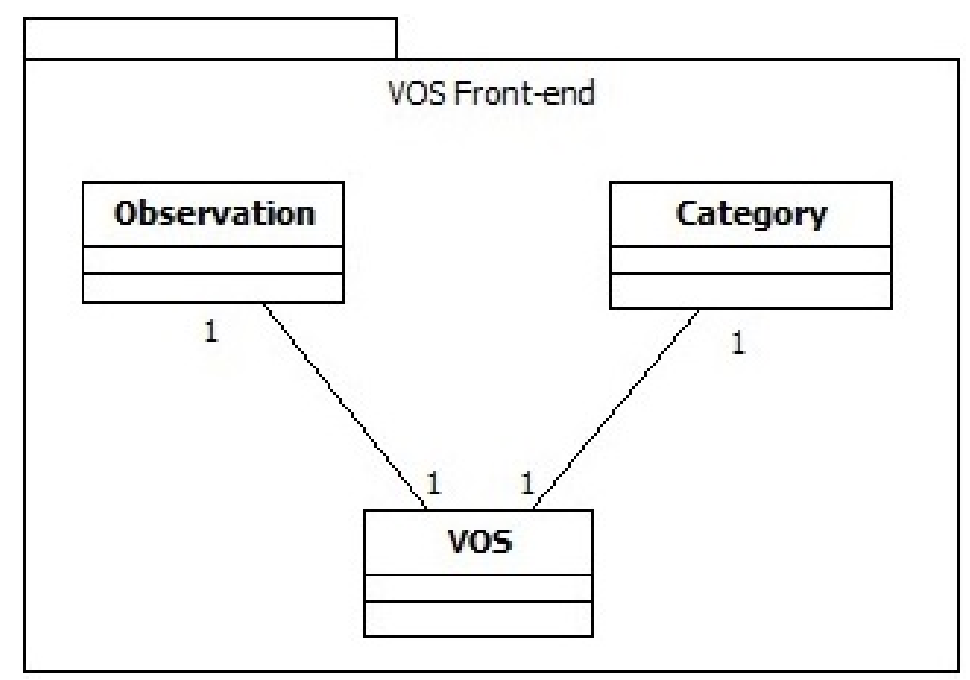

Figura 3.19: Diagrama de classe do front-end do VOS.

\section{Módulo Back-end}

O módulo back-end é responsável pela obtenção das categorias e relatos da plataforma de crowdsourcing. Além disso, esse módulo é encarregado de registrar um novo sensor no 
Tabela 3.2: Descrição das classes do módulo front-end.

\begin{tabular}{|l|l|}
\hline \multicolumn{1}{|c|}{ Classe } & \multicolumn{1}{c|}{ Função } \\
\hline VOS & $\begin{array}{l}\text { Realiza a comunicação com o back-end e apresenta as infor- } \\
\text { mações ao usuário }\end{array}$ \\
\hline Observation & Representa uma observação \\
\hline Category & Representa uma categoria \\
\hline
\end{tabular}

SOS e inserir as observações a ele relacionadas. O diagrama de classes que representa os objetos utilizados nesse módulo é apresentado na Figura 3.20, sendo cada classe descrita na Tabela 3.3.

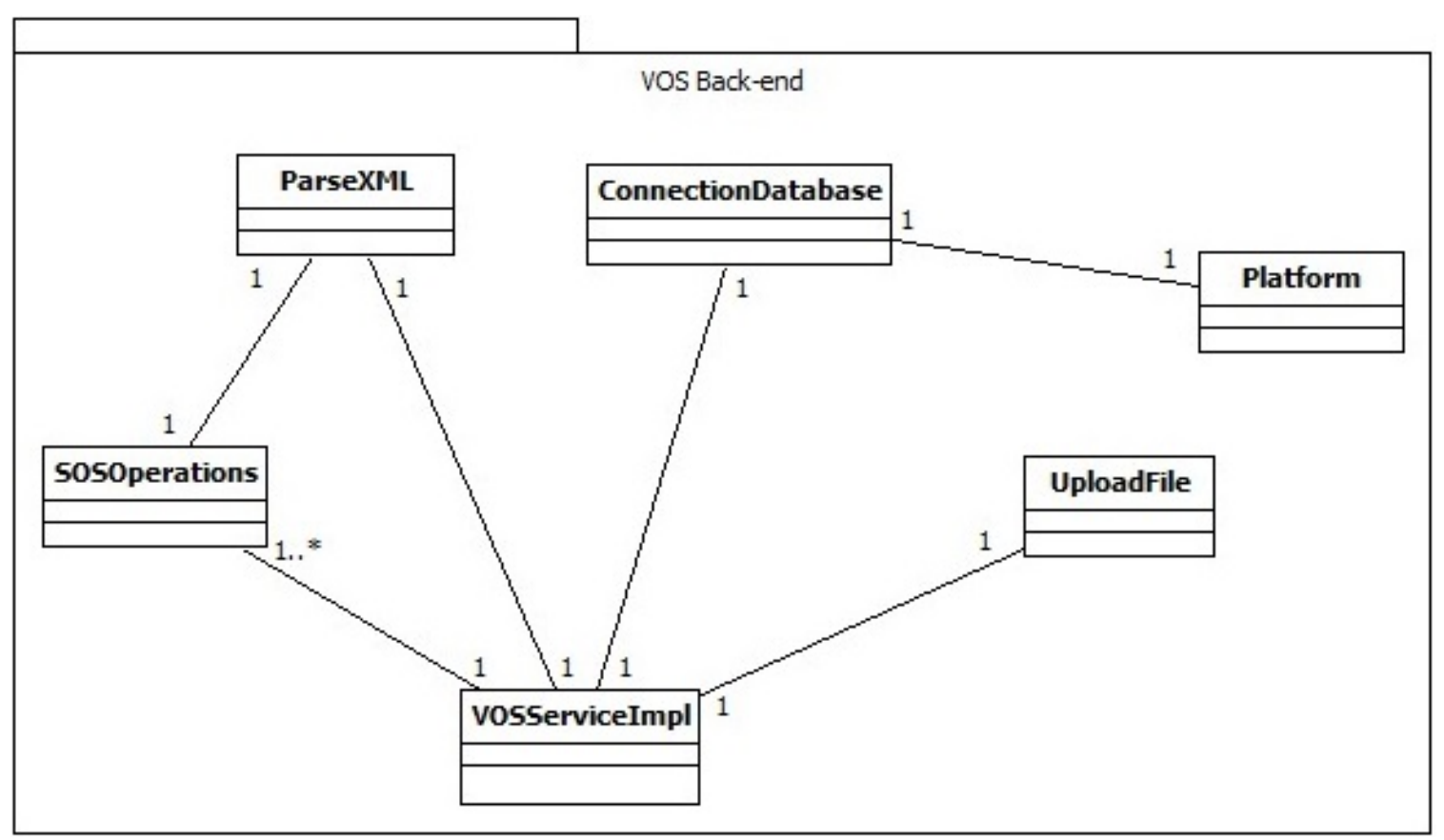

Figura 3.20: Diagrama de classe do back-end do VOS.

Tabela 3.3: Descrição das classes do módulo back-end.

\begin{tabular}{|l|l|}
\hline \multicolumn{1}{|c|}{ Classe } & \multicolumn{1}{c|}{ Função } \\
\hline VOSServiceImpl & $\begin{array}{l}\text { Realiza a comunicação com o front-end e é responsável por } \\
\text { recuperar as categorias e os relatos da plataforma de crowd- } \\
\text { sourcing }\end{array}$ \\
\hline SOSOperations & $\begin{array}{l}\text { Responsável por realizar o registro do sensor e a inserção das } \\
\text { observações no SOS, além de obter, também, as observações } \\
\text { nele inseridas }\end{array}$ \\
\hline ParseXML & $\begin{array}{l}\text { Responsável por analisar um documento XML e extrair as } \\
\text { informações nele contidas. }\end{array}$ \\
\hline
\end{tabular}




\begin{tabular}{|l|l|}
\hline ConnectionDatabase & $\begin{array}{l}\text { Responsável por realizar a conexão com a base de dados, ar- } \\
\text { mazenando as informações relacionadas ao framework }\end{array}$ \\
\hline UploadFile & $\begin{array}{l}\text { Responsável por salvar o documento XML, contendo a descri- } \\
\text { ção do sensor, no SOS }\end{array}$ \\
\hline Platform & Representa uma plataforma de crowdsourcing \\
\hline
\end{tabular}

A relação entre os módulos front-end e back-end, a plataforma de crowdsourcing Ushahidi e o serviço SOS, bem como informações trocadas entre as partes, é apresentada na Figura 3.21.
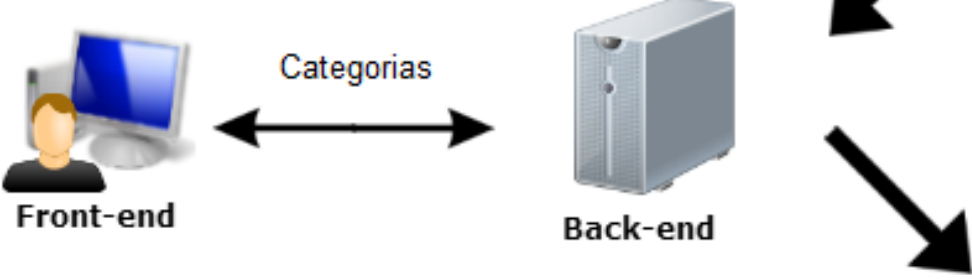

Dados sensor Observações

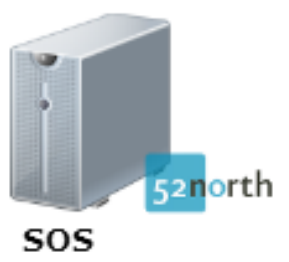

Figura 3.21: Relação entre os módulos front-end, back-end, plataforma Ushahidi e serviço SOS.

\subsubsection{Aspectos de Implementação}

Para o desenvolvimento do framework foram utilizados os seguintes softwares: o ambiente de desenvolvimento Eclipse Juno $^{7}$, o sistema gerenciador de banco de dados PostgreSQL ${ }^{8}$ e o servidor Web Apache Tomcat $7^{9}$. O framework foi implementado na linguagem de programação Java para o back-end e o toolkit Google Web Toolkit 2.5.1 ${ }^{10}$ (GWT) para o desenvolvimento do front-end, pois permite criar aplicações AJAX (Asynchronous Javascript and XML) utilizando a linguagem de programação Java. O framework foi desenvolvido como uma aplicação Web, logo, foi utilizada a tecnologia Servlets (Oracle, 2014).

\footnotetext{
${ }^{7}$ http://www.eclipse.org/juno/

${ }^{8}$ http://www.postgresql.org/

${ }^{9}$ http://tomcat.apache.org/

${ }^{10}$ http://www.gwtproject.org/
} 
Para a manipulação do XML ${ }^{11}$, uma biblioteca padrão do Java foi utilizada, seguindo a estrutura de representação do padrão DOM ${ }^{12}$ (Document Object Model).

A persistência dos dados foi realizada em um banco de dados PostgreSQL. Para manter a flexibilidade do framework, informações como URL, login e senha do banco de dados são fornecidas por meio de um documento XML (Figura 3.22). Dessa forma, o framework pode se conectar a qualquer banco de dados.

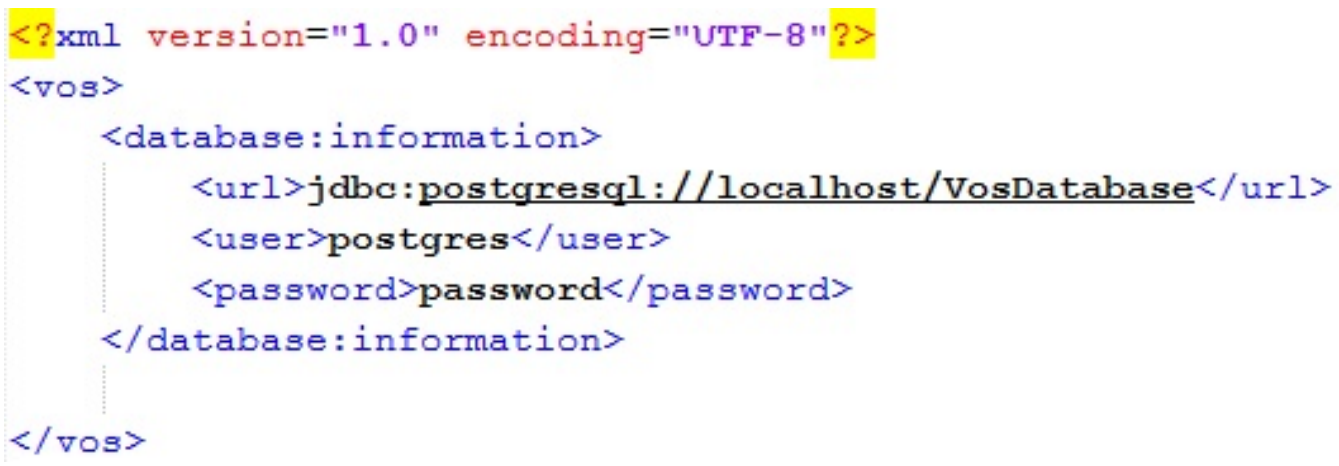

Figura 3.22: Documento XML com informações do banco de dados.

Em particular, o SOS usado pelo framework é fornecido pela $52^{\circ}$ North - Initiative for Geospatial Open Source Software $\mathrm{GmbH}^{13}(52 \mathrm{~N})$. A vantagem desse está relacionada ao fato de que esse é de código aberto distribuído sob os termos da licença GNU (General Public License), o que lhe permite ser facilmente adaptado. Além disso, é um dos mais utilizados atualmente e está sendo constantemente atualizado. O SOS consiste em um servidor de aplicativos e um servidor de dados. O servidor de aplicativo é implementado utilizando a tecnologia Java Servlet e servidor Web Apache Tomcat. O servidor de dados é baseado no sistema de gerenciamento de banco de dados PostgreSQL e sua extensão para base de dados geográfica, PostGIS.

\subsubsection{Interações}

A interação com o framework ocorre quando o cliente tem como objetivo disponibilizar as informações voluntárias de forma interoperável, juntamente com os dados de sensores. Primeiramente, a fim de recuperar as informações voluntárias (relatos), o cliente fornece quatro informações ao framework: o nome da plataforma de crowdsourcing e sua URL, a URL do serviço SOS, onde as informações serão integradas, e, por fim, um documento XML que descreve o sensor, baseado na especificação SensorML. Em seguida, o front-end envia essas informações ao back-end, que é responsável por efetuar uma solicitação à plataforma de crowdsourcing para a obtenção das categorias nela cadastradas. Uma vez

\footnotetext{
${ }^{11}$ http://www.w3.org/

${ }^{12}$ http://www.w3.org/DOM/

${ }^{13}$ http://52north.org/
} 
retornadas, as categorias são, então, enviadas ao front-end para a apresentação para o cliente. Esse seleciona de quais categorias ele deseja recuperar as informações voluntárias. Nessa etapa, o framework permite que o cliente faça modificações no título e descrição das categorias, tornando-o assim mais flexível. Depois de terem sido selecionadas, essas são enviadas ao back-end, o qual efetua uma nova solicitação à plataforma para recuperar os relatos relacionados às categorias selecionadas. Posteriormente, esses relatos são inseridos no SOS.

Vale ressaltar que essa sequência de passos é realizada uma única vez pelo cliente, sendo, em seguida, os relatos recuperados e disponibilizados de forma automática. A interação realizada com o framework pode ser observada em detalhes na Figura 3.23.

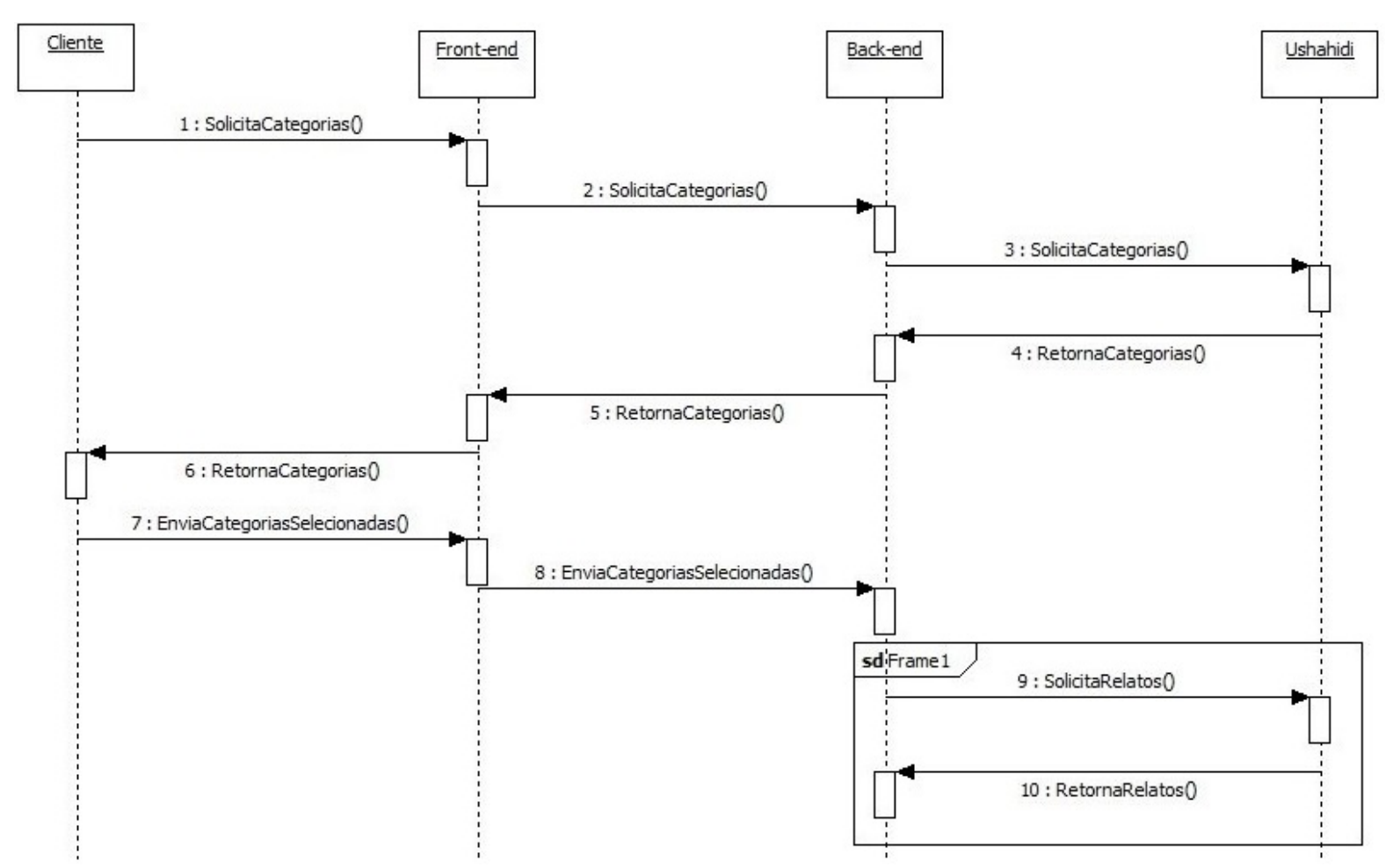

Figura 3.23: Interação entre o cliente e o framework.

Em um cenário distinto, o cliente que desejar obter as informações voluntárias, recuperadas da plataforma de crowdsourcing, realiza uma interação diretamente com o serviço SOS. Para isso, a sequência de operações especificadas pelo serviço deve ser realizada (Figura 3.24). Primeiramente, o cliente efetua a operação GetCapabilities para a obtenção dos metadados do serviço sobre uma instância específica. Em seguida, se o cliente desejar obter mais informações sobre um sensor em particular, esse deve efetuar a operação DescribeSensor. Por fim, o cliente realiza a operação GetObservation a fim de recuperar as observações produzidas pelos voluntários. 


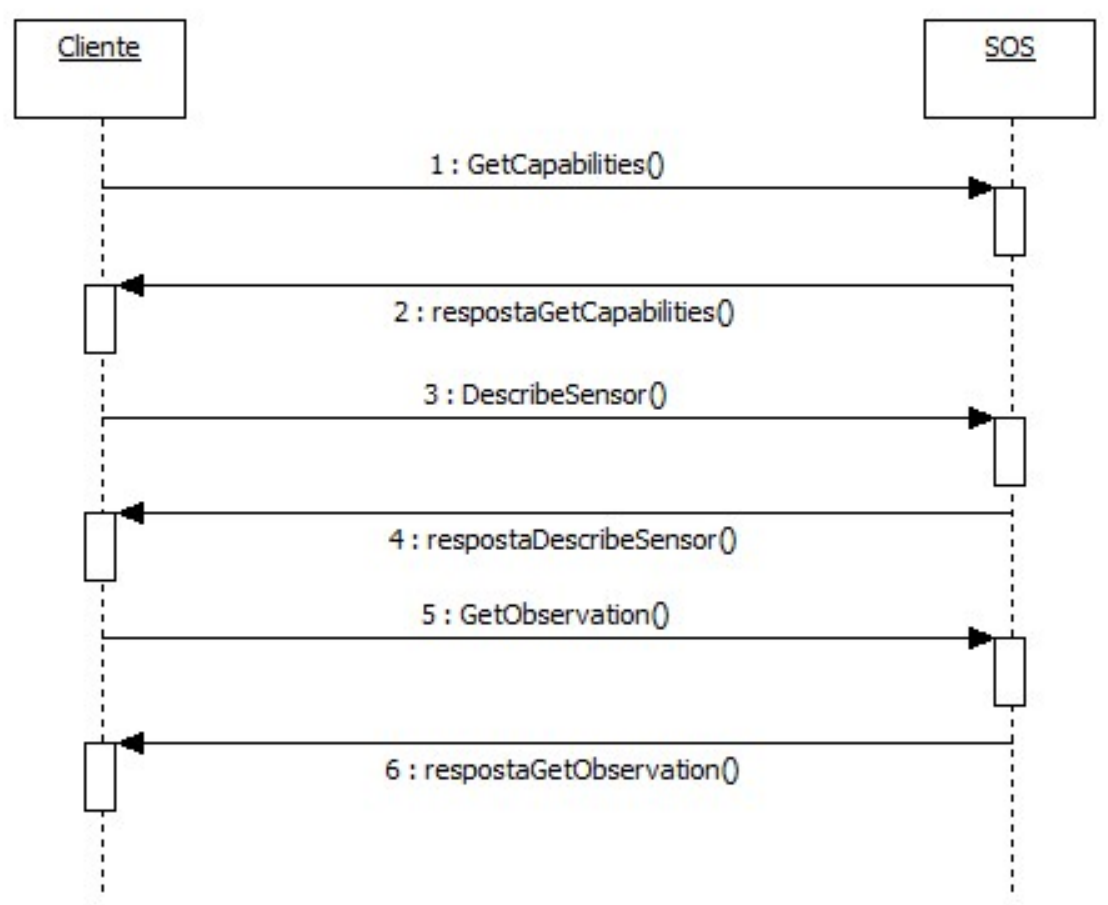

Figura 3.24: Interação entre o cliente e o SOS.

\subsection{Considerações Finais}

Neste capítulo foi apresentada uma abordagem para apoiar a gestão de risco de inundação, sendo as informações voluntárias o principal foco dessa. Até o momento, nenhum trabalho foi encontrado na literatura sobre o uso dessas informações como fonte de dados para a fase de prevenção da gestão de risco de inundação, sendo os trabalhos concentrados na utilização das informações para a fase de resposta. Assim, espera-se que essa abordagem contribua para melhorar a obtenção de informações voluntárias para o contexto de gestão de risco de inundação, bem como sua integração a outras fontes de dados, por meio da disponibilização dessas de forma interoperável.

Os mecanismos de interpretação foram propostos, juntamente com especialistas da área de hidrologia, para apoiar os voluntários a melhor determinar a altura da água no leito do rio. Além disso, neste trabalho foi proposta uma plataforma de crowdsourcing para melhorar a obtenção dessas informações. Ainda, foi desenvolvido um framework para a disponibilização de informações voluntárias, provenientes de plataformas de crowdsourcing, de forma interoperável por meio de serviços geoespaciais.

No próximo capítulo, é apresentada a avaliação dessa abordagem e seus resultados discutidos. 


\subsection{Considerações Iniciais}

O objetivo desse trabalho foi propor uma abordagem que visa apoiar a gestão de risco de inundação por meio da configuração de uma plataforma de crowdsourcing existente, para a obtenção de informações voluntárias, e da disponibilização desse tipo de informação na forma de serviços geoespaciais interoperáveis. Neste capítulo será detalhada a avaliação experimental realizada a fim de avaliar a plataforma de crowdsourcing proposta e os principais resultados obtidos apresentados. Além disso, será apresentado o emprego das informações voluntárias recuperadas por meio do framework.

Na Seção 4.2 é abordado o conceito de experimentação, utilizado para avaliação da plataforma. Na Seção 4.3 é apresentada a avaliação experimental, a qual foi aplicada em um ambiente real. Na Seção 4.4 são apresentados os resultados obtidos após a realização do experimento. Por fim, na Seção 4.5 é discutida a avaliação do framework.

\subsection{Experimentação}

Um experimento é um tipo de pesquisa científica que tem como objetivo verificar a previsão teórica de encontro à realidade. Ele pode ser usado para testar uma teoria ou hipótese (Wohlin et al., 2000). Para tanto, uma ou algumas variáveis são manipuladas e outras mantidas fixas, medindo, assim, o efeito do resultado (Travassos et al., 2002). 
Segundo Travassos et al. (2002), "a experimentação é o centro do processo científico". Por meio da realização de experimentos é possível verificar teorias, explorar fatores críticos e dar luz ao fenômeno novo para que as teorias possam ser formuladas e corrigidas. Para melhor entender a experimentação, é preciso, primeiramente, compreender os principais elementos de um experimento. Segundo Travassos et al. (2002) e Wohlin et al. (2000), os principais elementos são as variáveis, os objetos, os participantes, o contexto do experimento, as hipóteses e o tipo de projeto do experimento. Esses elementos podem ser entendidos como:

- Variáveis: representam a entrada do processo de experimentação, bem como o sua saída. Elas são divididas em variáveis dependentes e independentes. As variáveis dependentes representam a saída do processo de experimentação, ou seja, apresentam o efeito que é causado pelas variáveis independentes do experimento. As variáveis independentes representam a entrada do processo de experimentação e apresentam a causa que afeta o resultado desse processo;

- Objeto: é uma ferramenta usada para verificar o relacionamento causa-efeito numa teoria. Juntamente com o sistema de medição e diretrizes de execução, esses compõem a instrumentação do experimento;

- Participantes: são os indivíduos que foram selecionados da população sob interesse para conduzir o experimento;

- Contexto do experimento: composto pelas condições em que o experimento está sendo executado;

- Hipóteses: o experimento é composto por dois tipos de hipótese, a hipótese nula e a hipótese alternativa. A primeira é a hipótese sob a qual o teste é realizado, que queremos refutar com a maior significância possível. A hipótese alternativa é contrária à hipótese nula;

- Projeto do experimento: determina a maneira como o experimento será conduzido;

Para que um experimento forneça resultados válidos, esse deve ser tratado como um processo de verificação da teoria e deve ser propriamente organizado e controlado (Travassos et al., 2002). Para tanto, a execução de um experimento deve seguir uma sequência de atividades, sendo que o número e a complexidade dessas atividades podem variar conforme as características de cada experimento. Cinco atividades principais estão sempre presentes no processo de experimentação, são elas: definição, planejamento, avaliação, execução e análise e interpretação (Travassos, 2011; Travassos et al., 2006; Wohlin et al., 
2000). Na fase de definição, os problemas e objetivos do experimento são definidos. Na fase de planejamento, é determinado o projeto do experimento, a instrumentação e os aspectos da validade são avaliados. Na fase de execução, os dados experimentais são coletados, os quais são analisados e avaliados na fase de análise e interpretação. Ao final do processo de experimentação, as atividades e os resultados do experimento são empacotados, permitindo, assim, sua repetição. Na Figura 4.1 é apresentado o processo de experimentação.

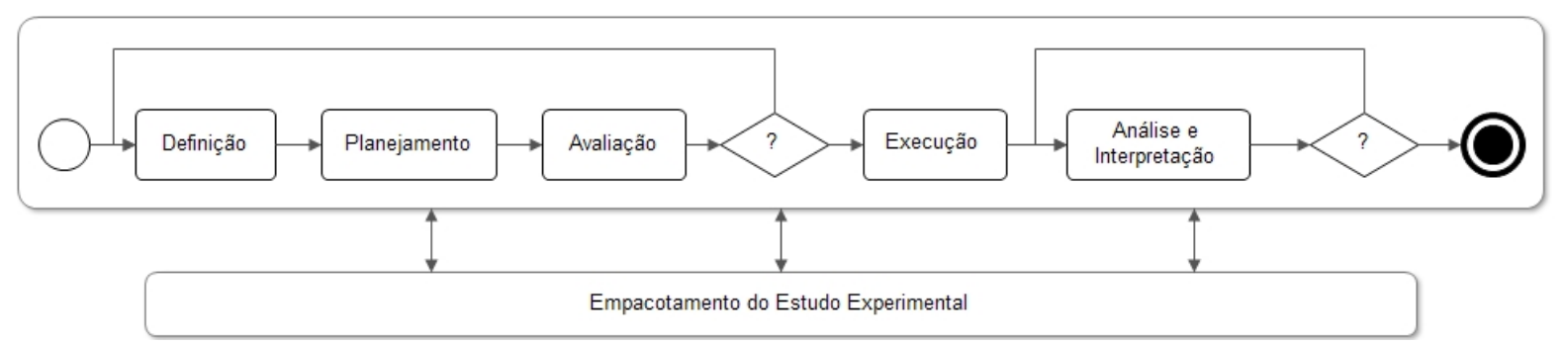

Figura 4.1: Processo de experimentação (Adaptado de (Wohlin et al., 2000)).

\subsection{Avaliação Experimental}

Como forma de avaliação da abordagem, um experimento foi realizado com o objetivo de verificar a obtenção de informações voluntárias úteis para o contexto de gestão de risco de inundação. Em particular, o experimento buscou verificar se a plataforma de crowdsourcing, Observatório Cidadão de Enchentes (Seção 3.4), é eficaz para a obtenção de informações voluntárias úteis e se a diferença entre a média dos valores contidos nessas informações e a média dos dados de sensores é significativa. Para alcançar tais objetivos, duas questões foram formuladas pelo autor desse trabalho, a fim de direcionar sua execução. A primeira questão faz referência à eficácia da plataforma em obter informações voluntárias para o contexto de gestão de risco de inundação. Dessa forma, essa questão foi definida como:

Q1) A plataforma de crowdsourcing, Observatório Cidadão de Enchentes, é eficaz para a obtenção de informações voluntárias úteis para o contexto de gestão de risco de inundação?

A segunda questão foi formulada a fim de verificar se a diferença entre a média das informações voluntárias e a média dos dados de sensores é significativa, pois caso haja uma diferença significativa, essas podem camuflar o real estado da variável ambiental, acarretando em previsões errôneas sobre o risco de inundação. Assim, a seguinte questão foi elaborada:

Q2) A diferença entre a média das informações voluntárias e a média dos dados de sensor é significativa? 
Uma vez formuladas, para cada questão foi definida uma hipótese nula, a qual se deseja refutar com maior significância possível, e uma hipótese alternativa, a qual se pretende comprovar. Em relação à eficácia da plataforma de crowdsourcing, levantada pela Q1, procurou-se refutar a afirmação de que a porcentagem de informações voluntárias úteis obtidas pela plataforma é menor ou igual a 50\% (Hipótese Nula). Por outro lado, buscou-se comprovar que a porcentagem de informações voluntárias úteis obtidas pela plataforma é maior que 50\% (Hipótese Alternativa). Uma informação voluntária é considerada útil se essa pode ser utilizada por modelos hidrológicos ou para a tomada de decisão por agências de emergência. Dessa forma, é possível assegurar que a plataforma proposta é eficaz se a porcentagem de informações voluntárias úteis por ela obtidas for elevada. Em relação à diferença entre a média das informações voluntárias e a média dos dados de sensor, levantada pela Q2, procurou-se refutar a afirmação de que a média dos valores contidos nas informações voluntárias é diferente da média dos valores medidos pelo sensor (Hipótese Nula). Por outro lado, buscou-se comprovar que a média dos valores contidos nas informações voluntárias é igual à média dos valores medidos pelo sensor (Hipótese Alternativa).

Durante a fase de planejamento do experimento, duas variáveis dependentes e uma independente foram definidas, as quais estão envolvidas no contexto dessa abordagem (Figura 4.2).

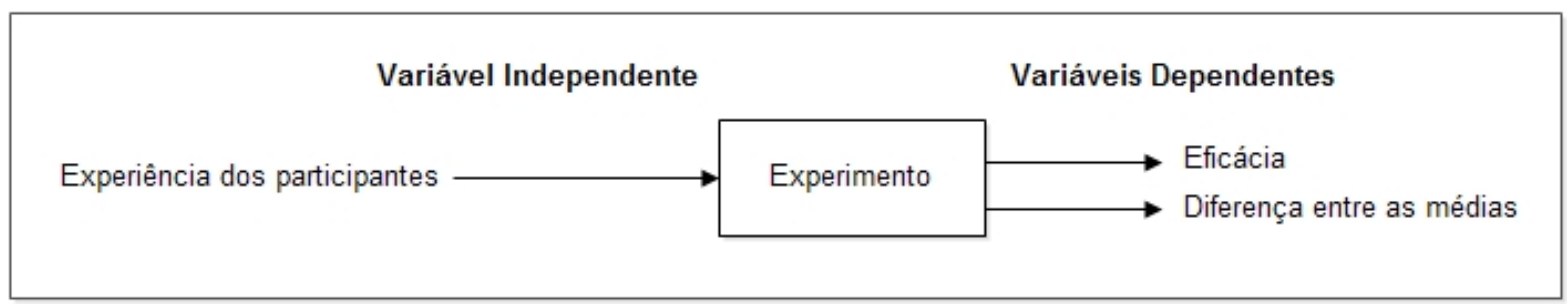

Figura 4.2: Variáveis Dependentes e Independentes do Experimento.

Após a definição das variáveis do experimento, métricas foram elaboradas para medir essas variáveis. No contexto da plataforma, uma informação voluntária é considerada útil se a categoria selecionada pelo voluntário representar o cenário por ele observado. Dessa forma, um critério foi definido a fim de determinar a utilidade dessa informação para o contexto de gestão de risco de inundação. Para tanto, três valores distintos foram atribuídos ao critério: zero (não representa o cenário observado, ou seja, a categoria selecionada não condiz com a descrição do relato), cinco (representa parcialmente o cenário observado, isto é, o voluntário selecionou mais de uma categoria), dez (representa completamente o cenário observado, ou seja, o voluntário selecionou apenas uma categoria que representa exatamente o cenário descrito). Assim, a eficácia da plataforma é calculada pela porcentagem de informações voluntárias que possuem nota maior ou igual a cinco nesse critério. 
Ainda, a média dos valores obtidos nas informações voluntárias é calculada pela soma dos valores contidos na descrição do relato, referente à altura da água na régua, e dividida pelo número de relatos com essa informação (Tabela 4.1). Por outro lado, a média dos valores medidos pelo sensor é calculada pela soma das medições por ele realizadas, no período de tempo em que os voluntários realizaram as observações, e dividida pelo número de medições realizadas nesse período (Tabela 4.2). Além disso, para a fase de execução do experimento, foram levados em consideração um fator, altura da água, e dois tratamentos, altura da água observada pelos voluntários e altura da água medida pelo sensor.

Tabela 4.1: Média das informações voluntárias

$$
\mu(\mathrm{VGI})=\sum(\text { Altura da água na régua }) / \mathrm{N}
$$

Tabela 4.2: Média dos dados de sensor

$$
\left.\mu(\text { Sensor })=\sum \text { (Medições do sensor }\right) / N_{T}
$$

Antes da execução do experimento, foi realizado um estudo piloto para averiguar a adequação do protocolo experimental. Para tanto, nove participantes foram selecionados com diferentes níveis de experiência e conhecimento na área de gestão de risco de inundação. Em seguida, para a execução do experimento, novos participantes foram escolhidos de forma estratégica, visando selecionar participantes com diferentes níveis de experiência e conhecimento na área de gestão de risco de inundação. Ainda, antes da realização do experimento, os participantes passaram por um treinamento, o qual possibilitou apresentar os principais pontos abordados durante o experimento. Durante o treinamento, o autor desse trabalho, primeiramente, apresentou a plataforma de crowdsourcing proposta nesse trabalho, demonstrando aos participantes como enviar um relato por meio da mesma. Além disso, foi apresentado aos participantes os mecanismos utilizados para a interpretação da altura da água no leito do rio. Em seguida, todos os participantes foram conduzidos a um ponto da bacia hidrográfica da cidade de São Carlos/SP para a realização do experimento. Vale ressaltar que este ponto foi escolhido pois no mesmo encontra-se instalado um sensor que mede a altura da água no leito do rio. No local, os participantes encontraram os diferentes mecanismos de interpretação definidos neste trabalho. Cada participante, então, observou o local de forma independente e, em seguida, enviou um relato sobre a altura da água na régua linimétrica, podendo esse enviar um novo relato sobre a altura da água em um outro mecanismo de interpretação à escolha do participante. Alguns dos participantes inseriram suas observações por meio do aplicativo 
para celular, outros realizaram anotações, durante o experimento, sobre suas observações e, posteriormente, as inseriram na plataforma por meio do Web site. Ao final da execução do experimento, foi disponibilizado um questionário (Apêndice A) para a obtenção do feedback dos participantes acerca de sua experiência com o contexto de gestão de risco de inundação, bem como sua opinião sobre a utilidade da plataforma de crowdsourcing, facilidade de uso e de aprendizagem.

Para a fase de análise e interpretação dos resultados, foram utilizados três testes estatísticos. Primeiramente, o Teste de Shapiro-Wilk (Royston, 1983) foi utilizado para verificar a normalidade das amostras. Em seguida, o Teste de Levene (Olkin, 1960) foi aplicado para verificar a homocedasticidade da amostra, ou seja, se as amostras apresentam igualdade de variância. Por fim, o Teste T (Wohlin et al., 2000) foi aplicado a fim de refutar ou aceitar estatisticamente a hipótese nula. Segundo Travassos (2011), é possível rejeitar a hipótese nula com base nos resultado do teste estatístico.

\subsection{Resultados}

O experimento foi realizado com dez voluntários (participantes), com diferentes níveis de experiência e conhecimento na área de gestão de risco de inundação (Tabela 4.3), em um ponto da bacia hidrográfica da cidade de São Carlos/SP. Durante a execução, os voluntários inseriram quinze relatos na plataforma.

Tabela 4.3: Experiência dos participantes no contexto de gestão de risco de inundação obtida por meio do questionário.

\begin{tabular}{|c|c|}
\hline ID do participante & Tempo de Experiência \\
\hline 10 & 0 mês \\
\hline 11 & 0 mês \\
\hline 12 & 1 mês \\
\hline 13 & 0 mês \\
\hline 14 & 0 mês \\
\hline 15 & 0 mês \\
\hline 16 & 7 meses \\
\hline 17 & 240 meses \\
\hline 18 & 12 meses \\
\hline 19 & 12 meses \\
\hline
\end{tabular}

Primeiramente, os relatos foram analisados quanto à categoria selecionada pelo voluntário, a fim de verificar a eficácia da plataforma. Para cada um dos relatos foi atribuído uma nota de acordo com o número de categorias selecionadas e se essas representavam 
completamente ou parcialmente o cenário observado ou, ainda, não o representavam, de acordo com a descrição presente no relato. Dentre os relatos inseridos, nove possuíam apenas uma categoria selecionada, a qual representava completamente o cenário observado. A esses foi atribuído o valor 10. Dois relatos possuíam mais de uma categoria selecionada, as quais representavam parcialmente o cenário observado. Para esses relatos foi atribuído o valor 5. Por fim, quatro relatos possuíam uma ou mais categorias selecionadas, porém essas não representavam o cenário observado, sendo a eles atribuído o valor 0. Assim, onze relatos obtiveram nota igual ou maior do que cinco, ou seja, aproximadamente $73 \%$ dos relatos inseridos podem ser utilizados para o contexto de gestão de risco de inundação. Dessa forma, é possível concluir que por meio das categorias da plataforma o voluntário consegue enviar informações úteis para esse contexto. Desse modo, a hipótese nula foi refutada, ou seja, a plataforma é eficaz para a obtenção de informações voluntárias úteis para o contexto de gestão de risco de inundação. Esse resultado pode ser justificado pelo fato de que todos os voluntários do experimento passaram por um treinamento antes da sua execução, auxiliando-os a determinar a altura da água com maior facilidade, além de inserir suas observações na plataforma mais facilmente. Dessa forma, é possível afirmar que o treinamento foi comprovadamente suficiente para que os voluntários produzissem observações úteis para o contexto de gestão de risco de inundação.

Em seguida, os relatos relacionados à altura da água na régua linimétrica foram analisados a fim de verificar se a diferença entre a média desses valores e média dos dados do sensor era significativa. Para tanto, apenas dez relatos foram considerados, visto que somente esses possuíam valor da altura da água na régua linimétrica. Primeiramente, foi realizada uma correspondência entre os valores observados pelos voluntários e os valores medidos pelo sensor, pois a régua linimétrica se encontrava mal fixada junto ao leito do rio. Para isso, o autor desse trabalho realizou duas observações, em dias distintos, sobre a altura da água na régua linimétrica no mesmo ponto onde o experimento foi realizado. Cada observação foi confrontada com o valor medido pelo sensor, a fim de determinar a diferença entre esses valores (Tabela 4.4). Assim, foi possível constatar que existe uma diferença de aproximadamente $7 \mathrm{~cm}$ entre o valor observado pelo voluntário e o valor medido pelo sensor. Essa diferença foi somada a cada uma das observações realizadas pelos voluntários antes da realização dos testes estatísticos.

Tabela 4.4: Diferença entre o valor observado pelo voluntário e o valor medido pelo sensor.

\begin{tabular}{|c|c|c|c|}
\hline Data & $\begin{array}{l}\text { Valor observado pelo vo- } \\
\text { luntário }\end{array}$ & $\begin{array}{l}\text { Valor medido pelo sen- } \\
\text { sor }\end{array}$ & Diferença \\
\hline $10 / 02 / 2014$ & $7 \mathrm{~cm}$ & $14,12 \mathrm{~cm}$ & $7,12 \mathrm{~cm}$ \\
\hline $12 / 02 / 2014$ & $6 \mathrm{~cm}$ & $13,82 \mathrm{~cm}$ & $7,82 \mathrm{~cm}$ \\
\hline
\end{tabular}


O Teste de Shapiro-Wilk foi realizado para averiguar se as amostras possuíam distribuição normal. A partir dos resultados obtidos (Tabela 4.5) foi possível constatar que a média dos valores contidos nas informações voluntárias não possui distribuição normal, pois o valor de Sig. (p-valor) é menor que o nível de significância ${ }^{1}$ adotado (5\%). Em contrapartida, a média dos valores medidos pelo sensor possui distribuição normal, pois o valor de Sig. é maior que o nível de significância.

Tabela 4.5: Resultado do Teste de Shapiro Wilk.

\begin{tabular}{|c|c|c|c|}
\hline \multirow{2}{*}{ Variável Testada } & \multirow{2}{*}{ Instrumento } & \multicolumn{2}{|c|}{ Teste de Shapiro Wilk } \\
\cline { 3 - 4 } & & Número de Elementos & Sig. \\
\hline \multirow{2}{*}{ Altura da Água } & Voluntário & 10 & 0,004 \\
\cline { 2 - 4 } & Sensor & 5 & 0,494 \\
\hline
\end{tabular}

Para amostras com distribuição normal, o teste de hipótese mais adequado é o Teste T, sendo esse paramétrico em sua vertente não pareada. Segundo Wohlin et al. (2000), esse teste pode, também, ser aplicado para amostras que não possuem distribuição normal desde que essas não contenham muitos elementos. Assim, esse teste foi selecionado para verificar se a diferença entre a média dos valores contidos nas informações voluntárias e a média dos valores medidos pelo sensor era significativa.

Para a realização do Teste $\mathrm{T}$, primeiramente foi realizado o Teste de Levene para analisar a homocedasticidade das amostras, isto é, analisar se as amostras possuem igualdade de variância. Ao verificar o valor obtido de Sig. (p-valor) (Tabela 4.6) foi possível constatar que as amostras não possuem igualdade de variância, visto que esse valor é menor que o nível de significância. Assim, ao realizar o Teste $\mathrm{T}$, o valor analisado corresponde a amostras que não possuem igualdade de variância. Em seguida, o Teste $\mathrm{T}$ foi realizado para verificar se a diferença entre as médias era estatisticamente significativa. O resultado obtido (Tabela 4.6) comprova que a diferença entre as médias não é estatisticamente significativa, pois o valor de Sig (2-tailed) é maior que o nível de significância. Esse resultado foi confirmado ao observar a diferença entre as médias, apresentada na Tabela 4.7. Assim, foi possível rejeitar a hipótese nula. Contudo, vale ressaltar que esse resultado pode ter sido ameaçado, pois a régua linimétrica não estava bem fixada à margem do leito do rio, o que pode ter ocasionado uma interpretação errônea da altura da água pelos voluntários. A diferença entre as médias pode ser observada na Figura 4.3.

Ao final do experimento, os voluntários responderam a um questionário sobre a utilidade da plataforma de crowdsourcing utilizada, bem como sua facilidade de uso e de aprendizagem. Para cada afirmação presente no questionário, o voluntário pode optar por cinco diferentes respostas, dentro do intervalo de "discordo totalmente" até "concordo

\footnotetext{
${ }^{1} \mathrm{O}$ nível de significância corresponde a probabilidade de rejeitar a hipótese nula sendo a mesma verdadeira.
} 
Tabela 4.6: Resultado do Teste de Levene e do Teste T.

\begin{tabular}{|c|c|c|c|}
\hline \multirow{2}{*}{ Variável Testada } & Teste de Levene & \multicolumn{2}{|c|}{ Teste T } \\
\cline { 2 - 4 } & Sig. & Sig. (2-tailed) & Diferença Média \\
\hline Altura da Água & 0,002 & 0,093 & $-2,799$ \\
\hline
\end{tabular}

Tabela 4.7: Média dos valores das informações voluntárias e do sensor.

\begin{tabular}{|c|c|c|c|c|}
\hline Variável Testada & Instrumento & $\begin{array}{l}\text { Número de } \\
\text { Elementos }\end{array}$ & Média & Desvio Padrão \\
\hline \multirow{2}{*}{ Altura da Água } & Voluntário & 10 & 21,13 & 4,58 \\
\cline { 2 - 5 } & Sensor & 5 & 23,93 & 0,99 \\
\hline
\end{tabular}

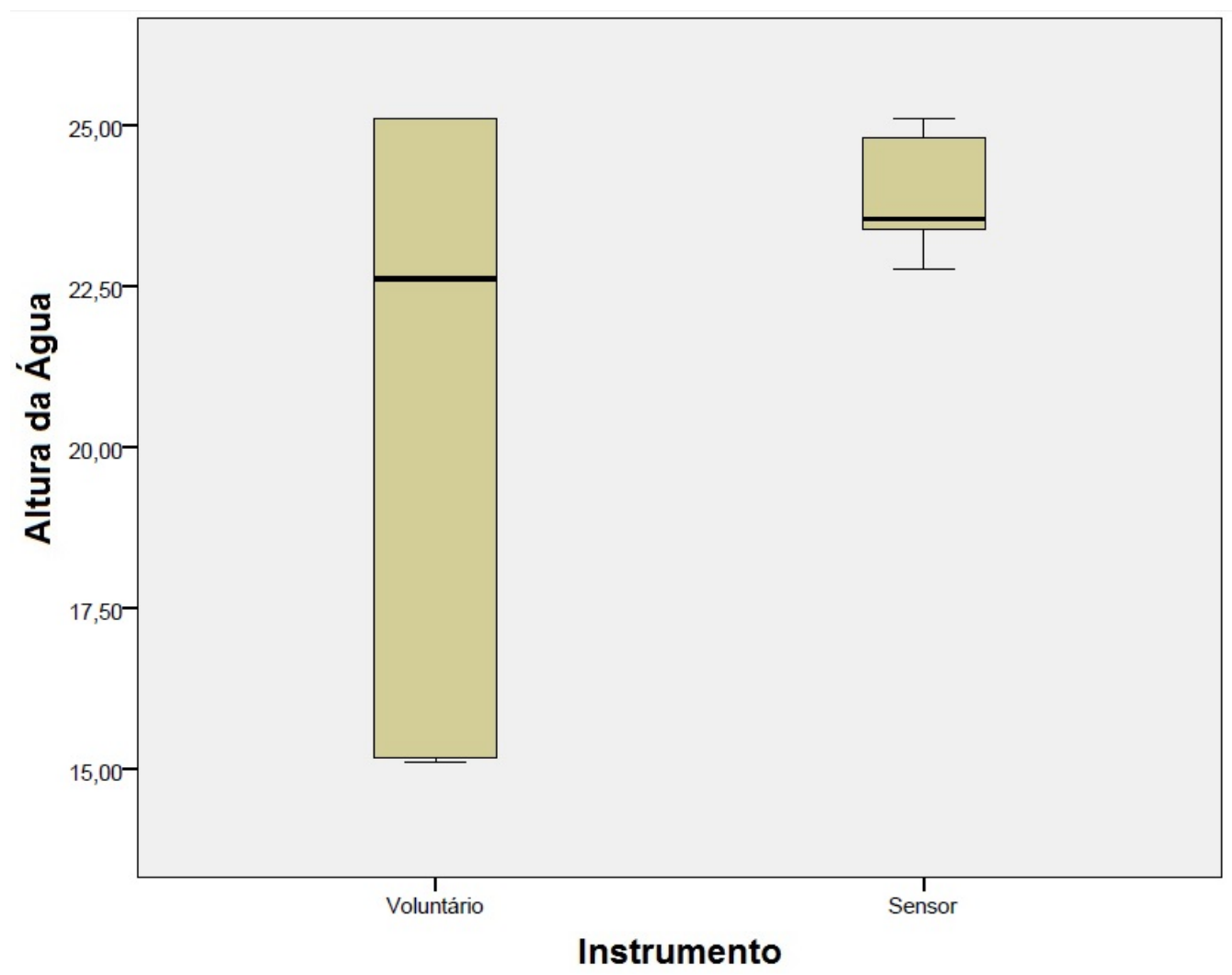

Figura 4.3: Diferença entre as médias dos valores das informações voluntárias e dos dados do sensor.

totalmente". Primeiramente, foi perguntado aos voluntários se a plataforma Observatório Cidadão de Enchentes facilita o fornecimento de informações para o contexto de gestão de risco de inundação. Seis, dos dez voluntários participantes, disseram que concordam plenamente com essa afirmação. Além disso, foi questionado se os mecanismos de interpretação utilizados facilitam a determinação da altura da água. Segundo as respostas obtidas, grande parte dos voluntários concorda ou concorda totalmente com tal afirmação. Ainda, seis voluntários disseram que foi fácil utilizar os mecanismos para a interpretação 
da altura da água. Por fim, oito voluntários disseram que concordam, ou concordam totalmente, sobre a afirmação de que essa plataforma é fácil de usar.

Assim, podemos concluir que a plataforma Observatório Cidadão de Enchentes facilita o fornecimento de informações pelos voluntários para o contexto de gestão de risco de inundação. Além disso, os mecanismos de interpretação definidos auxiliam os voluntários a determinar a altura da água mais facilmente.

\subsection{Avaliação do Framework}

O framework proposto nesse trabalho tem como objetivo recuperar informações voluntárias de instâncias da plataforma de crowdsourcing Ushahidi e disponibilizá-las de forma interoperável por meio de serviços geoespaciais, propostos pela OGC. Como forma de avaliação desse framework, as informações voluntárias presentes na plataforma de crowdsourcing, Observatório Cidadão de Enchentes, foram recuperadas e disponibilizadas por meio do serviço SOS. Além disso, essas informações foram consumidas por uma aplicação (GeoDashboard), a qual foi desenvolvida por pesquisadores do projeto de pesquisa no qual essa abordagem também faz parte. O GeoDashboard é uma aplicação web que visa apoiar a tomada de decisão em tempo real por meio de um conjunto de indicadores de desempenho, os quais são fundamentais para a gestão de risco de inundação.

Primeiramente, o autor desse trabalho forneceu os dados necessários sobre a plataforma de crowdsourcing, onde os relatos foram recuperados, e sobre o serviço SOS, onde as observações foram inseridas. Em seguida, todas as categorias da plataforma foram selecionadas, a fim de recuperar todas as informações voluntárias nela presentes (Figura 4.4). Uma vez disponibilizadas as observações, essas foram recuperadas por meio da operação GetObservation do serviço SOS e inseridas na aplicação GeoDashboard (Figura 4.5). Para tanto, foi utilizado a tecnologia OpenLayers $^{2}$ para a apresentação das informações voluntárias na aplicação. Com isso, as informações voluntárias complementam outras fontes de informação, como o índice de perigo, dados de sensores, presentes na aplicação. Dessa forma, os tomadores de decisão terão uma visão mais abrangente do cenário em questão, auxiliando-os, assim, a decidir sobre as ações de resposta mais adequadas.

\subsection{Considerações Finais}

Com base na avaliação experimental realizada, foi possível constatar que a plataforma de crowdsourcing, Observatório Cidadão de Enchentes, é eficaz para a obtenção de informações voluntárias úteis para o contexto de gestão de risco de inundação. Isso ocorre, pois

\footnotetext{
${ }^{2}$ http://www.openlayers.org/
} 


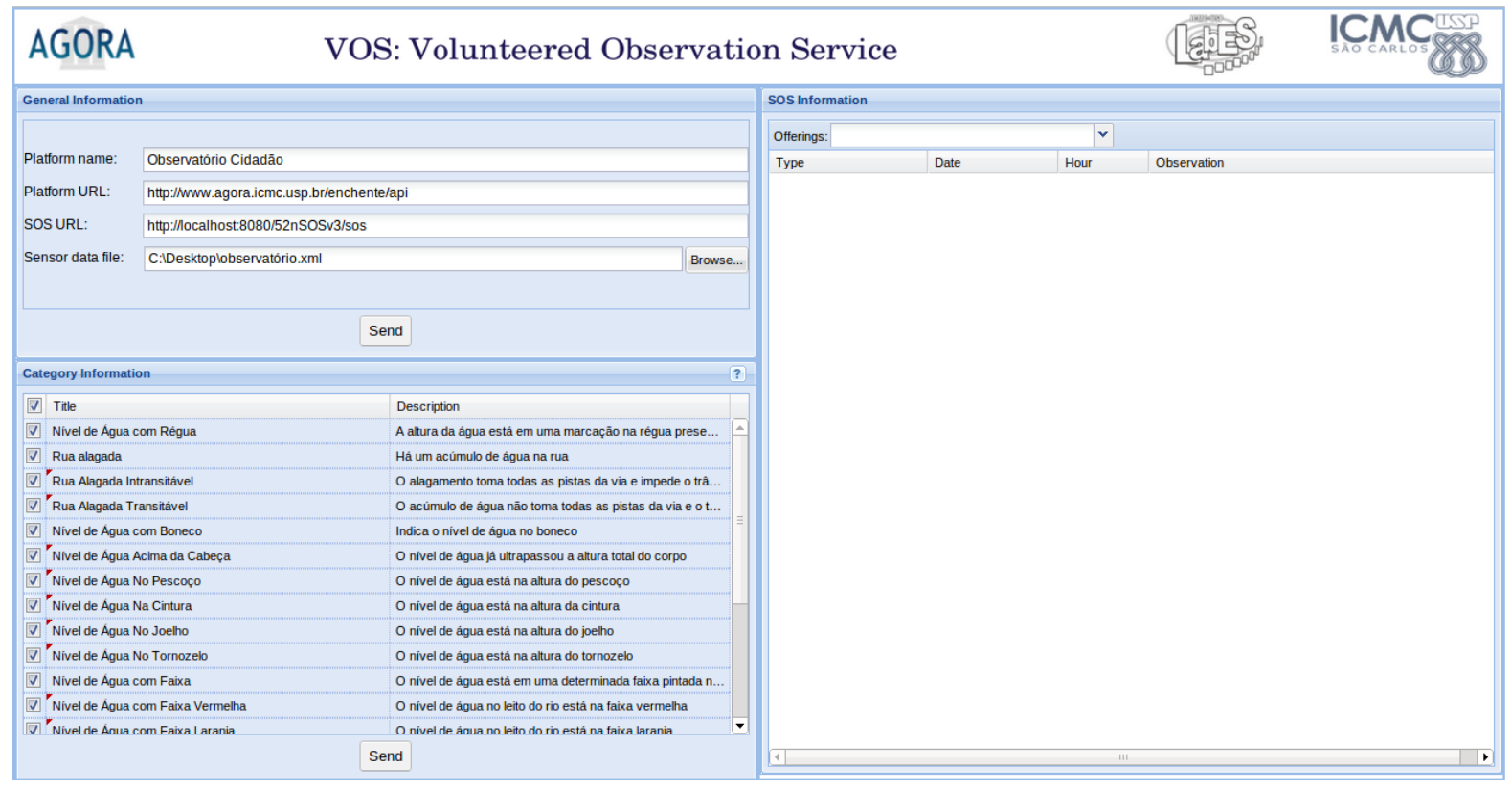

Figura 4.4: Recuperação das informações voluntárias do Observatório Cidadão de Enchentes pelo framework.

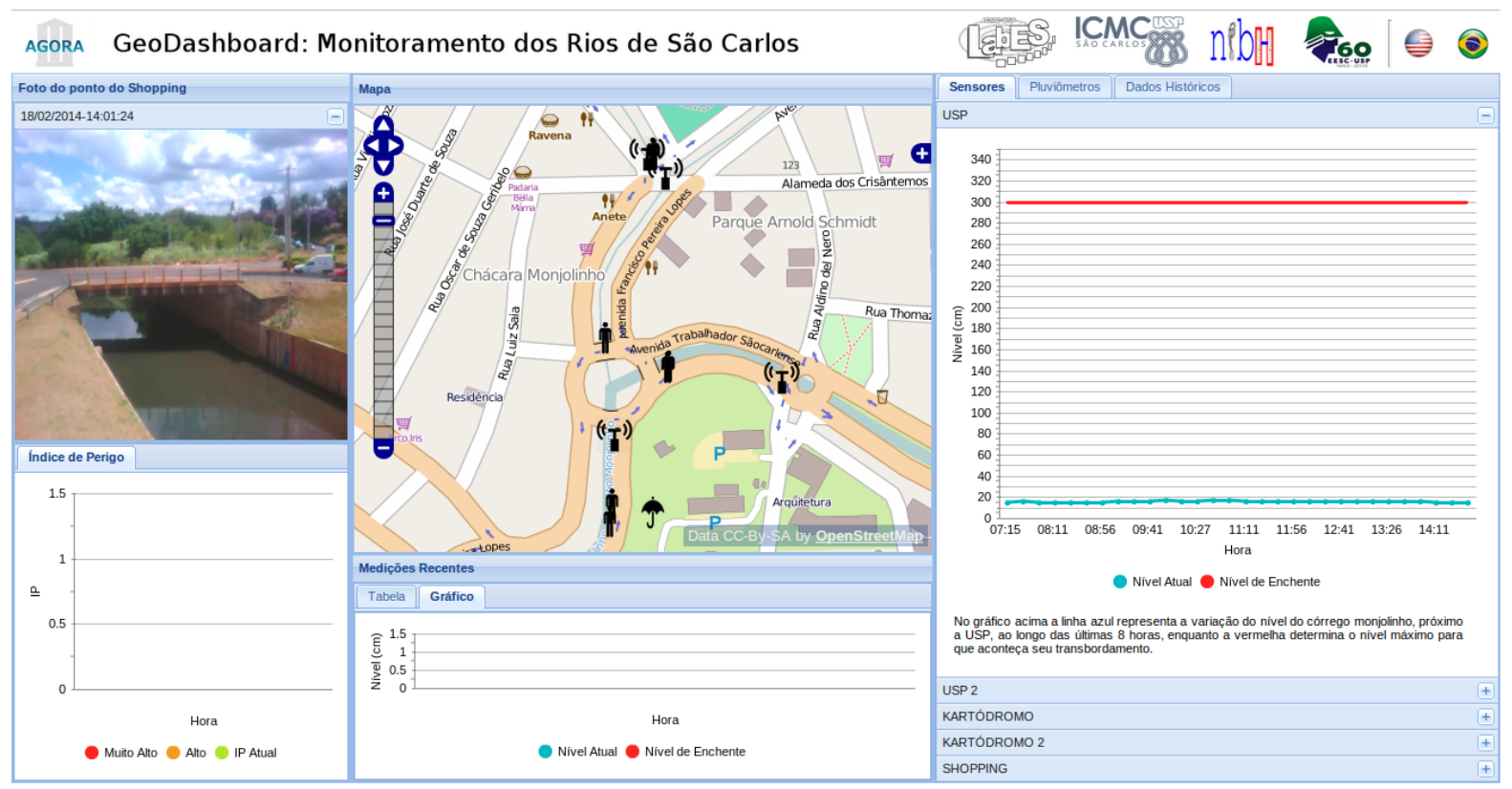

Figura 4.5: Aplicação GeoDashboard para o monitoramento de rios da cidade de São Carlos/SP. 
os voluntários podem representar o estado das variáveis ambientais (altura da água e área alagada), no cenário por eles observado, por meio da seleção da categoria mais adequada. Além disso, foi possível comprovar estatisticamente que não existe uma diferença significativa entre a média dos valores contidos nas informações voluntárias e a média dos valores medidos pelo sensor. Ainda, de acordo com o feedback obtido, os voluntários relataram que essa plataforma facilita o fornecimento de informações relacionadas ao contexto de gestão de risco de inundação e que os mecanismos de interpretação definidos facilitam a determinação da altura da água no leito do rio. Assim, pode-se concluir que essa plataforma é relevante para a obtenção de informações voluntárias úteis para o contexto de gestão de risco de inundação.

Por outro lado, a utilização das informações voluntárias por uma aplicação comprovou que essas informações podem ser facilmente consumidas por aplicações que seguem os mesmos padrões de interoperabilidade. Dessa forma, as informações voluntárias podem, também, ser facilmente integradas a outras fontes de informação.

No próximo capítulo, as conclusões deste trabalho serão apresentadas, destacando as principais contribuições, limitações e dificuldades encontradas e sugestões de trabalhos futuros. 


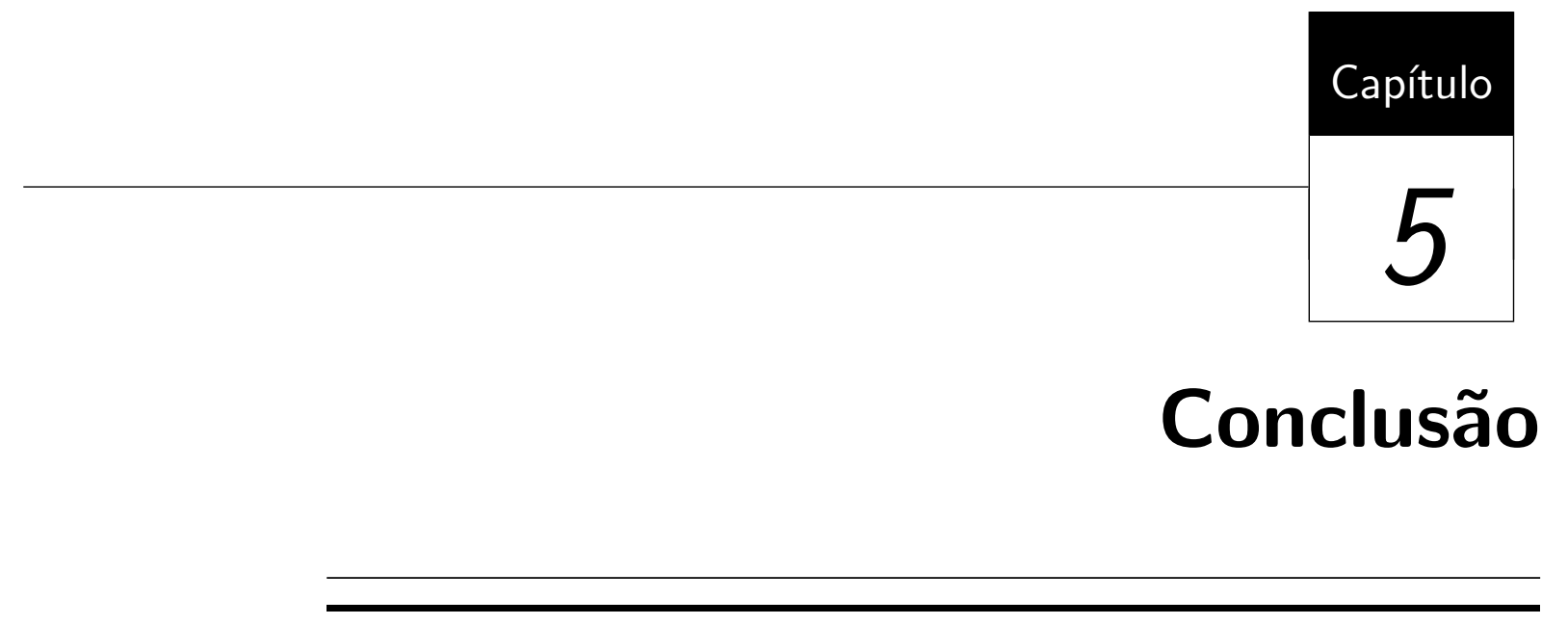

\subsection{Visão Geral}

A gestão de risco de inundação visa gerenciar uma situação de risco de inundação existente, controlando-a e estando preparado para ela. As informações voluntárias são utilizadas como fonte de informação complementar sobre os impactos provocados por esse tipo desastre, visto que uma grande quantidade de voluntários observam importantes parâmetros da gestão de risco de inundação em um ambiente local. Nesse contexto, diferentes plataformas de crowdsourcing foram propostas a fim de obter informações voluntárias sobre as vítimas desse desastre e sobre os impactos provocados. Contudo, não há uma plataforma de crowdsourcing configurada que possibilite coletar informações voluntárias úteis relacionadas à fase de preparação da gestão de risco de inundação. Além disso, essas informações não são disponibilizadas de forma interoperável, dificultando sua integração com outras fontes de informação. Assim, a criação de uma plataforma de crowdsourcing que possibilita a obtenção de informações voluntárias úteis para esse contexto, bem como a disponibilização dessas informações de forma interoperável, torna-se fundamental.

Nesse trabalho foi proposta uma plataforma de crowdsourcing para a obtenção de informações voluntárias úteis para o contexto de gestão de risco de inundação. Além disso, foi desenvolvido um framework que possibilita recuperar as informações voluntárias presentes em instâncias da plataforma de crowdsourcing Ushahidi e disponibilizá-las de forma interoperável por meio de serviços geoespaciais (SOS). Dessa forma, as informa- 
ções voluntárias podem não só serem obtidas, mas também disponibilizadas, permitindo sua integração com outras fontes de informação. A seguir são apresentadas as principais contribuições desse trabalho, bem como as dificuldades e limitações encontradas, e perspectivas de trabalhos futuros.

\subsection{Contribuições}

A principal contribuição desse trabalho de mestrado é a proposta de uma abordagem colaborativa que visa apoiar a gestão de risco de inundação. Para tanto, foi criada uma plataforma de crowdsourcing, a partir da configuração de uma plataforma de crowdsourcing existente. Diferentemente dessas, a plataforma Observatório Cidadão de Enchentes possibilita a obtenção de informações voluntárias úteis para a fase de preparação no contexto de gestão de risco de inundação, podendo essas informações ser utilizadas em modelos hidrológicos e por tomadores de decisão. Além disso, como apoio para a obtenção das informações voluntárias, mecanismos de interpretação foram definidos, os quais visam auxiliar os voluntários a determinar a altura da água no leito do rio. Esses mecanismos foram incorporados à plataforma por meio das categorias nela presentes. Ainda, a eficácia da plataforma foi determinada por meio de uma avaliação experimental. Nessa avaliação, os voluntários inseriram informações sobre a altura da água no leito do rio de um ponto da bacia hidrográfica da cidade de São Carlos/SP. Os resultados obtidos mostram que a plataforma não só é eficaz para a obtenção de informações voluntárias úteis para o contexto de gestão de risco de inundação, como a diferença entre os valores contidos nessas informações e os valores medidos pelo sensor não é estatisticamente significativa.

Por outro lado, o framework permite que as informações voluntárias, presentes em plataformas de crowdsourcing, possam ser disponibilizadas de forma interoperável por meio de serviços geoespaciais. Outras abordagens, como a proposta por Schade et al. (2013), não levam em consideração as informações voluntárias presentes nessas plataformas. O emprego dessas informações na aplicação GeoDashboard ${ }^{1}$ mostrou que as informações voluntárias podem ser facilmente consumidas pelas aplicações, desde que essas sigam os mesmos padrões de interoperabilidade.

\subsection{Dificuldades e Limitações}

A primeira dificuldade encontrada está relacionada à plataforma de crowdsourcing Ushahidi, pois essa não disponibiliza informações relacionadas ao usuário que inseriu o relato, acar-

\footnotetext{
${ }^{1}$ http://www.agora.icmc.usp.br/geodashboard
} 
retando em uma limitação do framework, pois a comunidade de voluntários foi considerada como um único sensor.

Outra dificuldade encontrada está relacionada às particularidades das plataformas de crowdsouring existentes. Assim, somente informações voluntárias de instâncias da plataforma Ushahidi estão sendo recuperadas pelo framework.

Por fim, a última dificuldade encontrada está relacionada ao mecanismo empregado na plataforma de crowdsourcing para verificação dos relatos inseridos. Nesse mecanismo, os relatos inseridos precisam ser aprovados manualmente antes de serem disponibilizados online.

\subsection{Trabalhos Futuros}

No contexto do framework desenvolvido, esse deve recuperar não somente informações da plataforma de crowdsourcing Ushahidi, mas também de outras fontes de informação voluntária, visto que redes sociais como Twitter, Instagram, Flickr, entre outras, são fontes valiosas de informações voluntárias. Além disso, é essencial que cada voluntário seja considerado como um único sensor. Assim, análises de confiabilidade podem ser realizadas, agregando maior credibilidade às informações.

Por outro lado, é necessário que informações sobre o risco de inundação sejam disponibilizadas não somente para tomadores de decisão e agências de emergência, mas, também, para a população, visto que esses são os mais afetados. Dessa forma, é relevante o desenvolvimento de um sistema de alerta que notifique a população sobre o risco de inundação. Agregado a isso, a elaboração de um mapa de risco de inundação direcionado para a população torna-se essencial. Assim, esses poderão visualizar os diferentes cenários encontrados na cidade em questão.

Ainda, a eficácia da plataforma de crowdsourcing, Observatório Cidadão de Enchentes, pode ser, também, reavaliada por meio de um experimento com um grupo de voluntários não treinados, os quais deverão utilizaram seus conhecimentos e experiências para determinar a altura da água no leito do rio. Outra possibilidade é o desenvolvimento de uma nova plataforma de crowdsourcing que atenda às necessidades de usabilidade e acessibilidade do usuário, visto que alguns voluntários relataram encontrar dificuldades ao inserir um relato na plataforma de crowdsourcing proposta. Essa dificuldade pode acarretar não somente na desistência da inserção de um relato, mas também na inserção de informações errôneas, que não representam o real estado do cenário observado. 



\section{Referências Bibliográficas}

Aalders, H. J. G. L.; Moellering, H. Spatial data infrastructure henri. In: Proceedings of the 20th International Cartographic Conference, 2001, p. 2234-2243.

de Albuquerque, J. P.; Zipf, A. Collaborative information systems for disaster management: Building resilience against disasters by combining participatory environmental monitoring and vulnerability communication. Relatório Técnico, Alumni Seminar natural hazards - research on natural disasters, civil defense, disaster prevention, and aid, 2012 .

Alcántara-Ayala, I. Geomorphology, natural hazards, vulnerability and prevention of natural disasters in developing countries. Geomorphology, v. 47, p. 107-124, 2002.

Asimakopoulou, E.; Bessis, N. Buildings and crowds: Forming smart cities for more effective disaster management. In: Fifth International Conference on Innovative Mobile and Internet Services in Ubiquitous Computing, 2011.

Baharin, S. S. K.; Shibghatullah, A. S.; Othman, Z. Disaster management in malaysia: An application framework of integrated routing application for emergency response management system. In: International Conference of Soft Computing and Pattern Recognition, 2009.

Béjar, R.; Latre, M. .; Lopez-Pellicer, F. J.; Nogueras-Iso, J.; Zarazaga-Soria, F. J.; Muro-Medrano, P. R. Sdi-based business processes: A territorial analysis web information system in spain. Computers $\mathscr{G}$ Geosciences, v. 46, p. 66-72, 2012.

Botts, M.; Percivall, G.; Reed, C.; Davidson, J. Ogc sensor web enablement: Overview and high level architecture. In: Proceedings of the 5th International ISCRAM Conference, 2008, p. 713-723. 
Butenuth, M.; v. Gösseln, G.; Tiedge, M.; Heipke, C.; Lipeck, U.; Sester, M. Integration of heterogeneous geospatial data in a federated database. ISPRS Journal of Photogrammetry \& Remote Sensing, v. 62, p. 328-346, 2007.

Carlsen, J.; Dougherty, J.; Iacucci, A. A.; Rodriguez, D.; Sonoyama, S.; Stauffer, C. Grant report. Relatório Técnico, Mozilla Corporation, 2011.

Crichton, D.; Mounsey, C. How the insurance industry will use its floods research. In: Proceedings of the Third MAFF Conference of Coastal and River Engineers, 1997.

Erl, T. SOA - princípios de design de serviços. 1 ed. São Paulo: Pearson, 322 p., 2009.

Erskine, M. A.; Gregg, D. G. Utilizing volunteered geographic information to develop a real-time disaster mapping tool: A prototype and research framework. In: International Conference on Information Resources Management, 2012.

Fava, M. C.; Mendiondo, E. M.; Souza, V. C. B.; de Albuquerque, J. P.; Ueyama, J. Proposta metodológica para previsão de enchentes com uso de sistemas colaborativos. In: XX Simpósio Brasileiro de Recursos Hídricos, 2013.

Fugita, H. S.; Hirama, K. Soa-modelagem, análise e design. Elsevier, 7-13 p., 2012.

Giordano, R.; Preziosi, E.; Romano, E. Integration of local and scientific knowledge to support drought impact monitoring: some hints from an italian case study. Nat Hazards, v. 69, p. 523-544, 2013.

Goodchild, M. F. Citizens as sensors: the world of volunteered geography. GeoJournal, v. 69 , n. 4, p. 211-221, 2007.

Goodchild, M. F.; Li, L. Assuring the quality of volunteered geographic information. Spatial Statistics, v. 1, p. 110-120, 2012.

GSDI, G. S. D. I. The sdi cookbook. Relatório Técnico, GSDI, 2004.

Iacucci, A. A. Ushahidi guide - a step-by-step guide on how to use the ushahidi platform, acessado em: 10/06/2013, 2013.

Disponível em http://community.ushahidi.com/uploads/documents/ Ushahidi-Manual.pdf

Jha, A. K.; Bloch, R.; Lamond, J. Cidades e inundações - um guia para a gestão integrada do risco de inundação urbana para o século xxi. Relatório Técnico, GFDRR, 2012a. 
Jha, A. K.; Bloch, R.; Lamond, J. Cities and flooding: A guide to integrated urban flood risk management for the 21st century. Washington, DC, USA: The World Bank, 2012b.

Kaewkitipong, L.; Chen, C.; Ractham, P. Lessons learned from the use of social media in combating a crisis a case study of 2011 thailand flooding disaster. In: Thirty Third International Conference on Information Systems, 2012.

Kobiyama, M.; Mendonça, M.; Moreno, D. A.; de Oliveira Marcelino, I. P. V.; Marcelino, E. V.; Gonçalves, E. F.; Brazetti, L. L. P.; Goerl, R. F.; Molleri, G. S. F.; de Moraes Rudorff, F. Prevenção de desastres naturais - conceitos básicos. Organic Trading, 2006.

van der Kooij, M. Flood monitoring and disaster management response. GEOconnexion International Magazine, p. 26-28, 2013.

Levy, J. K.; Gopalakrishnan, C.; Lin, Z. Advances in decision support systems for flood disaster management: Challenges and opportunities. International Journal of Water Resources Development, v. 21, n. 4, p. 593-612, 2005.

Leyh, W.; Gutierrez, L. A. R.; de Almeida Bressiani, D.; Mendiondo, E. M.; de Albuquerque, J. P. Sdi - geo web services for research, administration and sharing of environmental data and information of different climate change scenarios at peri-urban river basin scales. In: 5th International Seminar on Environmental Planning and Management Urban Responses for Climate Change, 2012.

Longueville, B. D.; Annoni, A.; Schade, S.; Ostlaender, N.; Whitmore, C. Digital earth's nervous system for crisis events: real-time sensor web enablement of volunteered geographic information. International Journal of Digital Earth, v. 3, n. 3, p. 242-259, 2010a.

Longueville, B. D.; Luraschi, G.; Smits, P.; Peedell, S.; Groeve, T. D. Citizens as sensors for natural hazards: A vgi intergration workflow. Geomatica, v. 64, p. 41-59, 2010b.

Longueville, B. D.; Smith, R. S.; Luraschi, G. Omg, from here, i can see the flames!- - a use case of mining location based social networks to acquire spatio-temporal data on forest fires. In: Proceedings of the 2009 International Workshop on Location Based Social Networks, 2009, p. 73-80.

Marcelino, E. V. Desastres naturais e geotecnologias: conceitos básicos. Relatório Técnico, Instituto Nacional de Pesquisas Espaciais (INPE), 2007. 
Marzullo, F. P. Soa na prática - inovando seu negócio por meio de soluções orientadas a serviços. N. 1. Novatec, 1-392 p., 2009.

McDougall, K. Using volunteered information to map the queensland floods. In: Proceedings of the Surveying $\&$ Spatial Sciences Biennal Conference, 2011.

Meier, P. Crisis maps: Harnessing the power of big data to deliver humanitarian assistance, acessado em 27/12/2013, 2013.

Disponível em http://www.forbes.com/sites/skollworldforum/2013/05/02/ crisis-maps-harnessing-the-power-of-big-data-to-deliver-humanitarian-assistance/

Mendiondo, E. M. Flood risk management of urban waters in humid tropics: early-warning, protection and rehabilitation. In: Workshop on Integrated Urban Water Management in Humid Tropics, 2005.

MIN, M. D. I. N. Defesa civil - apresentação, acessado em: 21/12/2013, 2013.

Disponível em http://www.integracao.gov.br/web/guest/sedec/apresentacao

Miorandi, D.; Carreras, I.; Gregori, E.; Graham, I.; Stewart, J. Neutrality in mobile internet: Towards a crowdsensing-based citizen observatory. In: IEEE International Conference on Communications, 2013.

Munro, R. Crowdsourcing for pakistan flood relief, acessado em: 27/11/2013, 2010. Disponível em http://www.crowdflower.com/blog/2010/08/ crowdsourcing-for-pakistan-flood-relief

OGC, O. G. C. Opengis $囚$ sensor model language (sensorml) - implementation specification. Relatório Técnico, Open Geospatial Consortium - OGC, 2007a.

Disponível em http://www.opengeospatial.org/standards/sensorml

OGC, O. G. C. Sensor observation service. Relatório Técnico, Open Geospatial Consortium - OGC, 2007b.

OGC, O. G. C. Observations and measurements - xml implementation. Relatório Técnico, Open Geospatial Consortium - OGC, 2011.

Disponível em http://www.opengeospatial.org/standards/om

OGC, O. G. C. About ogc, acessado em: 12/12/2013, 2013a.

Disponível em http://www.opengeospatial.org/ogc

OGC, O. G. C. Sensor observation service, acessado em: 12/12/2013, 2013b.

Disponível em http://www.opengeospatial.org/standards/sos 
Okolloh, O. Ushahidi,or 'testimony': Web 2.0 tools for crowdsourcing crisis information. Participatory Learning and Action, v. 59, p. 65-70, 2009.

Oliveira, P. F. A. d.; Oliveira, P. A. d.; Davis Junior, C. A. Arquitetura Orientada a Serviços (SOA): um estudo de caso em Sistemas de Informação Geográfico. Boletim de Ciências Geodésicas, v. 16, n. Ii, p. 295-308, 2010.

Olkin, I. Contributions to probability and statistics: Essays in honor of harold hotelling. Stanford University Press, 1960.

Oracle Java servlet technology, acessado em: 09/01/2014, 2014.

Disponível em http://www.oracle.com/technetwork/java/index.html

Papazoglou, M. P.; Heuvel, W. J. V. D. Life Cycle Methodology. Communications of the $A C M$, v. 50, n. 10, p. 79-85, 2007.

Plate, E. J. Flood risk and flood management. Journal of Hydrology, v. 267, p. 2-11, 2002.

Poser, K.; Dransch, D. Volunteered geographic information for disaster management with application to rapid flood damage estimation. Geomatica, v. 64, n. 1, p. 89-98, 2010 .

Rajabifard, A.; Williamson, I. P. Spatial data infrastructures: Concept, sdi hierarchy and future directions. In: Geomatics' 80 Conference, 1999.

Ramos, J. M.; Vandecasteele, A.; Devillers, R. Semantic integration of authoritative and volunteered geographic information (vgi) using ontologies. In: Association of Geographic Information Laboratories for Europe (AGILE), 2013.

Raymond, C. M.; Fazey, I.; Reed, M. S.; Stringer, L. C.; Robinson, G. M.; Evely, A. C. Integrating local and scientific knowledge for environmental management. Journal of Environmental Management, v. 91, p. 1766-1777, 2010.

Roche, S.; Propeck-Zimmermann, E.; Mericskay, B. Geoweb and crisis management: issues and perspectives of volunteered geographic information. GeoJournal, v. 78, n. 1, p. 21-40, 2011.

Roshen, W. Soa-based enterprise integration. McGraw-Hill, 233-272 p., 2009.

Rotava, J.; Mendiondo, E. M.; Souza, V. C. B. Simulação de instabilidade humana em inundações: Primeiras considerações. In: XX Simpósio Brasileiro de Recusos Hídricos, 2013. 
Royston, J. P. Some techiniques for assessing multivarate normality based on the shapiro-wilk w. Journal of the Royal Statistical Society, v. 32, p. 121-133, 1983.

Schade, S.; Díaz, L.; Ostermann, F.; Spinsanti, L.; Luraschi, G.; Cox, S.; Nuñez, M.; Longueville, B. D. Citizen-based sensing of crisis events: sensor web enablement for volunteered geographic information. Applied Geomatics, v. 5, n. 1, p. 3-18, 2013.

da Silva, J. P. R. P. Mapeamento de inundações no brasil: proposta de gestão ambiental através de um sistema de informações geográficas. In: VI Congresso de Meio Ambiente da AUGM, 2009.

Disponível em http://www . ambiente-augm.ufscar.br/uploads/A2-045.pdf

Sommerville, I. Engenharia de Software. 9 ed. São Paulo: Pearson, 355 - 374 p., 2011.

Travassos, G. H. Experimentação em engenharia de software: Fundamentos e conceitos. In: VIII Experimental Software Engineering Latin American Network, 2011.

Travassos, G. H.; Fabbri, S.; Maldonado, J. C. Experimental software engineering: an introduction. In: III Experimental Software Engineering Latin American Network, 2006.

Travassos, G. H.; Gurov, D.; do Amaram, E. A. G. Introdução à engenharia de software experimental. Relatório Técnico, Universidade Federal do Rio de Janeiro, 2002.

Tu, S.; Abdelguerf, M. Web services for geographic information systems. IEEE Internet Computing, p. 13-15, 2006.

Tu, Y.; Li, Q.; Liu, R. A geospatial information portal for emergency management of natural disasters. In: IEEE International Geoscience and Remote Sensing Symposium, 2009, p. II-404 - II-407.

UN, U. N. Humanitarian and disaster relief assistance, acessado em: 02/12/2013, 2013. Disponível em http://www.un.org/en/globalissues/humanitarian/

UNISDR, U. N. O. F. D. R. R. Economic losses from disasters set new records in 2012, acessado em: 02/12/2013, 2013.

Disponível em http: //www. unisdr .org/archive/31685

Ushahidi About us, acessado em: 23/12/2013, 2013.

Disponível em http: //www. ushahidi.com/about-us

Ushahidi The ushahidi platform, acessado em: 10/01/2014, 2014.

Disponível em http://ushahidi.com/products/ushahidi-platform 


\section{REFERÊNCIAS BIBLIOGRÁFICAS}

Vivacqua, A. S.; Borges, M. R. Collective intelligence for the design of emergency response. In: 14th International Conference on Computer Supported Cooperative Work in Design, 2010.

Vivacqua, A. S.; Borges, M. R. Taking advantage of collective knowledge in emergency response systems. Journal of Network and Computer Applications, v. 35, p. 189-198, 2012.

Wohlin, C.; Runeson, P.; Höst, M.; Ohlsson, M. C.; Regnell, B.; Wesslén, A. Experimentation in software engineering: an introduction. Kluwer Academic Publishers, 2000.

Zaffani, A. G.; Mendiondo, E. M. Poluição difusa da drenagem urbana ecohidrológica: diagnóstico atual e cenários de longo prazo em bacias urbanas de são carlos, sp. Dissertação de Mestrado, Escola de Engenharia de São Carlos - Universidade de São Paulo, 2012.

Zook, M.; Graham, M.; Shelton, T.; Gorman, S. Volunteered geographic information and crowdsourcing disaster relief: A case study of the haitian earthquake. World Medical E Health Policy, v. 2, p. 7-33, 2010. 



\section{Experimento: Volunteered Geographic Information para Gestão de Risco de}

Inundação

O Apêndice A apresenta o questionário disponibilizado aos participantes do experimento para a obtenção do feedback acerca de sua experiência com o contexto de gestão de risco de inundação, facilidade de uso e de apredizagem do mescanismo de interpretação proposto e da plataforma de crowdsourcing, bem como sua utilidade.

\section{Questionário}

Nota: Este questionário deverá ser respondido após o término do experimento e contém perguntas relacionadas às ferramentas utilizadas durante o experimento.

\section{Instruções:}

Por favor, responda às seguintes perguntas.

Seção (1) - Informações essenciais

1. Como você avalia seu conhecimento com relação a gestão de inundação? (selecione uma das opções abaixo - X) 
( ) Especialista

( ) Intermediário

( ) Novato

2. Você já havia tido contato com o ambiente de gestão de inundação? Em caso afirmativo, descreva sua(s) experiência(s) e por quanto tempo (meses)?

\section{Seção (2) - Informações sobre a tecnologia específica.}

Por favor, julgue as afirmações, listadas a seguir, em relação à plataforma de crowdsourcing Ushahidi. Apenas um dos níveis de satisfação descritos abaixo deve ser utilizado:

1: Discordo Totalmente 2: Discordo 3: Indeciso 4: Concordo 5: Concordo Totalmente

\section{A. Utilidade:}

1. A plataforma Ushahidi facilita o fornecimento de informações relevantes para o contexto de gestão de inundação.

Discordo Totalmente $1-2-3-4-5$ Concordo Totalmente

2. O mecanismo proposto facilita a interpretação das variáveis ambientais Discordo Totalmente $1-2-3-4-5$ Concordo Totalmente

\section{B. Facilidade de Uso:}

1. A plataforma Ushahidi é fácil de usar.

Discordo Totalmente $1-2-3-4-5$ Concordo Totalmente

2. O mecanismo para interpretação das variáveis ambientais me ajudou a melhor interpretar as variáveis.

Discordo Totalmente $1-2-2-3-4-4-5$ Concordo Totalmente

\section{Facilidade de Aprendizagem:}

1. Eu aprendi a usar a plataforma Ushahidi rapidamente.

Discordo Totalmente $1-2-2-3-4-4-5$ Concordo Totalmente 
APÊNDICE A. EXPERIMENTO: VOLUNTEERED GEOGRAPHIC INFORMATION PARA GESTÃO DE RISCO DE INUNDAÇÃO

2. Eu aprendi a usar a o mecanismo de interpretação das variáveis ambientais rapidamente.

Discordo Totalmente $1-2-3--4--5$ Concordo Totalmente

\section{Satisfação:}

1. Eu gostei de utilizar a plataforma Ushahidi para fornecer informações sobre a gestão de inundações.

Discordo Totalmente $1-2-3-1-4-5$ Concordo Totalmente

\section{E. Dimensões Cognitivas da Análise de Tarefas:}

1. fácil interpretar as variáveis ambientais utilizando o mecanismo de interpretação proposto.

Discordo Totalmente $1-2-3-3-4-5$ Concordo Totalmente

\section{Outros comentários:}

